\title{
Improved Prediction of the Temperature Feedback in TRISO-Fueled Reactors
}

\author{
Javier Ortensi
}

Abderrafi M. Ougouag

August 2009
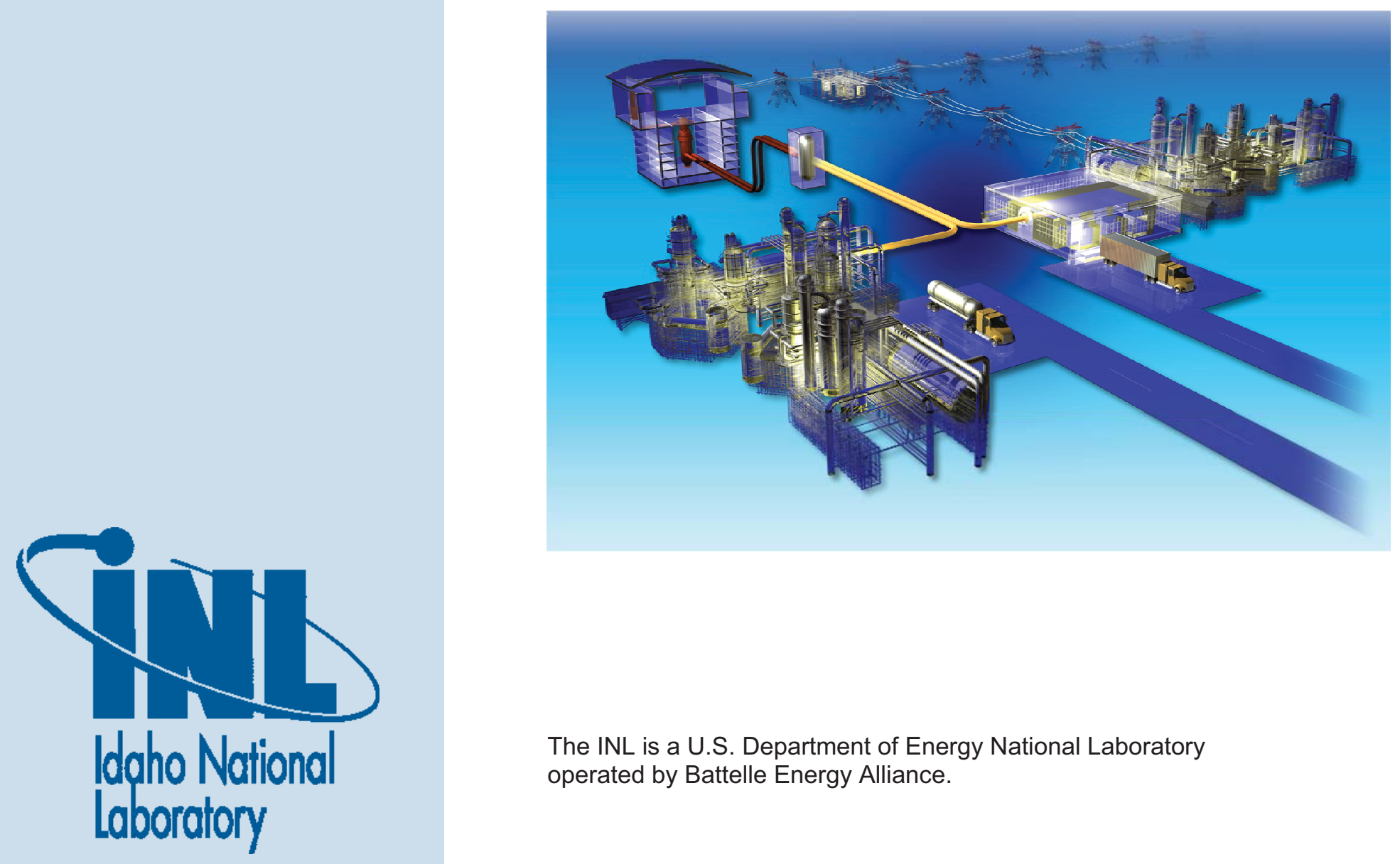

The INL is a U.S. Department of Energy National Laboratory operated by Battelle Energy Alliance. 


\section{DISCLAIMER}

This information was prepared as an account of work sponsored by an agency of the U.S. Government. Neither the U.S. Government nor any agency thereof, nor any of their employees, makes any warranty, expressed or implied, or assumes any legal liability or responsibility for the accuracy, completeness, or usefulness, of any information, apparatus, product, or process disclosed, or represents that its use would not infringe privately owned rights. References herein to any specific commercial product, process, or service by trade name, trade mark, manufacturer, or otherwise, does not necessarily constitute or imply its endorsement, recommendation, or favoring by the U.S. Government or any agency thereof. The views and opinions of authors expressed herein do not necessarily state or reflect those of the U.S. Government or any agency thereof. 


\title{
Improved Prediction of the Temperature Feedback in TRISO-Fueled Reactors
}

\author{
Javier Ortensi \\ Abderrafi M. Ougouag
}

August 2009

\begin{abstract}
Idaho National Laboratory
Next Generation Nuclear Plant Project

Idaho Falls, Idaho 83415
\end{abstract}

Prepared for the

U.S. Department of Energy

Office of Nuclear Energy

Under DOE Idaho Operations Office

Contract DE-AC07-05ID14517 



\section{Next Generation Nuclear Plant Project}

\section{Improved Prediction of the Temperature Feedback in TRISO-Fueled Reactors}

INL/EXT-09-16494

August 2009

Approved by:

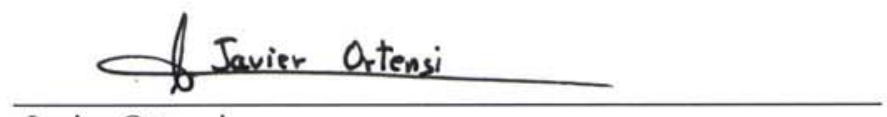

Javier Ortensi

NGNP Physics
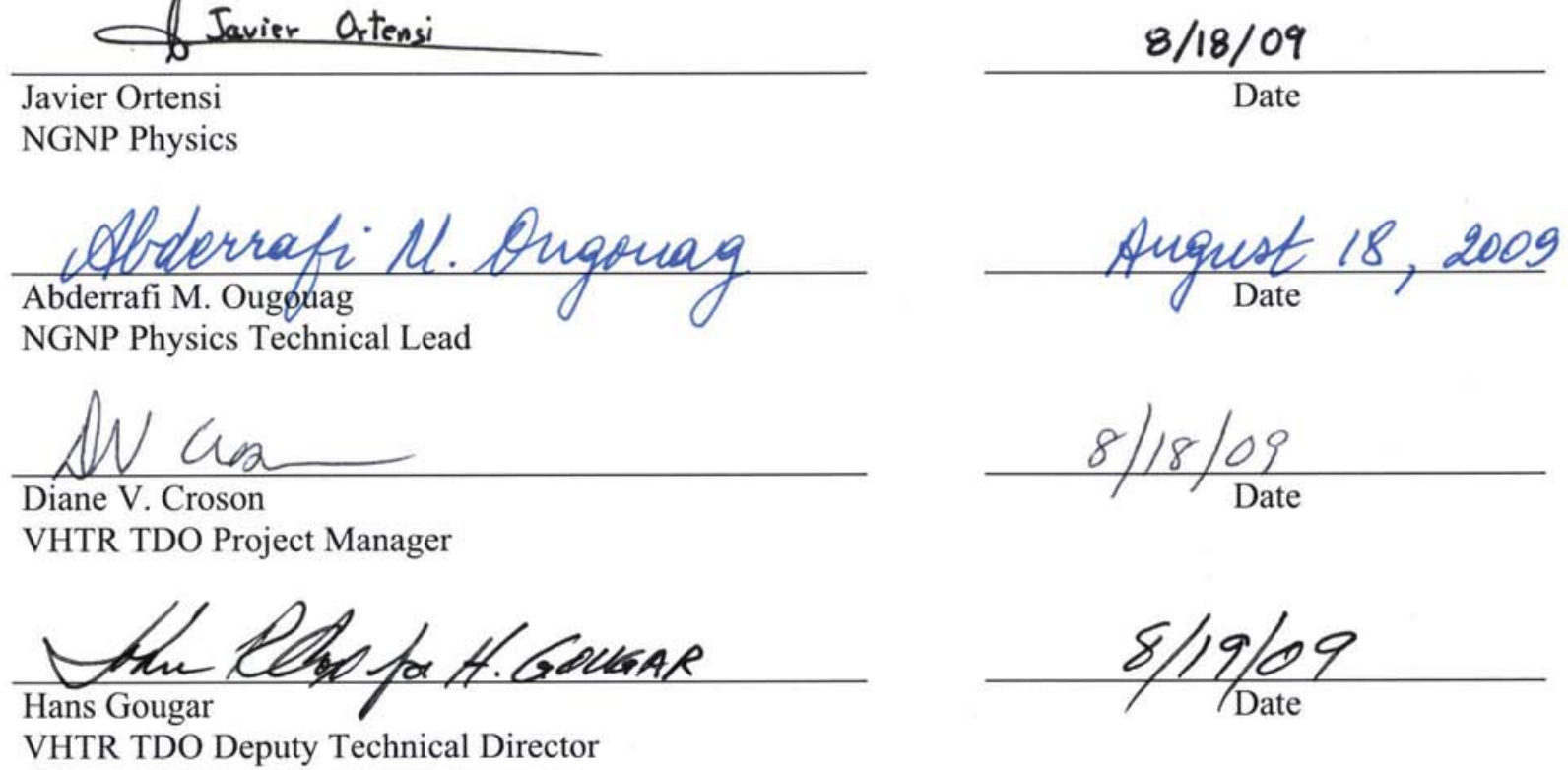



\begin{abstract}
The Doppler feedback mechanism is a major contributor to the passive safety of gas-cooled, graphite-moderated, high-temperature reactors that use fuel based on Tristructural-Isotropic coated particles. It follows that the correct prediction of the magnitude and time-dependence of this feedback effect is essential to the conduct of safety analyses for these reactors. This report presents a fuel conduction model for obtaining better estimates of the temperature feedback during moderate and fast transients. The fuel model has been incorporated in the CYNOD-THERMIX-KONVEK suite of coupled codes as a single Tristructural Isotropic (TRISO) particle within each calculation cell. The heat generation rate is scaled down from the neutronic solution and a Dirichlet boundary condition is imposed as the bulk graphite temperature from the thermal-hydraulic solution. This simplified approach yields similar results to those obtained with more complex methods, requiring multi-TRISO calculations within one control volume, but with much less computational effort. An analysis of the hypothetical total control ejection in the Pebble Bed Modular Reactor (PBMR)-400 design verifies the performance of the code during fast transients. In addition, the analysis of the earthquake-initiated event in the PBMR-400 design verifies the performance of the code during moderately slow transients. These analyses clearly depict the improvement in the predictions of the fuel temperature, and consequently, of the power escalations. In addition, a brief study of the potential effects of particle layer de-bonding on the transient behavior of high-temperature reactors is included. Although the formation of a gap occurs under special conditions, its consequences on the dynamic behavior of the reactor should be analyzed. The presence of a gap in the fuel can cause some unusual reactor behavior during fast transients, but still the reactor shuts down due to the strong feedback effects.
\end{abstract}




\section{ACKNOWLEDGEMENTS}

Work supported by the U.S. Department of Energy, Assistant Secretary for the office of Nuclear Energy, under DOE Idaho Operations Office Contract DEAC07-05ID14517. 


\section{CONTENTS}

ABSTRACT vi

ACKNOWLEDGEMENTS viii

ACRONYMS xiv

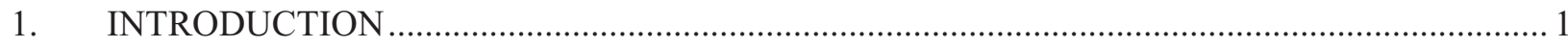

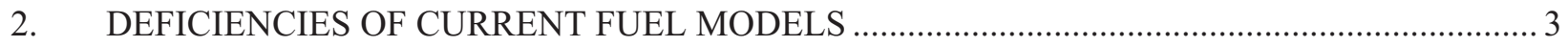

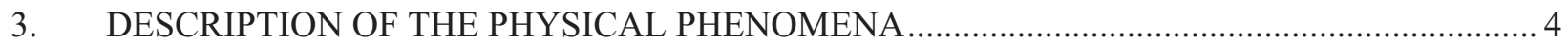

3.1 Temperature Feedback in HTGRs .............................................................................. 4

3.2 Effects from Thermo-Physical Properties .......................................................................... 4

4. DESCRIPTION OF THE MATHEMATICAL MODELS AND NUMERICAL

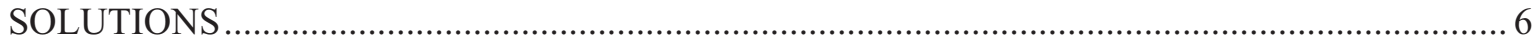

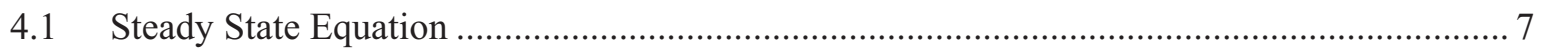

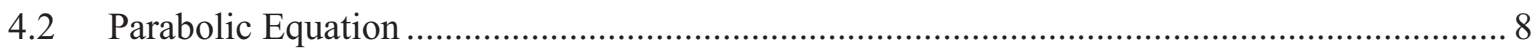

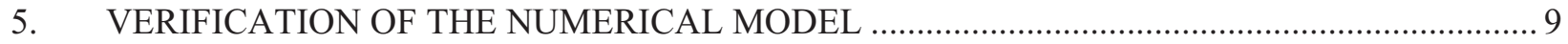

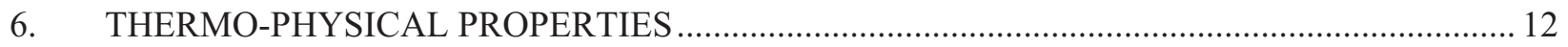

7. INTEGRATION INTO THE COUPLED NEUTRONIC-TH SYSTEM ....................................... 14

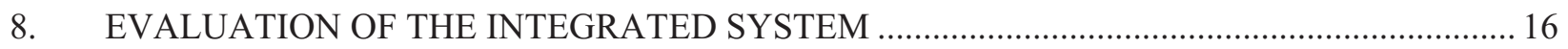

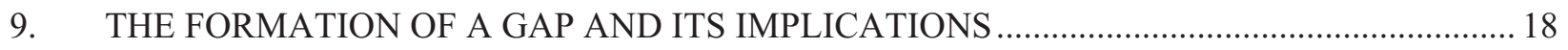

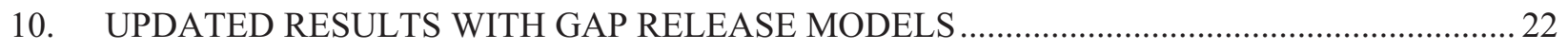

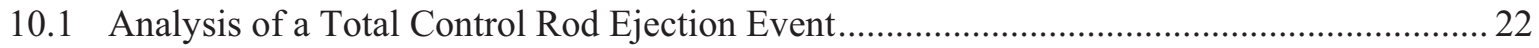

10.2 Analysis of an Earthquake-Initiated Transient Event ..................................................... 27

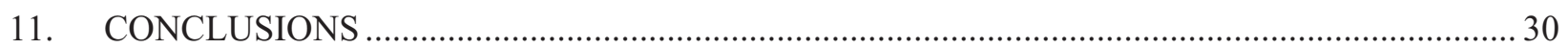

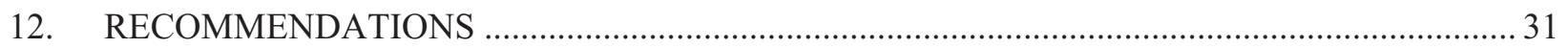

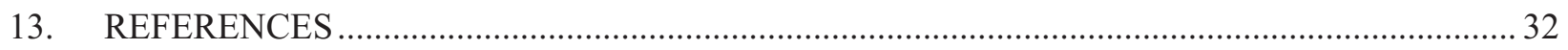

Appendix A-Analytic Solution to the 1-D Spherical Steady State Heat Conduction Equation ................ 33

Appendix B-Numerical Solution to the 1-D Spherical Parabolic Heat Conduction Equation .................. 37

Appendix C-Analytic Solution to the 1-D Spherical Parabolic Heat Conduction Equation .................... 43

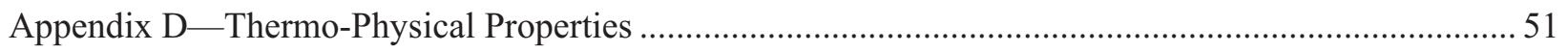




\section{FIGURES}

Figure 1. Composition of the fuel pebble. 1

Figure 2. Homogeneous and explicit models for a HTGR fuel pebble....................................................... 3

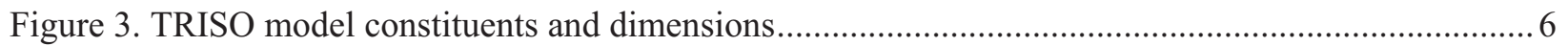

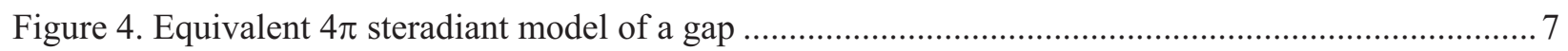

Figure 5. Benchmark with constant thermo-physical properties and constant heat generation................... 9

Figure 6. Benchmark with constant thermo-physical properties linear heat generation............................ 10

Figure 7. Benchmark with constant thermo-physical properties exponential heat generation. .................. 10

Figure 8. Benchmark with variable thermo-physical properties - Temperatures. .................................... 11

Figure 9. Benchmark with variable thermo-physical properties - Percent difference in

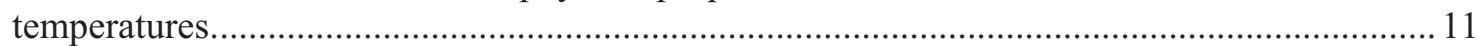

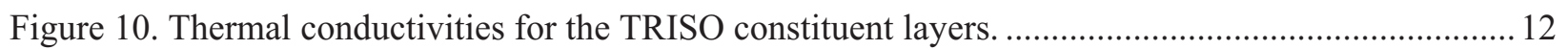

Figure 11. Specific heat capacities for the TRISO constituent layers..................................................... 12

Figure 12. Coupling between the neutronic code CYNOD and thermal-hydraulics THERMIX-

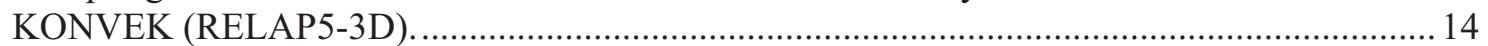

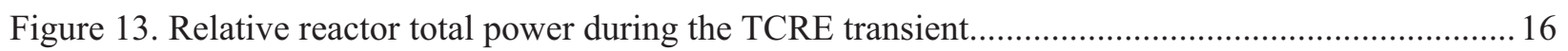

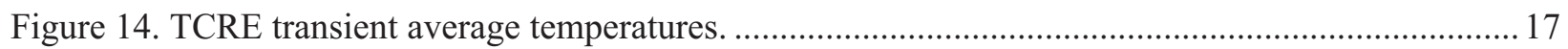

Figure 15. Effects of a TRISO gap on the relative core power............................................................... 18

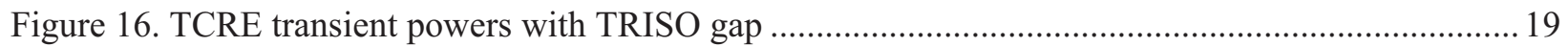

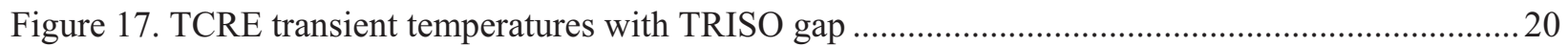

Figure 18. TCRE transient power with various effective gap conductivity values.................................2 21

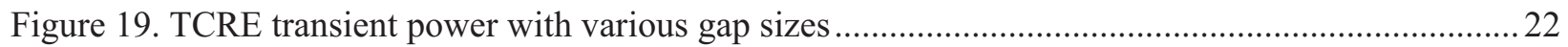

Figure 20. Maximum fuel temperature with various gap sizes during a TCRE.....................................22

Figure 21. Average fuel temperatures with various gap sizes during a TCRE ......................................23

Figure 22. TCRE average moderator temperatures with various gap sizes .......................................... 26

Figure 23. Fundamental mode eigenvalue with various gap sizes during a TCRE ................................26

Figure 24. Relative core power with a $15 \mu \mathrm{m}$ gap and various contact areas during a TCRE .................227

Figure 25. Relative core power during an earthquake transient in the PBMR-400 ................................28

Figure 26. Fundamental mode eigenvalue during an earthquake transient in the PBMR-400 ..................28

Figure 27. Fuel and moderator temperatures during the earthquake transient in the PBMR-400 .............29

Figure D-1 Thermal conductivity of UO2 as a function of temperature and burnup...............................5

Figure D-2. Thermal conductivity of the PyC layer as a function of temperature and fluence ................. 57

Figure D-3. Thermal conductivity of the porous carbon layer as a function of temperature and

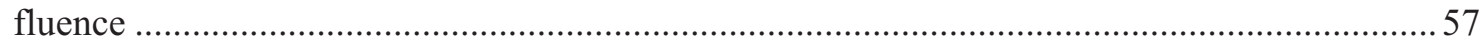

Figure D-4. Temperature and fluence dependent thermal conductivity of SiC ...................................... 59 
Figure D-5 Range of validity of $\mathrm{O} / \mathrm{f}$ equation in a multi-pass $\mathrm{PBR}$ with an average particle surface temperature of $1000^{\circ} \mathrm{C}$.

\section{TABLES}

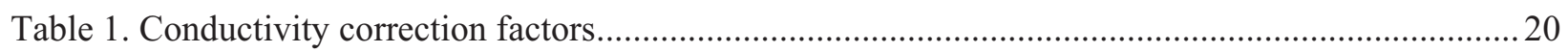

Table 2. Time evolution of the fuel temperature distribution during the TCRE Accident (no gap) ...........24

Table 3. Core distribution of TRISO internal gas pressures at 0.61 seconds during the TCRE (15

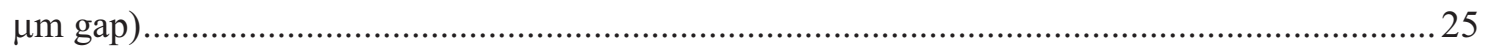

Table D-1. Parameters A and B used in gas conductivity calculation per Equation D-37 ....................... 64

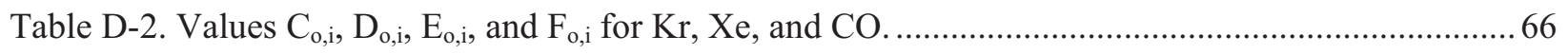




\section{ACRONYMS}

1-D one-dimensional

3-D three-dimensional

CEA Commissariat à l'Énergie Atomique

CVD Chemical Vapor Deposition

DBA Design Basis Accident

DNE Dido Nickel Equivalent

DOE Department of Energy

FIMA Fissions per Initial Metal Atom

HFP Hot Full Power

HTGR High Temperature Gas-Cooled Reactor

HTR High Temperature Reactor

INL Idaho National Laboratory

IPyC Inner Pyrolitic Carbon

KAIST Korea Advanced Institute of Science and Technology

NGNP Next-Generation Nuclear Plant

PBMR Pebble Bed Modular Reactor

PBR Pebble Bed Reactor

PDE Partial Differential Equation

QSHe Quasi-Static Heterogeneous

QSHo Quasi-Static Homogeneous

SAR Safety Analysis Report

TCRE Total Control Rod Ejection

TDHe Time Dependent Heterogeneous

TRISO Tristructural-Isotropic 


\section{Improved Prediction of the Temperature Feedback in TRISO-Fueled Reactors}

\section{INTRODUCTION}

Doppler, moderator, and reflector feedback are three essential temperature feedback mechanisms in gas-cooled, graphite-moderated high-temperature reactors (HTRs). These feedback effects provide the necessary passive safety for successful operation of these reactors. During moderately fast and fast reactor transients, the Doppler feedback mechanism is the dominating process that ensures this passive safety. Because the extent of the power escalation during these transients is determined by the fuel temperature, it is crucial to obtain accurate $\mathrm{UO}_{2}$ temperatures. Furthermore, the extent of the power escalation has an effect on the total energy deposition.

Modern designs of HTR cores are fueled with Tristructural-Isotropic (TRISO) coated particles. These particles are comprised of various layers acting in concert to provide a containment structure that prevent radioactive product release. For a pebble bed reactor (PBR), the TRISO particles are imbedded in a graphite matrix to form a pebble, as shown in Figure 1(OECD/NEA/NSC PBMR400 Benchmark 2007). The same particles are also used in the prismatic design by forming fuel compacts in a cylindrical graphite matrix. The TRISO particles include a fuel kernel, porous carbon layer, inner pyrolitic carbon (IPyC), $\mathrm{SiC}$, and outer pyrolitic carbon (OPyC). The main functions of the various layers are heat generation in the kernel, fission product retention in the porous layer, structural integrity in both pyrolitic carbons, and fission product barrier in the $\mathrm{SiC}$. The heat transfer characteristics of these components determine the ultimate temperature of the $\mathrm{UO}_{2}$ fuel kernel. The various materials that constitute TRISO particles have different thermo-physical and thermo-mechanical properties with varied dynamic behavior. Therefore, any improvement to the heat transfer model results in a more accurate calculation of the fuel temperature and the reactor power.

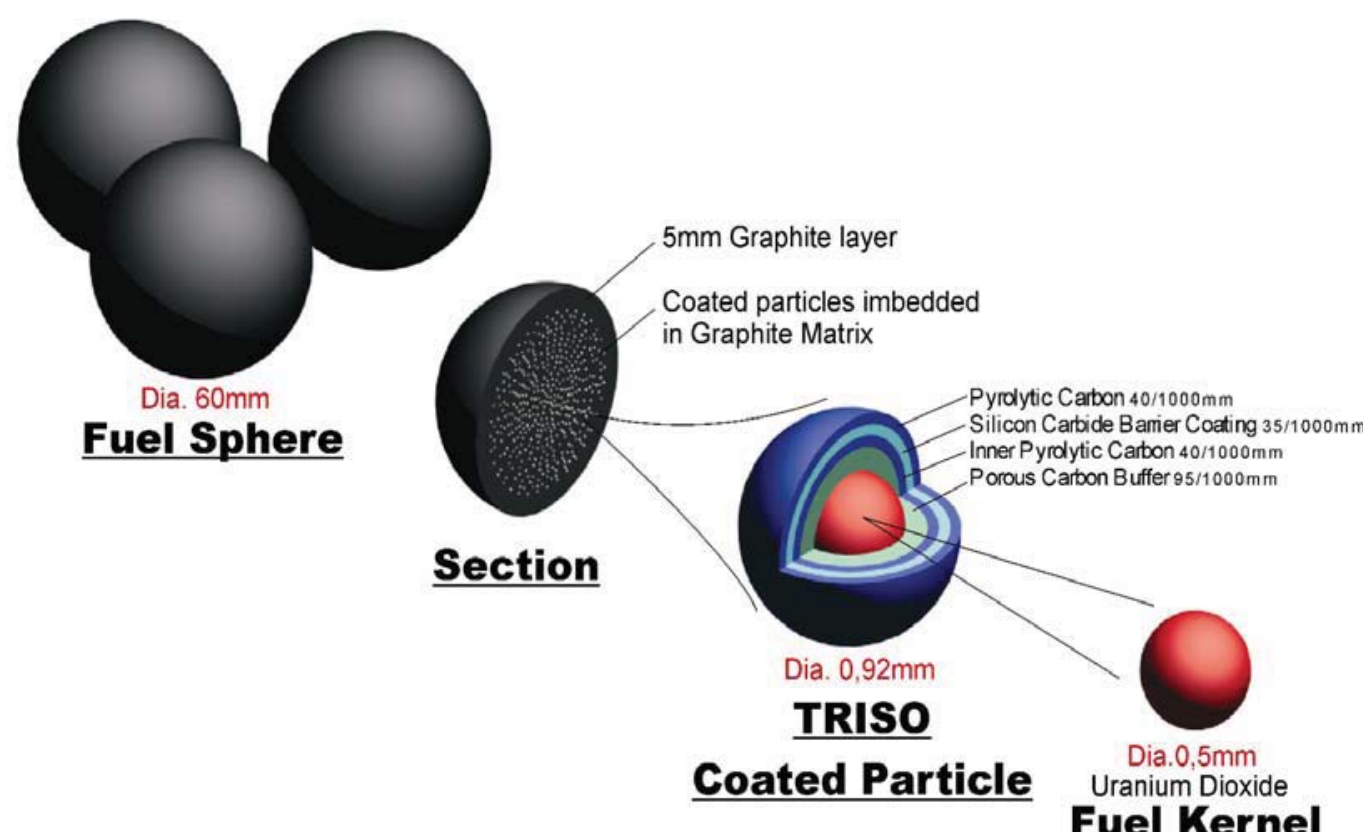

Figure 1. Composition of the fuel pebble. 
Most high-temperature gas-cooled reactor (HTGR) codes, like THERMIX (Teuchert 1994), only include a homogeneous model, which approximates the temperature of the fuel region. These models produce reasonable results for steady-state and very slow transient conditions. For moderate and fast transients, the models inadequately capture prompt effects. An alternative fuel model used in TINTE extrapolates the maximum fuel temperature from the solution to a homogenous model (Scherer 1989). The only HTR transient code before 2008 that appears to contain a fully explicit TRISO model is ZKIND (Rademer 2004). Unfortunately, no details on the development of ZKIND are available.

During the development of this work several articles have been published that specifically deal with explicit TRISO models. Noteworthy are the two-temperature models developed at Korea Advanced Institute of Science and Technology (KAIST) (Cho 2009), the multi-scale methods from Commissariat à l'Énergie Atomique (CEA) (Blanc 2008) and AMEC (Stainsby 2008), and finally the modifications to TINTE by PBMR Ltd. (Ubbink 2008). Of these works, only TINTE has been successfully used in full reactor transient analysis (Strydom 2008). 


\section{DEFICIENCIES OF CURRENT FUEL MODELS}

The current Idaho National Laboratory (INL) coupled neutronics-thermal-hydraulics code CYNODTHERMIX-KONVEK (Hiruta 2008) includes a shell model that approximates the temperature of the fuel region. Figure 2a includes an illustration for pebble bed fuel. Consequently, the fuel region, which contains a mixture of fuel and graphite matrix, is treated as a homogeneous domain with constant volumetric heat generation. This type of model overlooks the fact that the majority of the fission energy is deposited in the fuel kernel and that there can be a strong resistance to heat flow within the TRISO constituents. In addition, by not modeling the particles explicitly, it is assumed that the various materials in the fuel exhibit similar thermal inertia and play a small role in the dynamic behavior of the bulk macroscopic material. These models produce reasonable results for steady-state and very slow transient conditions where these assumptions are valid. For moderate and fast transients, these homogenous models underestimate the temperature in the fuel kernel and, consequently, significantly overestimate the neutron flux and power level.

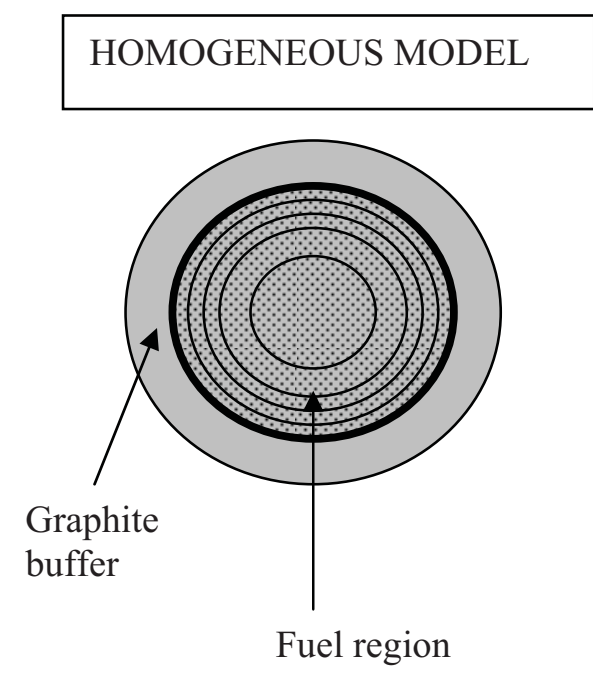

(2a)

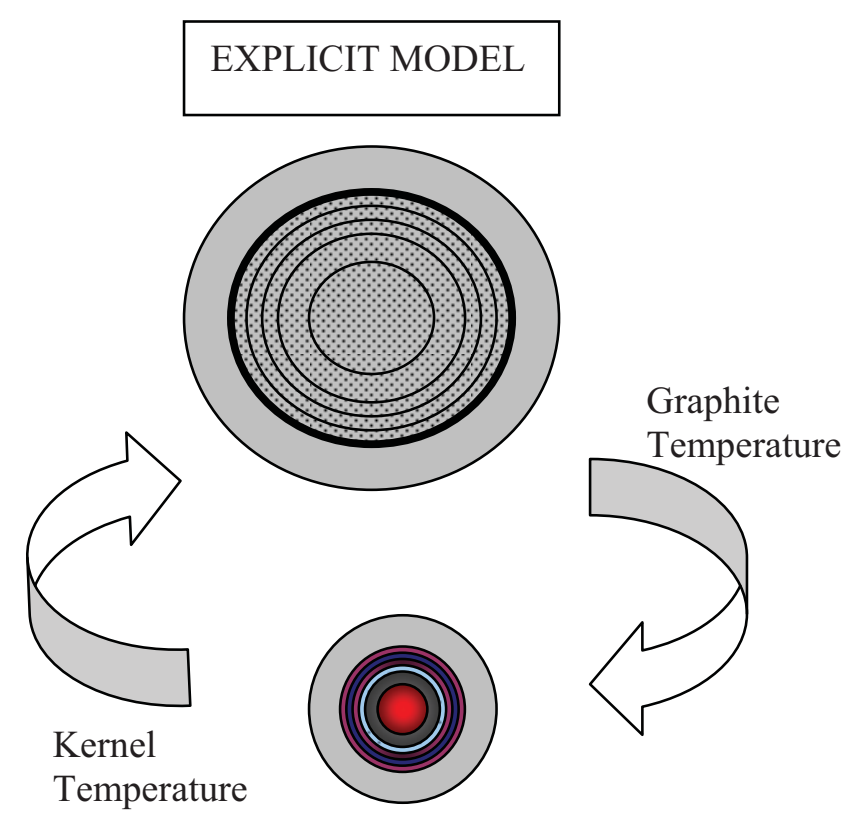

(2b)

Figure 2. Homogeneous and explicit models for a HTGR fuel pebble.

An explicit model, similar to the one depicted in Figure 2b, is necessary in order to accurately predict the fuel temperature in TRISO-fueled reactors. As depicted in the illustration, the explicit model uses the results from the homogeneous thermal-hydraulics calculation in order to determine the micro-scale heat transfer in the TRISO particle. 


\section{DESCRIPTION OF THE PHYSICAL PHENOMENA}

Nuclear fuel at steady state is in quasi-thermal equilibrium, where the reactor is kept in a quasicritical state by feedback mechanisms. Large departures from this quasi-equilibrium state are encountered when the neutron distribution changes significantly due to some material or geometrical modification of the system, which can arise from temperature changes or other means.

The effect that temperature changes have on the dynamic response of a nuclear reactor is commonly known as temperature feedback. A number of important physical phenomena determine the magnitude of temperature feedback. In HTRs, these phenomena are captured by essentially three feedback mechanisms: Doppler, moderator, and reflector.

\subsection{Temperature Feedback in HTGRs}

The Doppler temperature feedback is a stabilizing, almost instantaneous effect in fuel. This temperature feedback is the consequence of Doppler broadening, a neutronic phenomenon driven by changes in the relative velocities of the U-238 atoms and the neutrons and has a direct effect on the neutron population through resonance absorption. These atom velocities are represented by the macroscopic material temperatures. Therefore, changes to the fuel temperature affect the magnitude of Doppler feedback, which, in turn, modifies the neutron population and, thus, the power generation.

The moderator temperature feedback effect is due to the spectral shifting induced by scattering in graphite and by a reduction in absorption of thermal neutrons in graphite at higher temperatures. It is normally a stabilizing effect, but can, in the presence of some low-lying resonances, be de-stabilizing in nature. It is a delayed effect, when compared to the Doppler temperature feedback.

The reflector temperature feedback effect is a destabilizing mechanism in graphite-moderated reactors. It is a largely delayed effect since the heat up of the reflector region is a slow process during transients. The effect emerges from the reduced absorption of thermal neutrons in graphite at higher temperatures, which allows more thermal neutrons to enter the reactor core.

\subsection{Effects from Thermo-Physical Properties}

The various materials that constitute TRISO particles and the rest of core and reflector materials have different thermo-physical and thermo-mechanical properties with varied dynamic behavior. From a heat transfer perspective, the layered composition of the TRISO generates a natural resistance to heat flow. This effect was previously identified (Merrill 1963), but the explicit modeling of the fuel particles was never pursued, as far as the authors know, due to the lack of data for the heat transfer model.

The Doppler feedback is pronounced in HTRs mainly due to the relatively low heat capacity of $\mathrm{UO}_{2}$ when compared to the surrounding constituents of TRISO fuel. In addition, the majority of the energy deposition occurs in the fuel kernel as well. This allows the kernel temperature to increase significantly faster that its surroundings, a fact that is overlooked in homogenous models.

The delayed nature of both the moderator and reflector feedbacks are mainly due to the large volumetric heat capacity of graphite, which effectively delays the temperature rise in the core graphite and surrounding reflector. Since the nuclear phenomena of absorption and scattering of neutrons is highly sensitive to material temperatures, this delay is equally experienced in the changes to the neutron population.

A specific case study dealing with the formation of a gap inside the TRISO particle and its effect on the fuel temperature is further developed in this work. Under certain circumstances, determined by the 
fluence and temperature history, a gap forms between the buffer and the IPyC through irradiation-induced shrinkage. This phenomenon has been observed in some samples of current irradiation programs (Miller 2006). It is yet unclear if this effect is magnified by the higher dose rate that the samples experience during accelerated irradiation, but the constituent layers exhibit very different irradiation responses and detach. Nevertheless, the formation of a gap that fills with fission gases and CO, for oxide fuels, can have a significant impact. The fuel performance codes PARFUME and STRESS3 model the layer detachment (Miller 2004; Martin 2003). Results from these codes indicate that, under the circumstances analyzed, a gap quickly forms during irradiation and remains near a value of $20 \mu \mathrm{m}$ at fluence levels between $1 \times 10^{25}$ and $4 \times 10^{25} \mathrm{n} / \mathrm{m}^{2}$ (Miller 2006). 


\section{DESCRIPTION OF THE MATHEMATICAL MODELS AND NUMERICAL SOLUTIONS}

The approach developed in this work incorporates an explicit TRISO heat conduction model within the framework of the solution to the homogeneous fuel model attained via a thermal-hydraulic code. Figure 3 shows the materials and dimensions used in modeling the TRISO fuel particle.

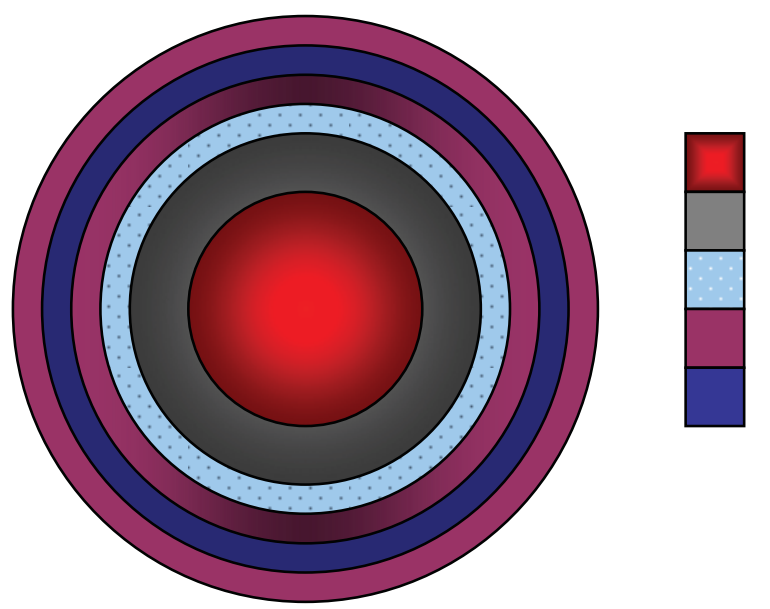

\section{Material/Layer Thickness}

$\mathrm{UO}_{2} /(250 \mu \mathrm{m})$

Porous Carbon/(80 $\mu \mathrm{m})$

$\mathrm{Gap} /(\sim 15-20 \mu \mathrm{m})$

Pyrolitic Carbon/(40 $\mu \mathrm{m})$

$\mathrm{SiC} /(35 \mu \mathrm{m})$

Figure 3. TRISO model constituents and dimensions.

A one-dimensional (1-D) geometrical model is used in this work. This assumes angular symmetry (i.e., heat conduction out of the TRISO particle only varies in the radial direction). The 1-D Partial Differential Equation (PDE) that governs heat conduction is:

$$
\nabla \cdot(k(r, t) \nabla T(r, t))+q^{\prime \prime}(r, t)=\frac{\partial \rho(r, t) C_{p}(r, t) T(r, t)}{\partial t} 0 \leq r \leq R \text { for } \mathrm{t} \geq 0
$$

where $\mathrm{k}, \rho$, and $\mathrm{C}_{\mathrm{p}}$ are the thermal conductivity, density, and specific heat capacity, respectively. In order to simplify the problem, it is assumed that the thermo-physical properties do not vary significantly in between time steps, thus yielding the following:

$$
\nabla \cdot(k(r) \nabla T(r, t))+q^{\prime \prime}(r, t)=\rho(r) C_{p}(r) \frac{\partial T(r, t)}{\partial t} 0 \leq r \leq R \text { for } \mathrm{t} \geq 0
$$

This implies an error in the energy conservation that is very small in magnitude when compared to the changes in temperature. This small error can be further reduced by performing nonlinear iterations to update the thermo-physical properties. The solution to this second order PDE requires two boundary conditions and one initial condition. The boundary conditions imposed are a Neumann ( $2^{\text {nd }}$ kind) condition at the center and Dirichlet $\left(1^{\text {st }}\right.$ kind $)$ at the outer surface:

$$
\left.\frac{\partial T(r, t)}{\partial r}\right|_{r=0}=\left.0 \quad T(r, t)\right|_{\partial D}=T_{g}(t) \text { for } \mathrm{t} \geq 0
$$

The initial condition will be the steady-state temperature distribution at the initial time:

$$
T(r, 0)=T_{s s}(r)
$$


The gap is modeled as a full $4 \pi$ steradiant region filled with a gas as shown in Figure 3. For simplification, a single gap size is assumed for all particles in the model. This assumption can be later expanded to include a gap size distribution in the core. Since, physically, the IPyC is not completely detached from the porous carbon layer, some contact area does remain, as depicted in Figure 4 . The heat transfer rate through this area $\left(\mathrm{q}_{\mathrm{c}}\right)$ can be quite different than that of the gap region $\left(\mathrm{q}_{\mathrm{g}}\right)$. An effective gap conductivity, $\mathrm{k}$, is used in order to capture the enhanced heat transfer through the contact region. A set of steady state HEATING 7.3 (Childs 2007) cases in three-dimensional (3-D) spherical geometry are used to determine the multipliers for the effective gap conductivity at various heat generation rates. The carbon density is adjusted in this calculation to maintain mass conservation. These multipliers increase the conductivity in the gap region, thus correcting the full ( $4 \pi$ steradiant) gap model.

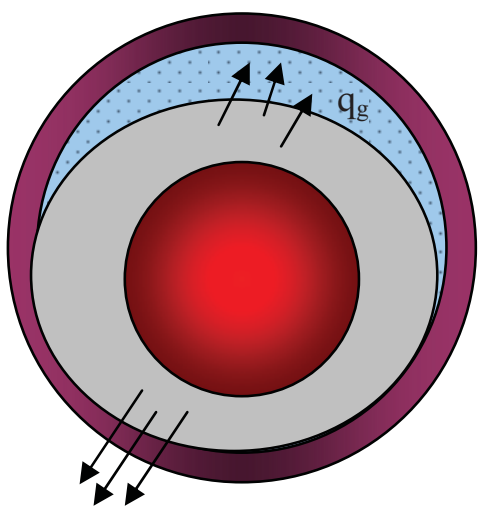

$\mathrm{q}_{\mathrm{c}}$

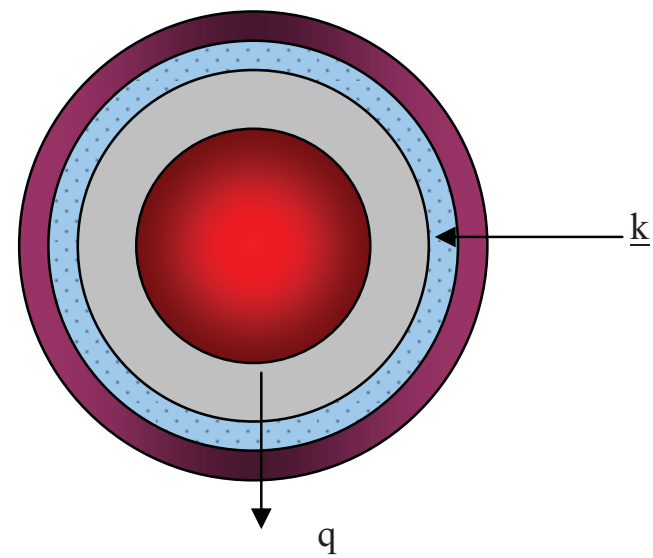

Figure 4. Equivalent $4 \pi$ steradiant model of a gap.

The effects of radiative heat transfer in the gap have been omitted in this analysis. A calculation with a 20 micron, $4 \pi$ steradiant gap during the Total Control Rod Ejection (TCRE) accident showed that radiative heat transfer in the TRISO with the largest temperature gradient in the entire core is in the order of $18 \%$. During steady-state operation and most transient, the maximum radiative heat transfer is expected to be around a few percent.

\subsection{Steady State Equation}

Equation 2 can be further simplified by eliminating the time dependence and assuming a homogeneous thermal conductivity yielding the 1-D spherical steady-state heat conduction equation:

$\frac{d^{2} T}{d r^{2}}+\frac{2}{r} \frac{d T}{d r}+\frac{q^{\prime \prime}}{k}=0 \quad 0 \leq r \leq R$

The derivation of the solution to this steady state problem can be found in Appendix A. The temperature field for heated region is given by:

$T_{\text {heated }}(r)=\frac{q_{i}^{\prime \prime}}{6 k_{i}}\left(r_{i+1}^{2}-r^{2}\right)+T_{i+1}$ 
The temperature field in non-heated regions is obtained by imposing to Equation A-1 a nonzero heat flux at the lower boundary, $-\left.k_{1} \frac{d T}{d r}\right|_{r=r_{i}}=\frac{r_{1} q_{1}^{\prime \prime}}{3}$, yielding:

$T_{\text {unheated }}(r)=\frac{r_{f s}^{3} q^{\prime \prime \prime}}{3 k_{i}}\left(\frac{1}{r}-\frac{1}{r_{i-1}}\right)+T_{i-1}$

\subsection{Parabolic Equation}

Equation 2 can be rewritten in the heat flux formulation via Fourier's law:

$-\nabla \cdot \vec{q}(r, t)+q^{\prime \prime}(r, t)=\rho(r) C_{p}(r) \frac{\partial T(r, t)}{\partial t} \quad 0 \leq r \leq R$ for $\mathrm{t} \geq 0$

Eq. 8

Appendix B contains the derivation for the numerical solution to this equation. Employing a theta time differencing scheme, using Fourier's law as the closure model, and forcing the continuity of the heat flux at the interfaces yields a three-point formulation with the average cell temperatures:

$$
\begin{aligned}
& \theta\left(a_{i+1} \widetilde{T}_{i+1}^{n+1}+a_{i} \widetilde{T}_{i}^{n+1}+a_{i-1} \widetilde{T}_{i-1}^{n+1}\right)=\left((1-\theta) q_{i}^{,{ }^{n}}+\theta q_{i}^{,{ }^{n+1}}\right) V_{i} \\
& +(1-\theta)\left(b_{i+1} \widetilde{T}_{i+1}^{n}+b_{i} \widetilde{T}_{i}^{n}+b_{i-1} \widetilde{T}_{i-1}^{n}\right)
\end{aligned}
$$

Since the final matrix is positive, definite, tri-diagonal, and symmetric, the direct inversion of the two-banded system of equations yields the final solution. 


\section{VERIFICATION OF THE NUMERICAL MODEL}

The numerical solution to the time-dependent equation developed in Section 4.2 was implemented into a FORTRAN 90 computer code and is referred to in this work as the Time Dependent Heterogeneous TDHe model. The results from this program are benchmarked against the analytic solution to the 1-D spherical time-dependent conduction equation developed in Appendix $\mathrm{C}$. The model used in the test is a sphere of $\mathrm{UO}_{2}$ with $0.042-\mathrm{cm}$ radius initially at $917 \mathrm{~K}$. In addition, the code is also compared to the finite difference code HEATING (Childs 2007). Similar spatial and time discretizations are used to generate consistent comparisons of the computer implementations.

Figure 5 shows the percent difference in the temperature calculations for a homogeneous sphere with constant thermo-physical properties and a constant heat generation rate. The small differences, in the order of $0.006 \%$, seen in HEATING 7.3 appear to arise from the solution methodology. The TDHe results are in excellent agreement with the analytic solution.

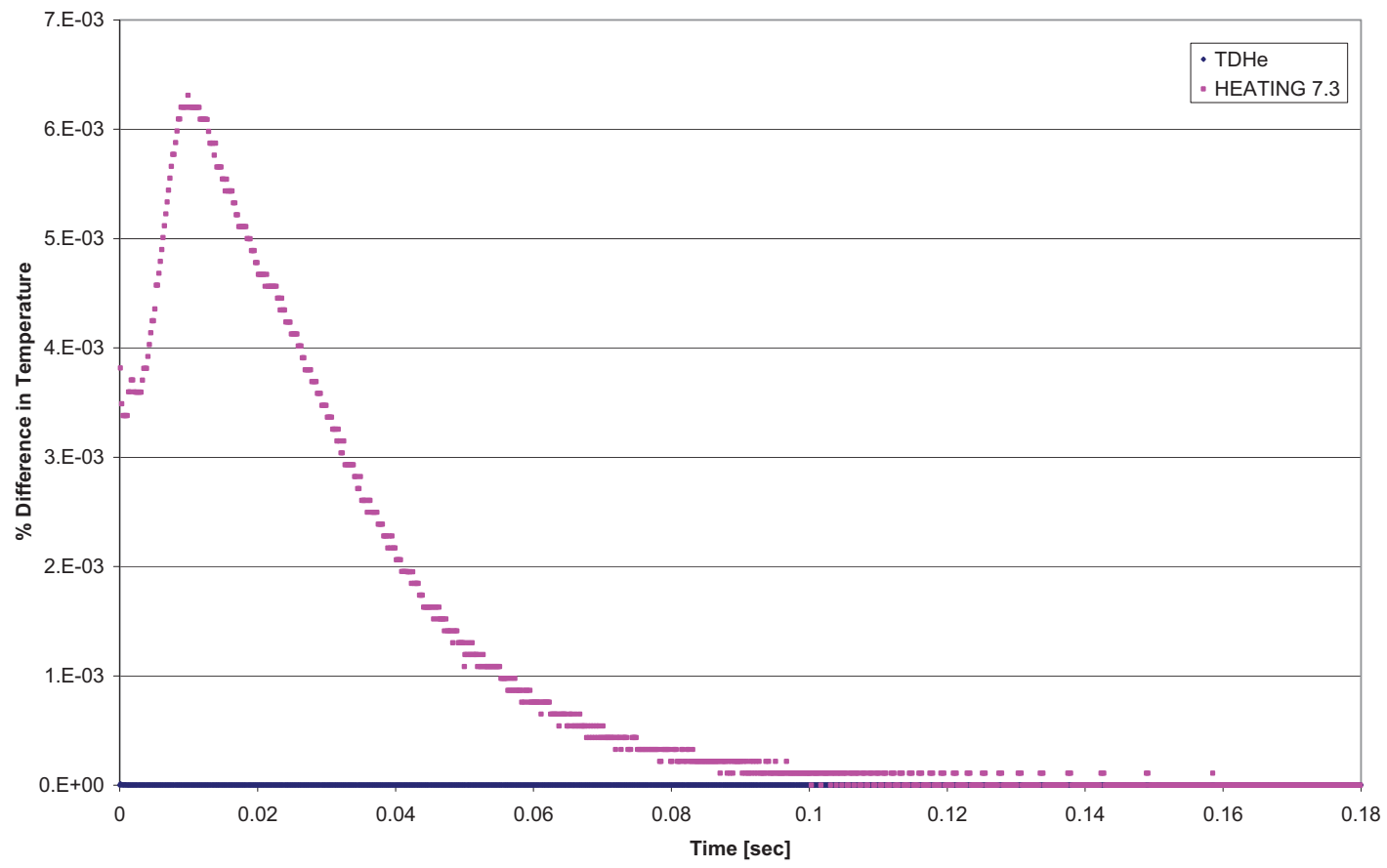

Figure 5. Benchmark with constant thermo-physical properties and constant heat generation.

The next test is used to study the solutions with a linear heat generation rate. Figure 6 shows that the TDHe results are also in good agreement with the rest of the solutions. The HEATING results reach a calculation precision limit of $1 \mathrm{E}-3 \%$ for this case with linear heat generation rate. 


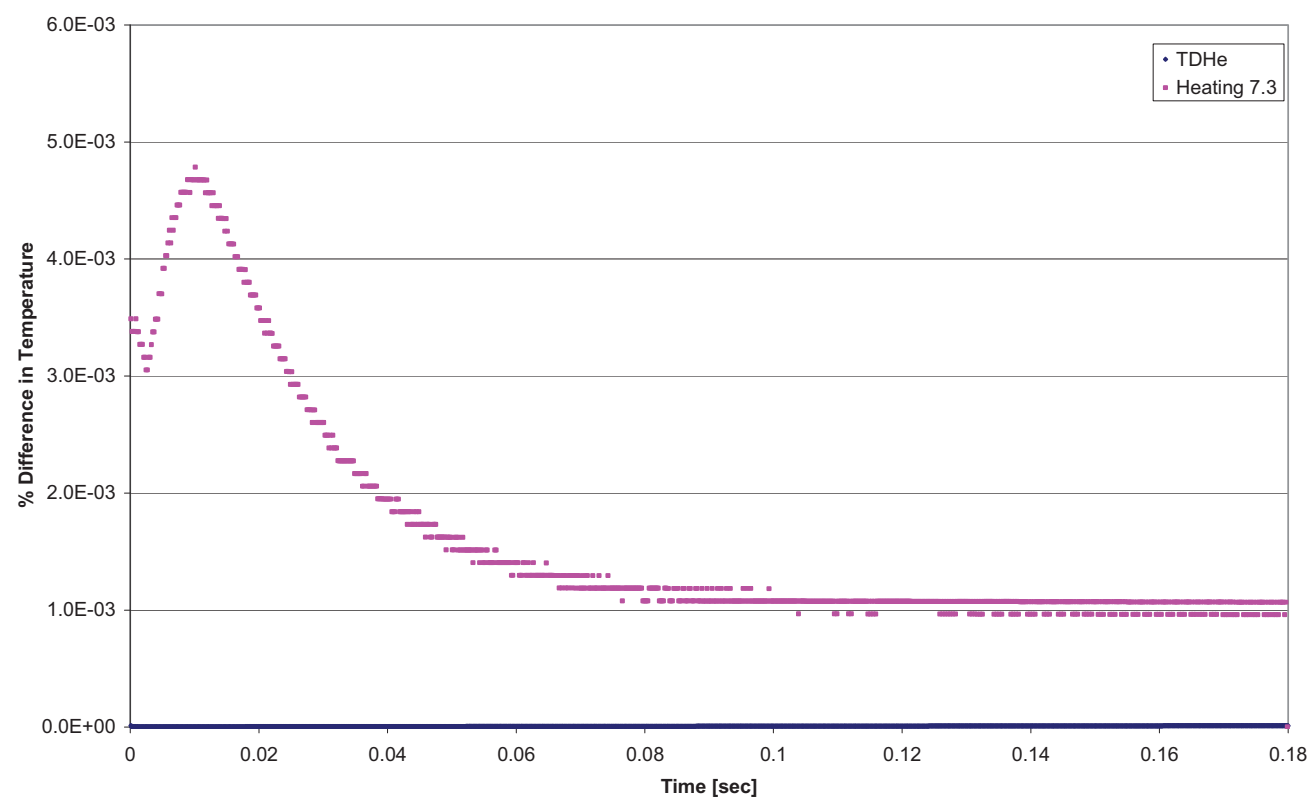

Figure 6. Benchmark with constant thermo-physical properties linear heat generation.

Figure 7 shows the percent difference in the temperature calculations for a homogeneous sphere with constant thermo-physical properties and an exponential heat generation rate. Again, very good agreement is obtained between the TDHe and the analytic solution and the same pattern is observed for the percent errors from HEATING.

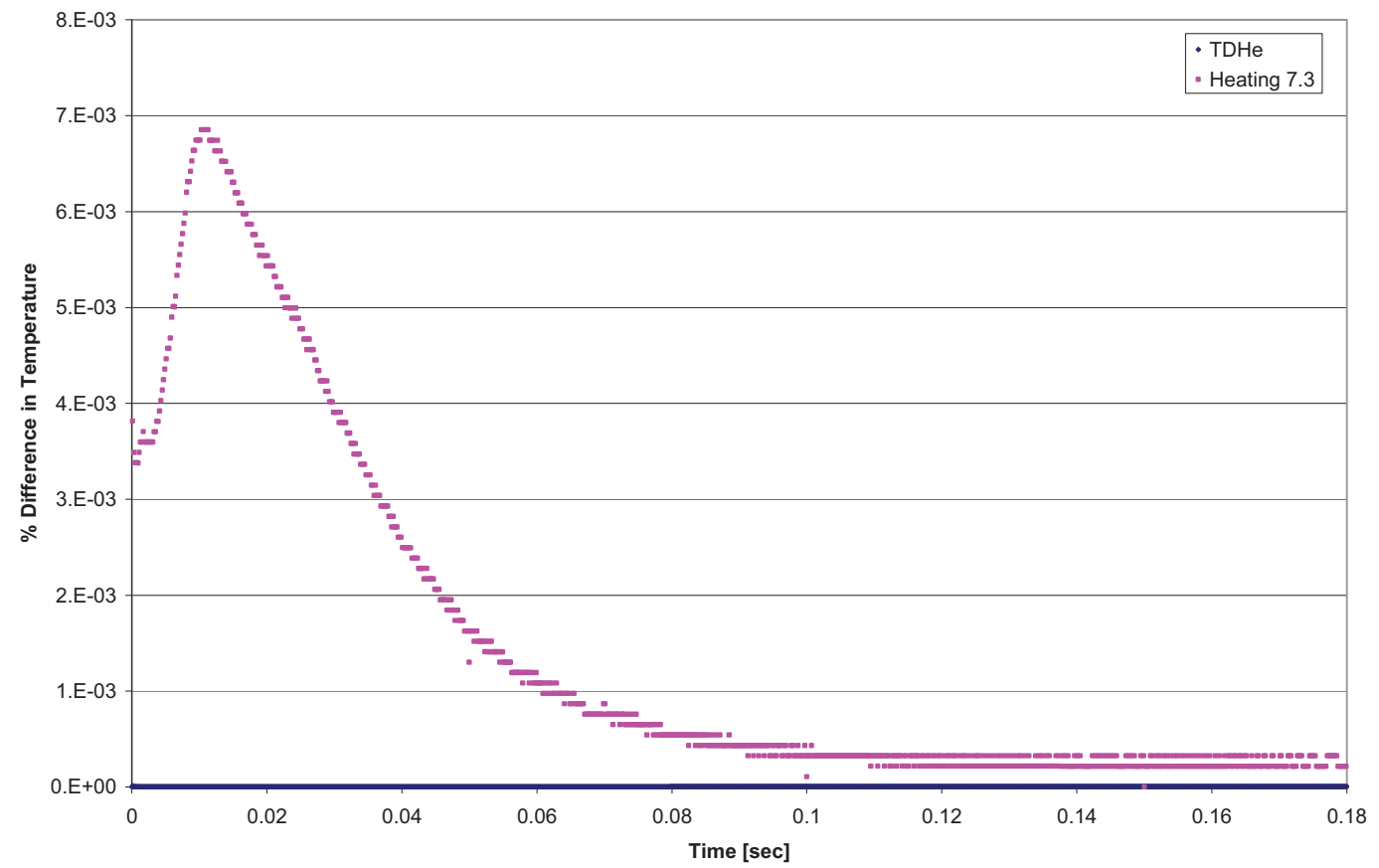

Figure 7. Benchmark with constant thermo-physical properties exponential heat generation. 
A code-to-code comparison is used to benchmark the nonlinear solution, since no analytic solution is available for the nonlinear case. Figures 8 and 9 present the comparison to HEATING for a model with variable properties in all of the layers and for an assumed power excursion. The code comparisons agree with maximum differences of $0.06 \%$.

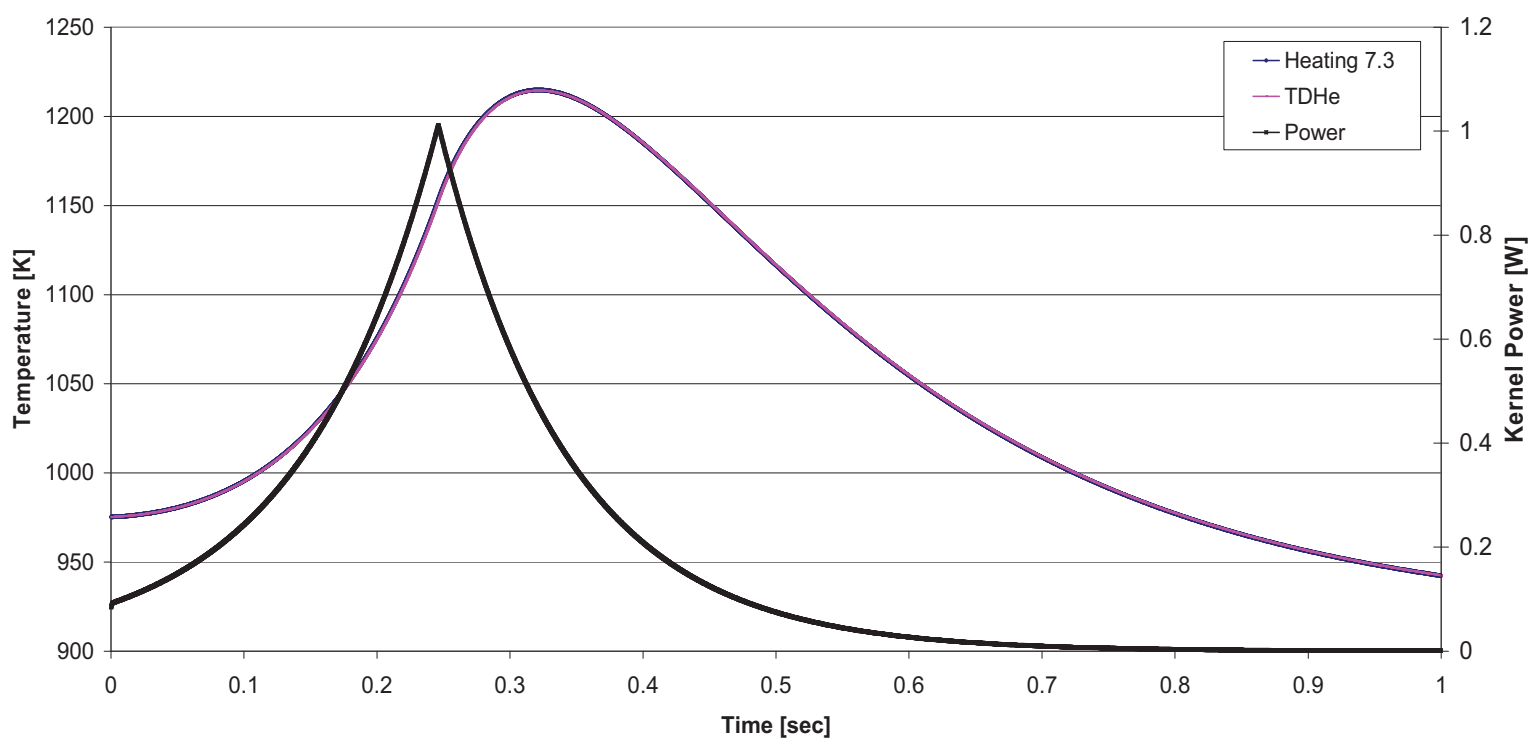

Figure 8. Benchmark with variable thermo-physical properties - Temperatures.

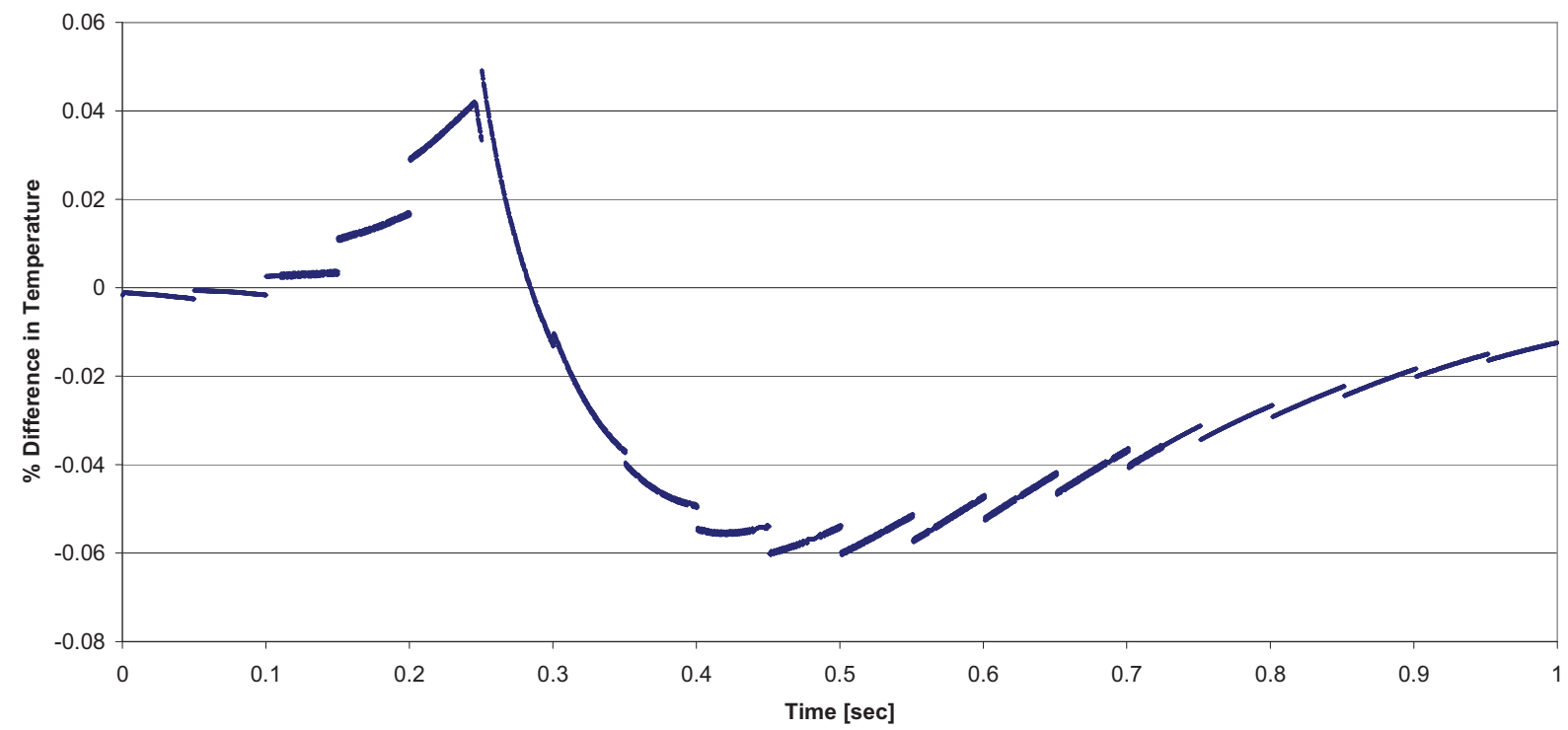

Figure 9. Benchmark with variable thermo-physical properties - Percent difference in temperatures. 


\section{THERMO-PHYSICAL PROPERTIES}

The initial part of the work and analysis was based on thermo-physical properties that did not consider the irradiation history of the various TRISO layers. The conductivities and specific heat capacities incorporated in this preliminary model are depicted in Figures 10 and 11, respectively. The calculation of the gap conductivity is based on approximated mole fractions for $\mathrm{CO}(75.9 \%)$ and fission gases $(14.1 \%)$.

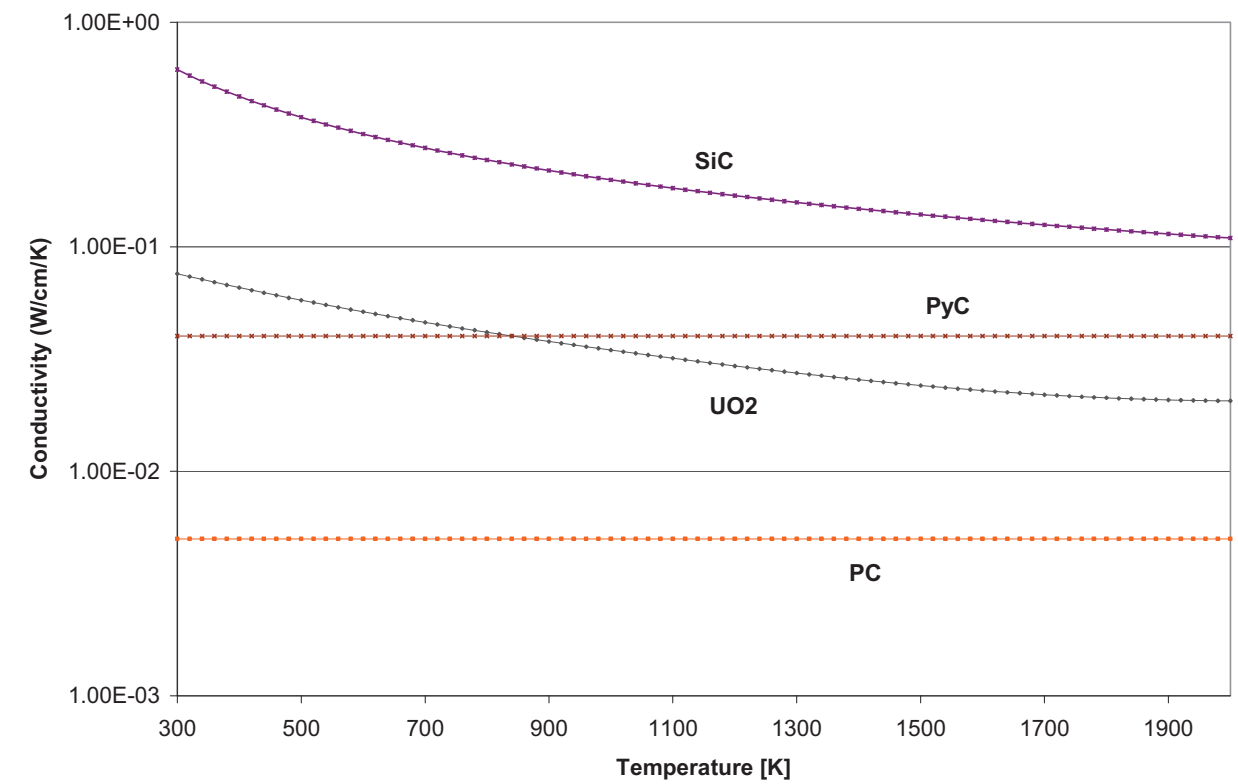

Figure 10. Thermal conductivities for the TRISO constituent layers.

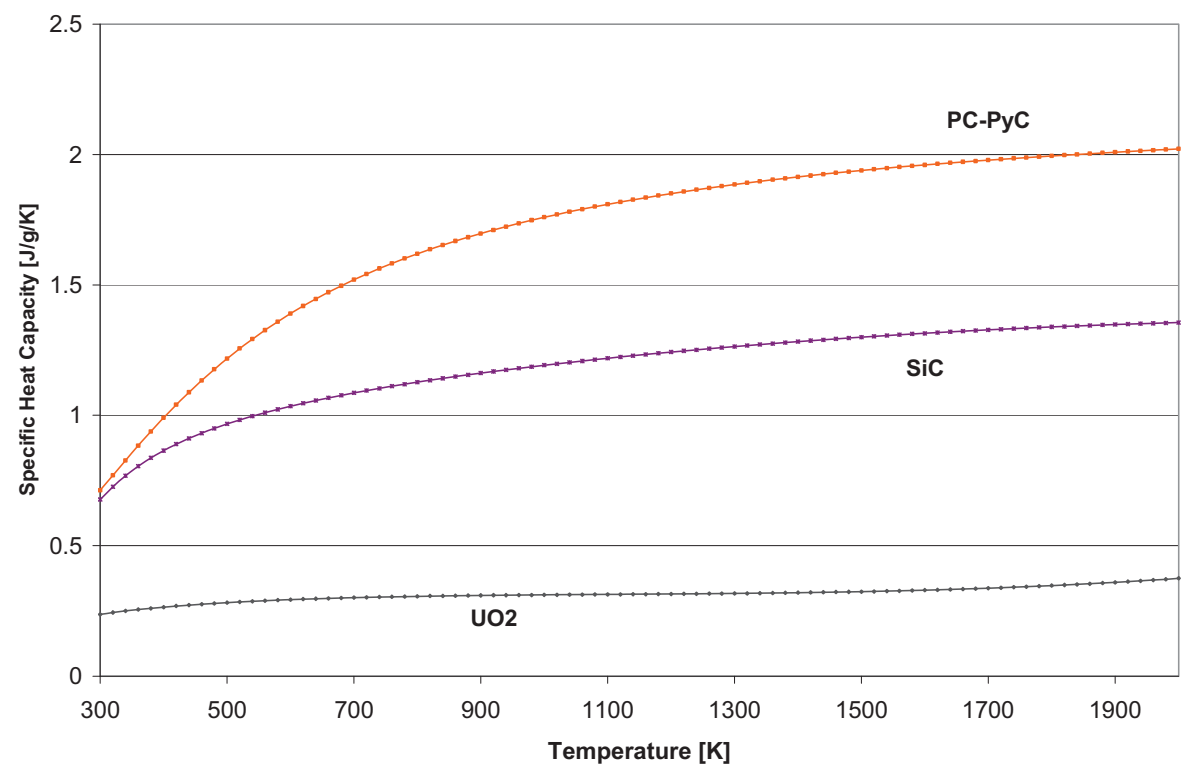

Figure 11. Specific heat capacities for the TRISO constituent layers. 
In order to improve the fidelity of the TRISO model, the material library is improved and expanded in Appendix D. Some of the improvements include irradiation-dependent properties of all materials, gas release models of $\mathrm{CO}, \mathrm{Kr}$, and $\mathrm{Xe}$ for both the steady state and the transient conditions, and the noncondensable heat capacity and conductivity models from RELAP5-3DC. Results with these model improvements are included in Section 10. 


\section{INTEGRATION INTO THE COUPLED NEUTRONIC-TH SYSTEM}

Fuel models developed during this study are integrated in the coupled CYNOD-THERMIXKONVEK suite of codes. CYNOD (Hiruta 2008) is a semi-analytical nodal diffusion code based on a Green's function method with an implicit time-dependent scheme. CYNOD is coupled to the thermalhydraulics code THERMIX-KONVEK (Teuchert 1994), a two-dimensional (R-Z) quasi-static code developed by the KFA-Jülich, which contains correlations and material properties developed in the German PBR program. The homogeneous fuel model that is used in THERMIX is referred to as the quasi-static homogeneous (QSHo) model in this work.

Figure 12 shows a schematic of the coupling arrangement. Note that CYNOD has been coupled separately to THERMIX-KONVEK and RELAP5-3D. THERMIX-KONVEK is the thermal-hydraulic solver used in this work. The TRISO model is applied within each calculation cell and uses the cell average power density, renormalized to the kernel volume, as the heat generation source. The bulk graphite temperature from the thermal hydraulics calculation is used as the boundary condition at the OPyC-matrix interface. The interface thickness can be varied in order to adjust the location of the bulk graphite temperature within the pebble or compact.

The main idea behind this simplified modeling is to capture the behavior of the average TRISO particle in each calculation cell in a manner that is easily implemented in the current suite of codes to provide an initial analysis capability. The use of the Dirichlet condition with the bulk graphite temperature allows for a fast coupling of the heat transfer models to obtain a representative fuel temperature.

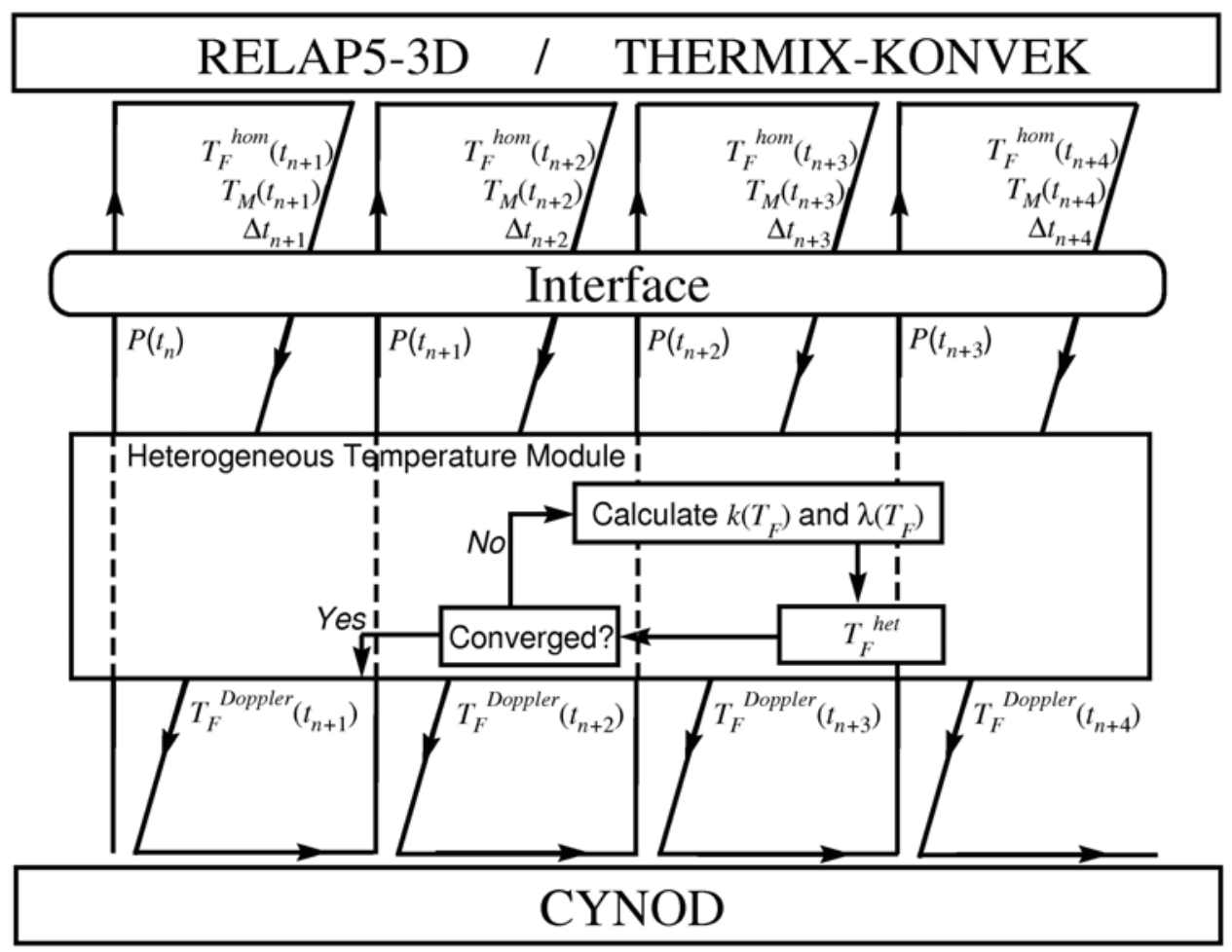

Figure 12. Coupling between the neutronic code CYNOD and thermal-hydraulics THERMIX-KONVEK (RELAP5-3D). 
Initially, a preliminary fuel temperature model was used to determine the potential benefits of developing a time-dependent kernel-level model. The steady-state equations from Section 4.1 were used for the model referred to as the quasi-static heterogeneous (QSHe) model. Given the success of the QSHe, the model developed in Section 4.2 (TDHe) and tested in Section 5 was incorporated in the coupled system. 


\section{EVALUATION OF THE INTEGRATED SYSTEM}

The TCRE problem from the PBMR benchmark exercise was used to examine the potential benefits of the new method. This transient is included in the PBMR safety analysis report (SAR) as a design basis accident (DBA) (Strydom 2008), but there are currently no known initiators that could lead to this transient. Nevertheless, it serves to determine the capabilities of the explicit TRISO model in extreme cases. The event initiates from Hot Full Power (HFP) and involves the withdrawal of all 24 control rods in 0.1 seconds.

The results to the TCRE transient confirm the considerable improvement obtained by using explicit TRISO models over the predictions from the homogeneous model. Figure 13 shows how the prompt reactor feedback driven by the Doppler Effect has a more significant role than predicted by the original homogeneous THERMIX model. The calculated maximum powers are roughly 160, 26, and 30 times the nominal power for the QSHo, QSHe, and TDHe, respectively. Therefore, the QSHo model overestimates the reactor power by a factor of 130, while the QSHe underestimates the reactor power by a factor of 4 . In addition, the power curve indicates that the reactor period during the cool down is longer than previously predicted with the homogenous fuel region model.

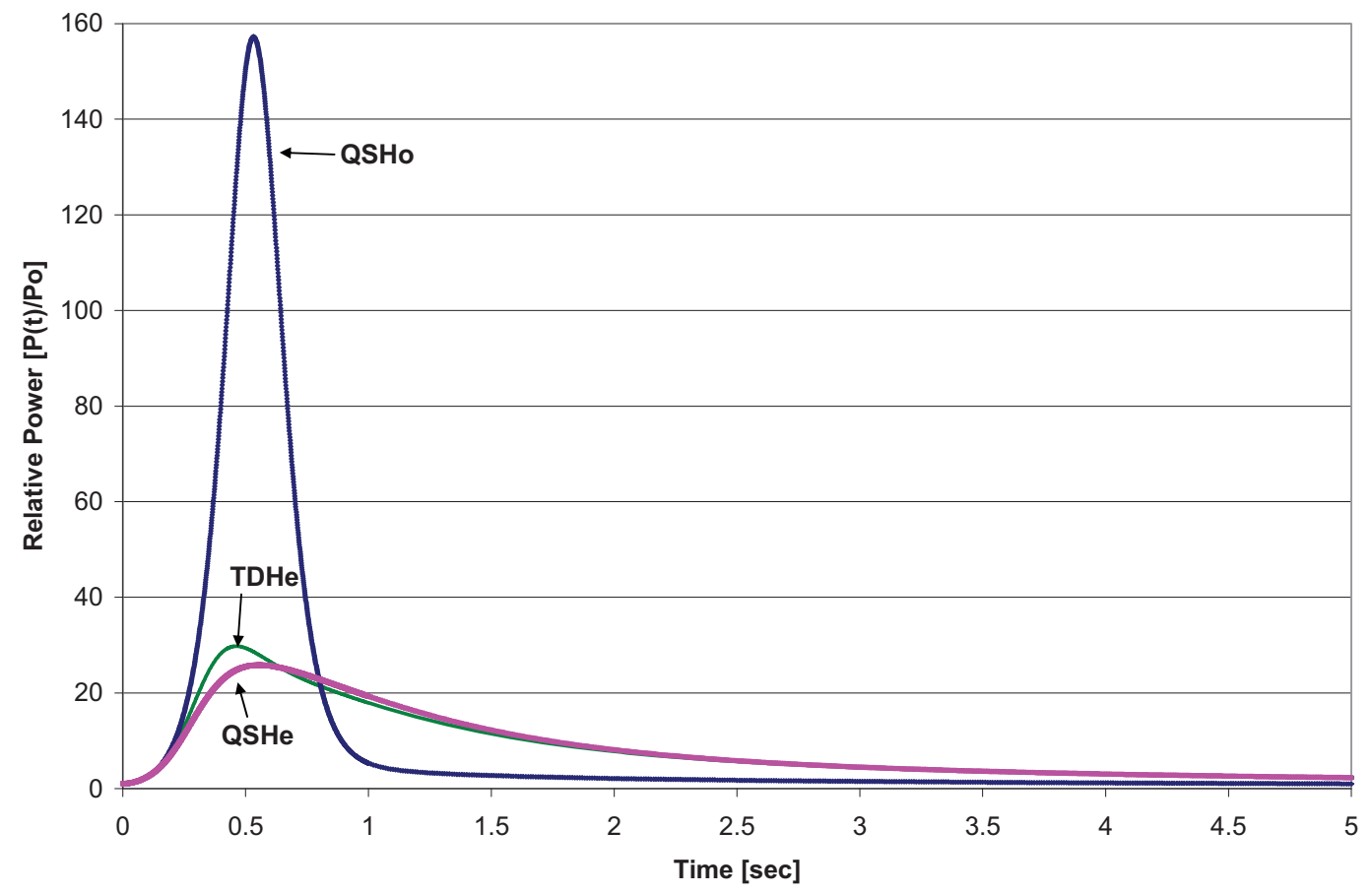

Figure 13. Relative reactor total power during the TCRE transient.

The maximum fission power calculated by the TDHe model is 11904 MW and agrees well with the value of $11750 \mathrm{MW}$ obtained with TINTE (Strydom 2008). The power decays slightly faster in the TDHe model that in the TINTE analysis, but this is probably due to differences in thermo-physical properties of the model, since the TDHe analysis uses variable properties. The new model also reveals that the overall energy generation, and thus deposition, during the rod ejection transient is $12 \%$ lower than predicted by the unenhanced model.

Figure 14 shows that the average fuel temperature in the core reaches a slightly higher maximum, but at no time does it approach the nominal, allowable average fuel temperature of $1600^{\circ} \mathrm{C}$. The 
homogeneous model predicts a delayed moderator and fuel temperature rise that not only delay the Doppler feedback, resulting in a sharp power escalation, but it also produces nearly simultaneous Doppler and moderator feedback, yielding an equally fast drop in relative core power.

The maximum fuel temperature obtained with the TDHe is $1700^{\circ} \mathrm{C}$. A value of $1768^{\circ} \mathrm{C}$ is reported in the TINTE study, but it is based on a peaking model, which yields a higher temperature than the explicit TRISO model. The TINTE kernel model (Ubbink 2008) yields a kernel maximum temperature of $1691{ }^{\circ} \mathrm{C}$. This shows that the INL results are in good agreement with the TINTE results for the PBMR benchmark case.

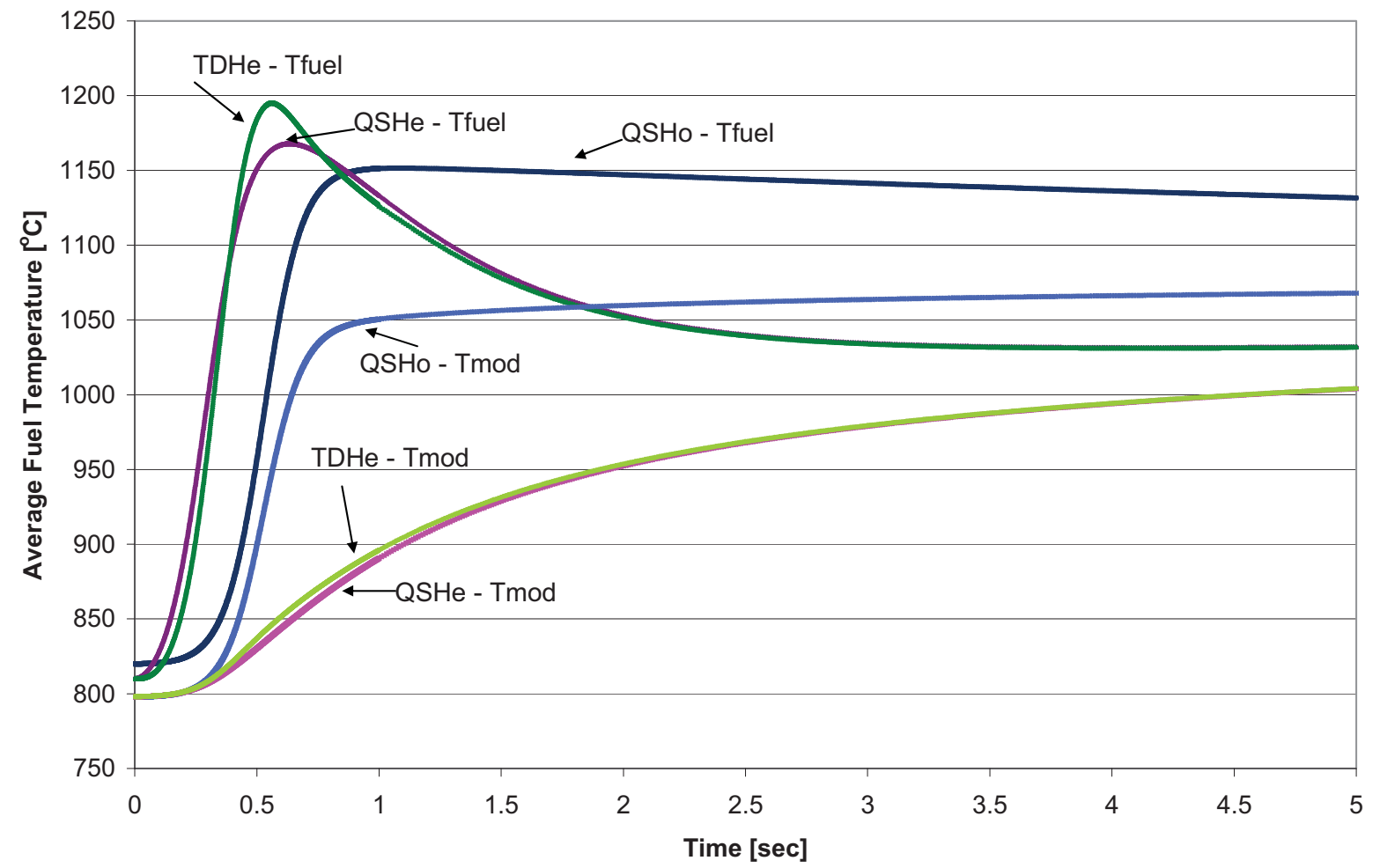

Figure 14. TCRE transient average temperatures. 


\section{THE FORMATION OF A GAP AND ITS IMPLICATIONS}

The presence of a gap magnifies the resistance to heat flow out of the fuel region. Essentially, the gap forms a semi-adiabatic system within the TRISO particle, which translates into higher fuel temperatures and, consequently, increased Doppler feedback effects. Figure 15 shows a set of calculations with the QSHe model with a $4 \pi$ steradiant gap without and effective conductivity correction. The gap size ranges from a closed gap to a 20 micron gap. The core power profile decreases in amplitude with an increasing gap size. The relative power drops by an additional factor of 20 with the 20 micron gap; the period of the reactor also increases with increasing gap size. The amount of energy generation during the rod ejection transient decreases with the enhanced calculation of the Doppler feedback since the area under the curve is reduced.

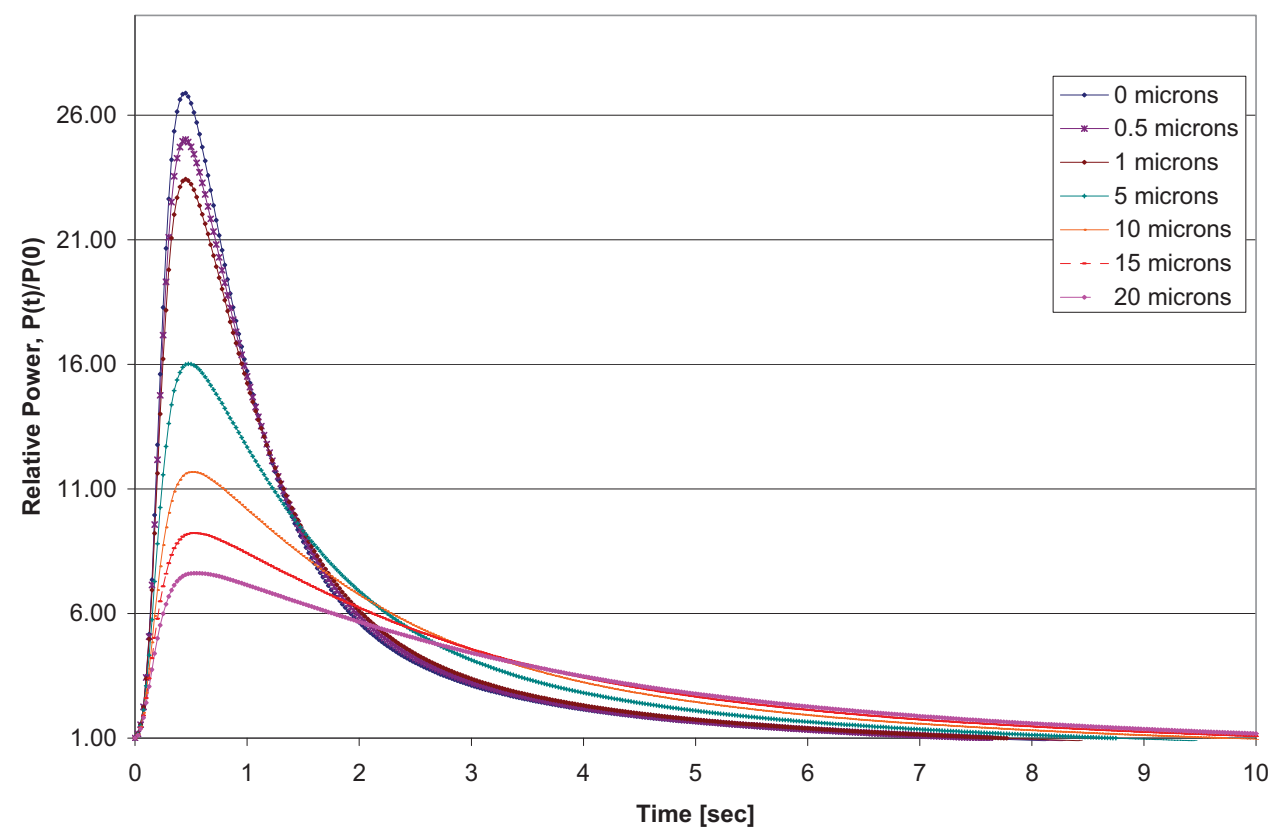

Figure 15. Effects of a TRISO gap on the relative core power.

Figures 16 and 17 show preliminary results for the core power and temperature profiles of the TCRE using the TDHe model with a $20 \mu \mathrm{m}$ gap. The plot also includes an eigenvalue calculation during the transient. There is a dramatic difference between the quasi-static and the time-dependent models. The QSHe is unable to capture the dynamic effects that take place in the TRISO particle with millisecond time steps. The relatively small conductivity of the gap establishes a large resistance to heat flow and results in higher fuel temperatures. These higher fuel temperatures and the consequent Doppler feedback place the reactor into a sub-critical condition within 0.4 seconds of the start of the transient. 


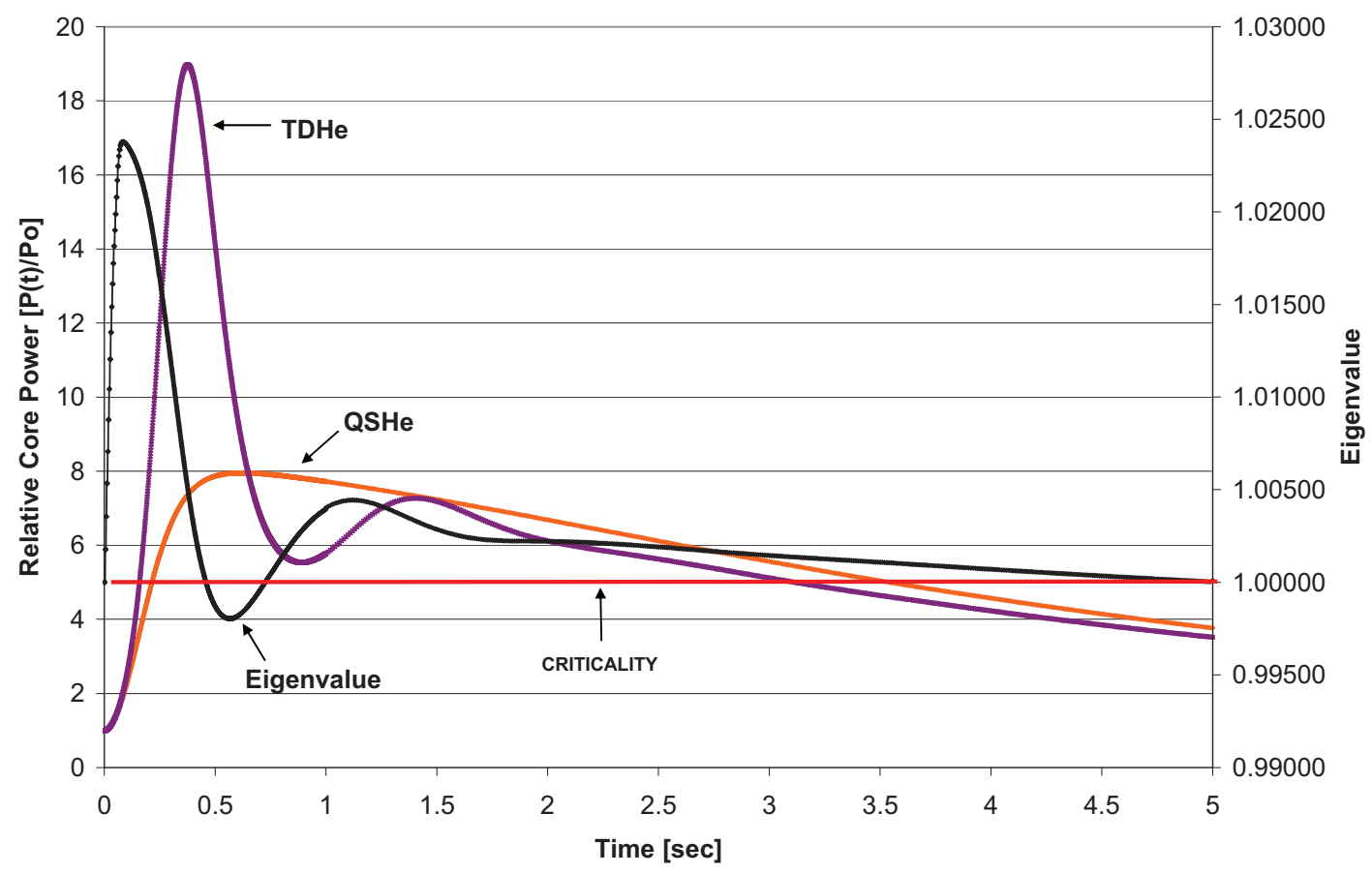

Figure 16. TCRE transient powers with TRISO gap.

In addition, as the fuel temperature increases the $\mathrm{UO}_{2}$ thermal conductivity decreases and its heat capacity increases, thus creating an energy storage or "capacitor" effect. This heat is subsequently released when the gap conductivity increases with temperature, thus allowing better heat transfer out of the kernel. The improved heat transfer and the rapid decrease in heat generation facilitate the fast cool down of the kernel, which in turn decrease resonance capture. This allows the neutron population to increase again as the reactor returns to a delayed-supercritical condition for approximately 4 seconds. These results are preliminary since there is a slight mismatch in the time scale of the solution. The relative power starts to turn at 0.38 seconds, but the sub-critical configuration is not attained until 0.46 seconds. The opposite is true for the next power escalation where the delayed super-critical condition is reached at 0.76 seconds and the power turns at 0.9 seconds. 


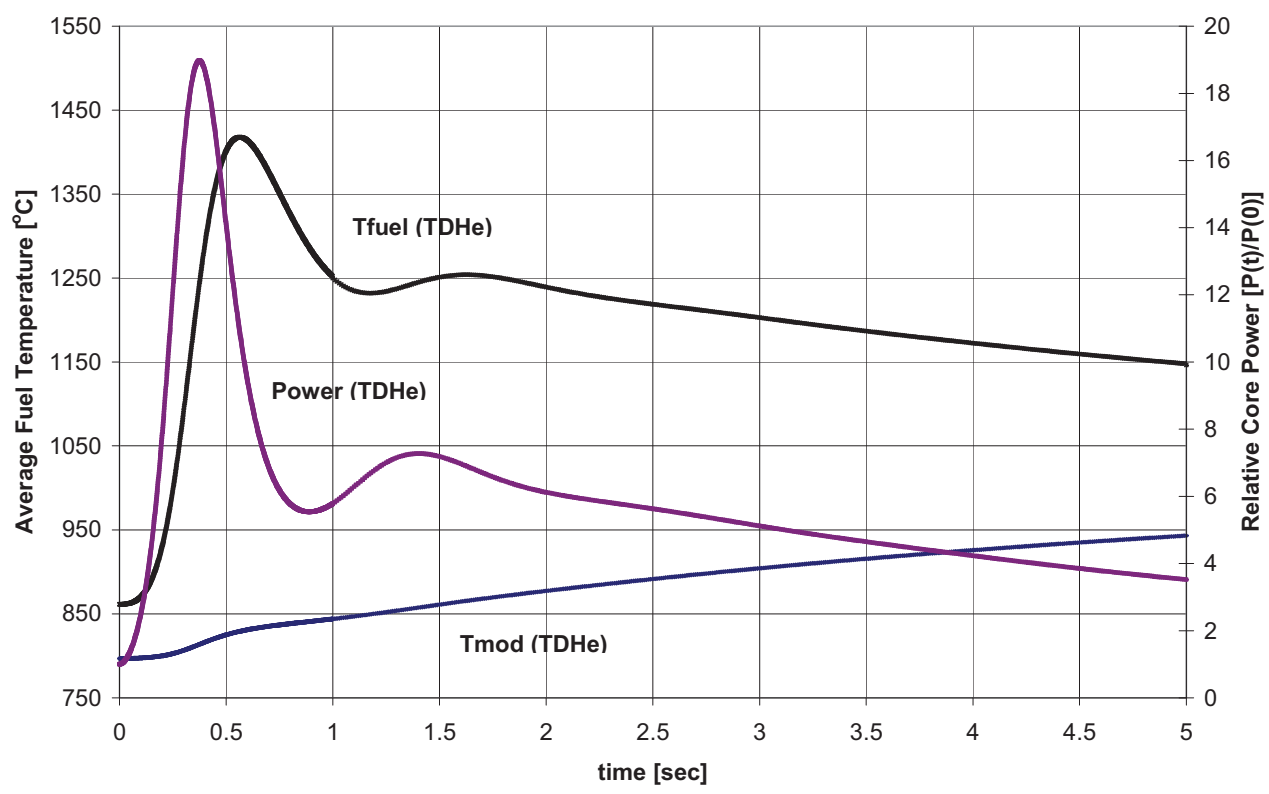

Figure 17. TCRE transient temperatures with TRISO gap.

Table 1 shows the results from the HEATING 7.3 3-D calculations used to determine the gap conductivity multipliers to correct the $4 \pi$ steradiant gap model for the presence of a contact area. The gap thickness was assumed to be $15 \mu \mathrm{m}$.

Table 1. Conductivity correction factors.

\begin{tabular}{|c|c|c|c|}
\hline $\begin{array}{c}\text { Heat Rate } \\
{[\mathbf{W}]}\end{array}$ & $\begin{array}{c}\theta=\pi / \mathbf{4} \\
\mathbf{A}=\mathbf{1 4 . 6 4} \%\end{array}$ & $\begin{array}{c}\theta=\pi / \mathbf{2} \\
\mathbf{A}=\mathbf{5 0} \%\end{array}$ & $\begin{array}{c}\theta=\mathbf{3} \pi / \mathbf{4} \\
\mathbf{A}=\mathbf{8 5 . 3 6} \%\end{array}$ \\
\hline $\mathbf{0 . 1 4 4}$ & 1.436 & 2.786 & 5.021 \\
\hline $\mathbf{0 . 3 1 1}$ & 1.448 & 2.713 & 4.892 \\
\hline $\mathbf{0 . 5 4 3}$ & 1.423 & 2.637 & 4.690 \\
\hline $\mathbf{0 . 6 9 9}$ & 1.416 & 2.606 & 4.608 \\
\hline
\end{tabular}

Figure 18 shows the results obtained with the various corrections to the gap conductivities from Table 1. As the gap closes, the core power profile approaches the behavior of the fuel without the gap, where the fluctuation between subcritical and delayed super-critical state is avoided. The $\pi / 4$ steradiant case shows a different core power behavior than the other runs, which seems to indicate the current functionalization of the conductivity in Table 1 is not completely adequate. 


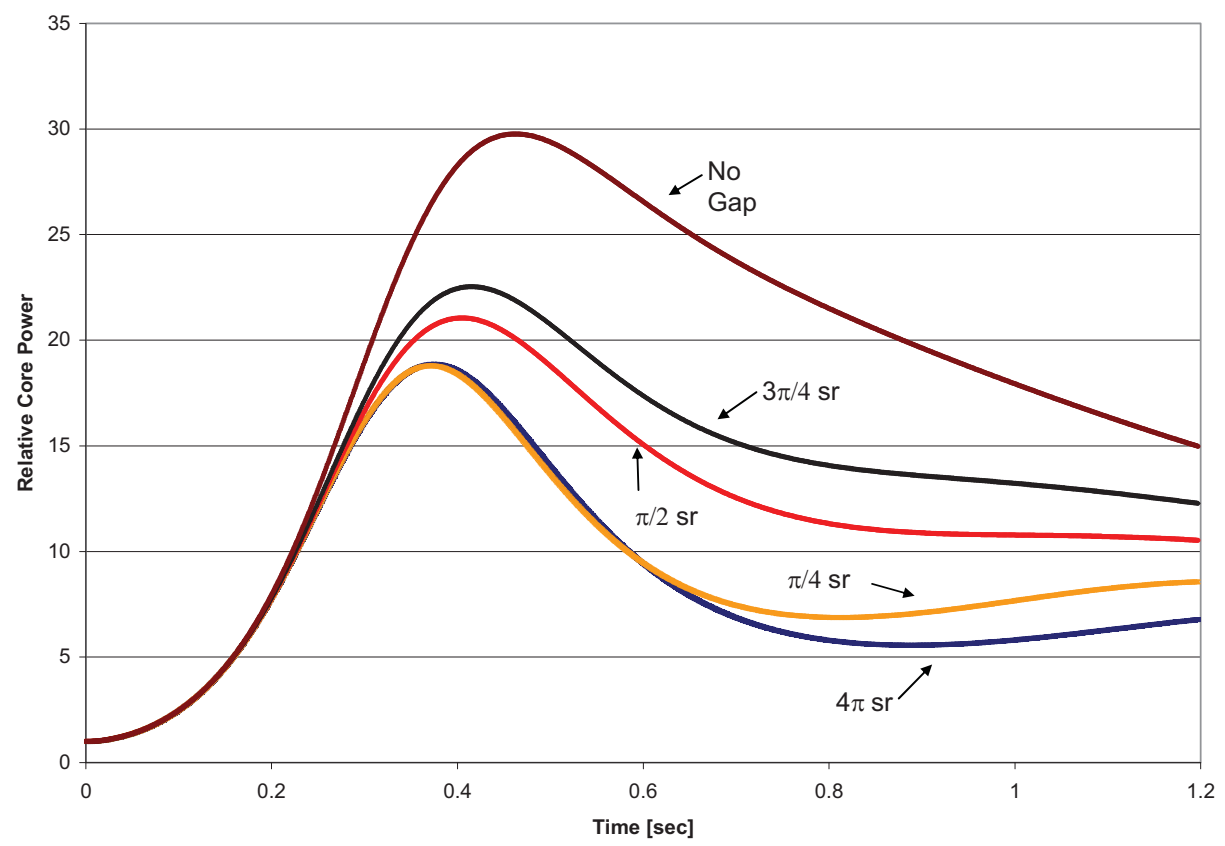

Figure 18. TCRE transient power with various effective gap conductivity values. 


\section{UPDATED RESULTS WITH GAP RELEASE MODELS}

Additional model enhancements described in Appendix IV were implemented. These models improve the calculation of the gap conductivity and the determination of an internal gas pressure during the transient for each average TRISO particle. Two transient cases are evaluated in this section: (1) the TCRE event, a fast transient, and (2) an earthquake-initiated event, which is a slow transient that captures the core densification during the INL's design basis earthquake starting from the HFP condition.

\subsection{Analysis of a Total Control Rod Ejection Event}

Figure 19 shows the various dynamic effects attributed to the time-dependent model that were absent from Figure 15. The results indicate a reduction by a factor of 14 in power from modeling a range that includes no gap to a $20 \mu \mathrm{m}$ gap (without effective conductivity correction).

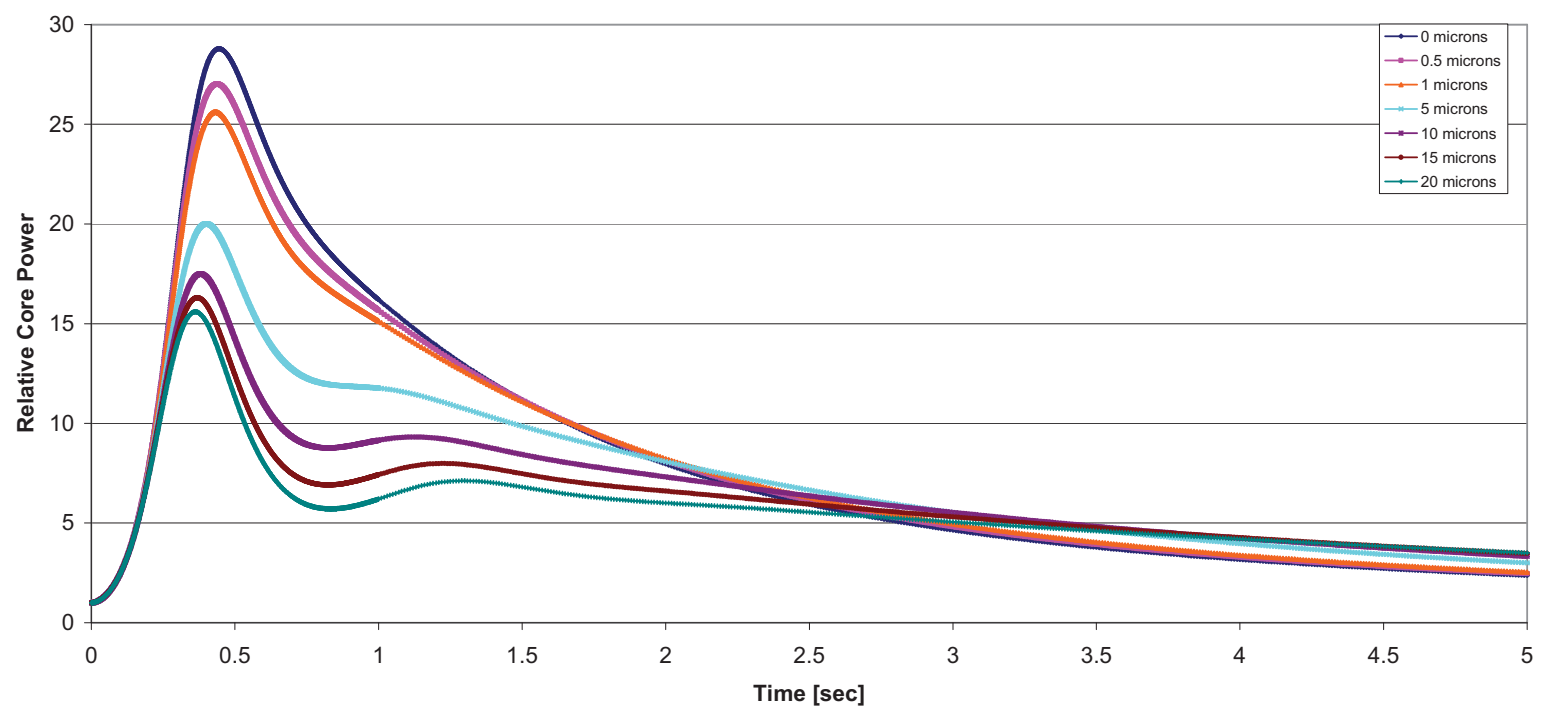

Figure 19. TCRE transient power with various gap sizes.

The maximum and average fuel temperatures in the core for the various gap sizes are included in Figures 20 and 21, respectively. The maximum temperature is higher for the models without a gap driven mainly by the higher power level reached during the transient. This model with the improved material properties shows a maximum fuel temperature in excess of $2500^{\circ} \mathrm{C}$. There is a $300^{\circ} \mathrm{C}$ difference between the maximum of the 0 and the 20 micron gap models. In contrast, the average temperatures are higher with the 20 micron gap by $170^{\circ} \mathrm{C}$, which effectively establishes the onset of the strong Doppler feedback. 


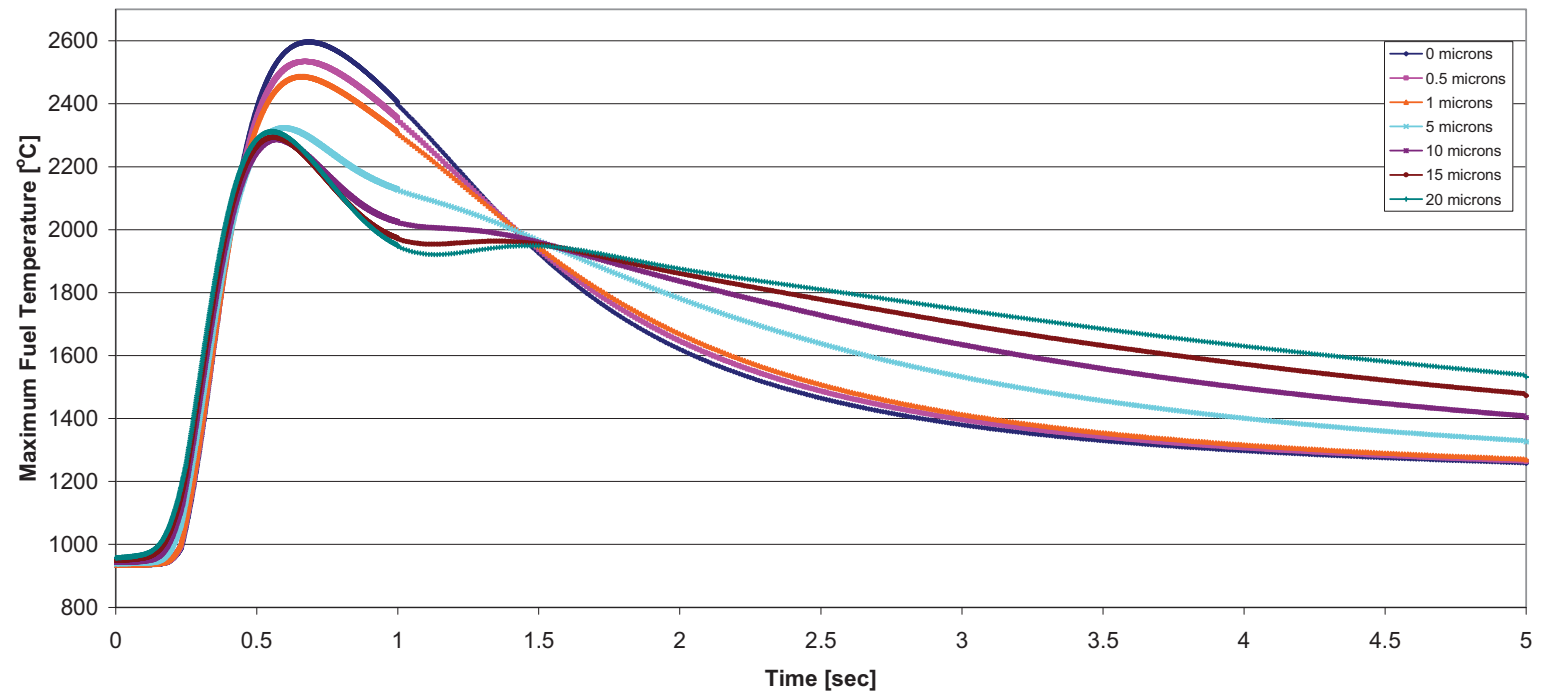

Figure 20. Maximum fuel temperature with various gap sizes during a TCRE.

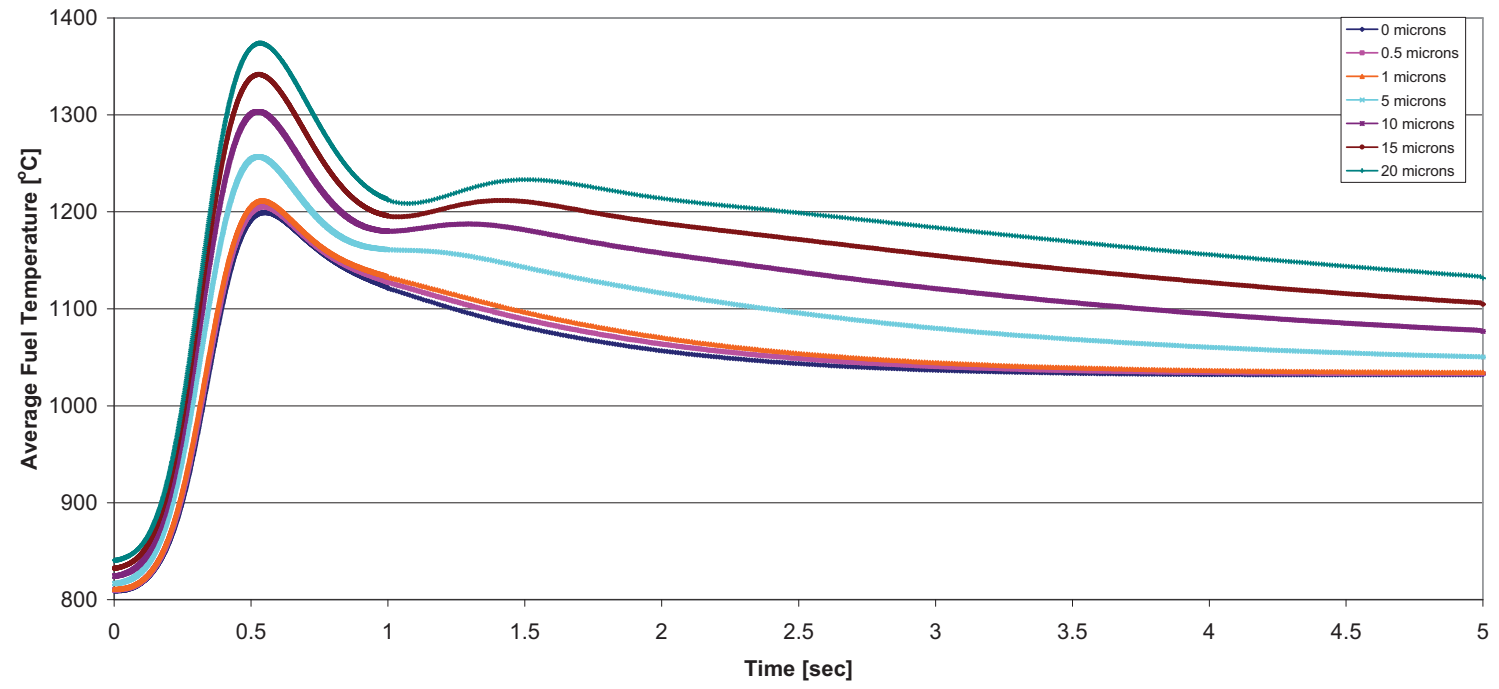

Figure 21. Average fuel temperatures with various gap sizes during a TCRE.

Table 2 shows the changes to the fuel temperature distribution in the core during the TCRE transient. The axial dimensions are measured from the top of the core, whereas the radial dimensions are measured from the center of the core. As the control rods are ejected, the maximum temperatures clearly shift to the regions with high localized power at the top of the core, especially near the center and side reflectors. This strong temperature peaks start flattening as the fission power in the core is quickly shutdown by the temperature feedback effects. 


$$
\begin{aligned}
& 6, \pi \\
& 5,2 \\
& 12
\end{aligned}
$$




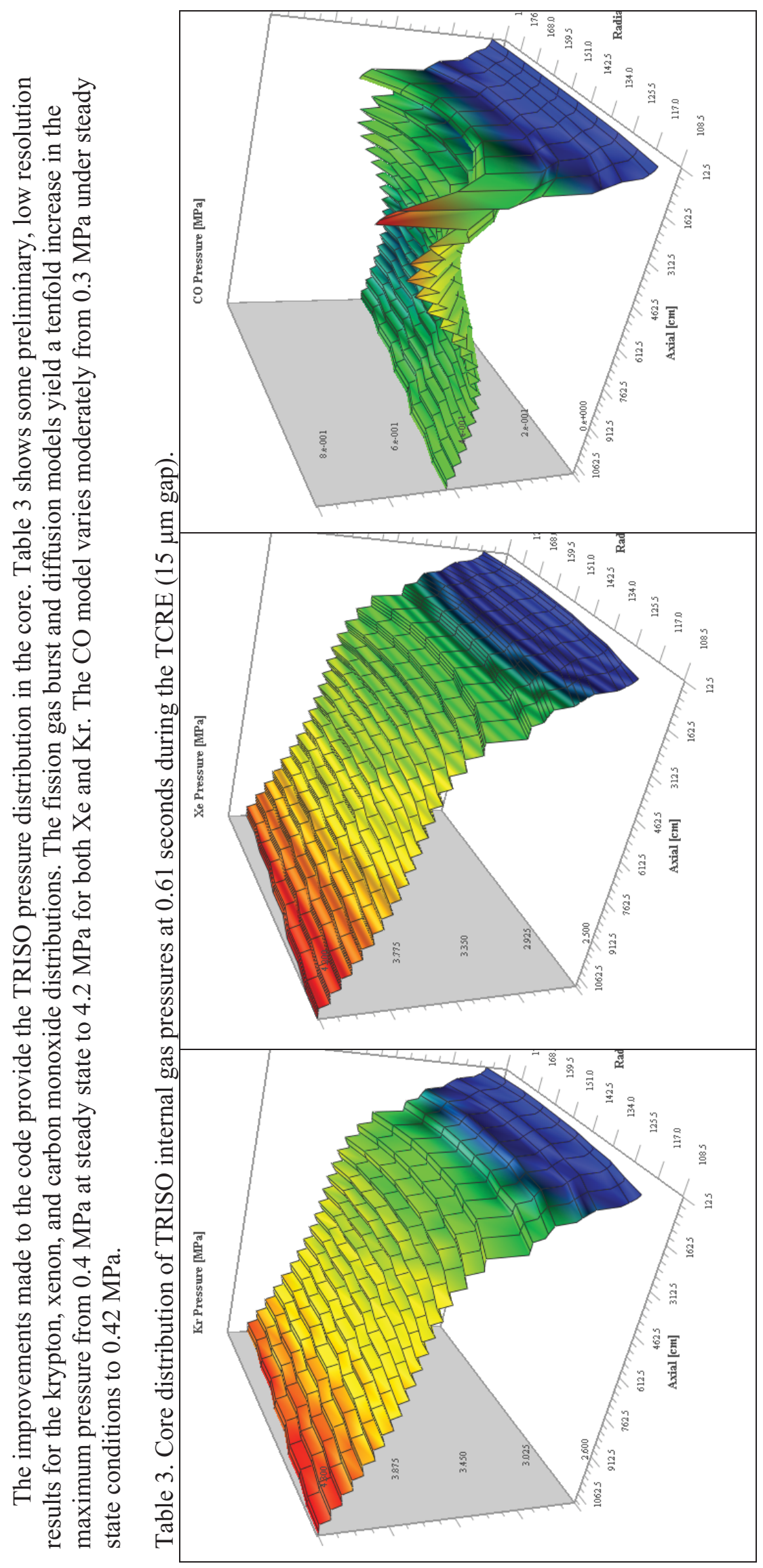


The models without a gap experience higher moderator temperatures, as seen in Figure 22. This results in a stronger, but delayed, moderator feedback, which produces a steeper exponential tail in the relative power profile shown in Figure 19.

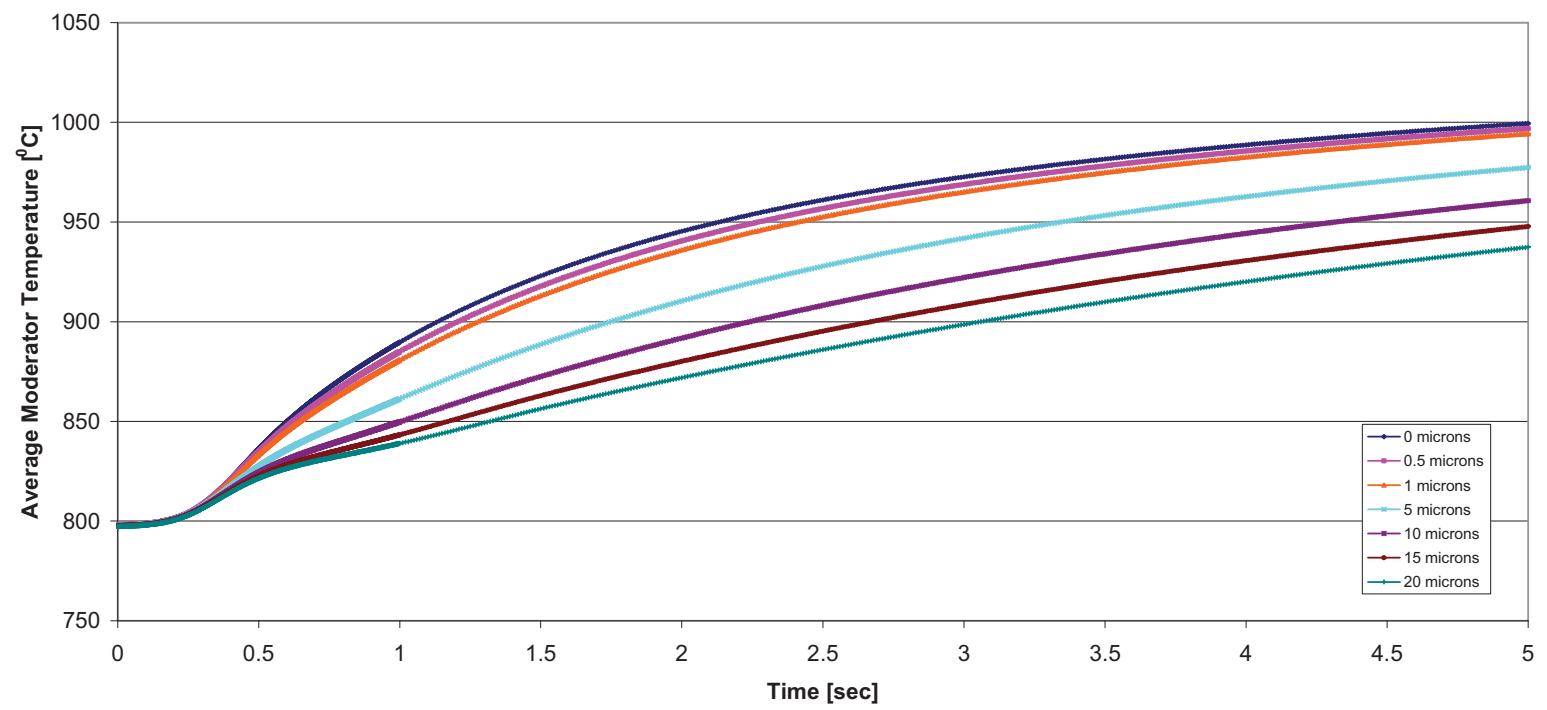

Figure 22. TCRE average moderator temperatures with various gap sizes.

Figure 23 shows how the models with large gaps experience a rapid cool-down and the loss of the critical configuration, as previously discussed in Figure 16. The rest of the models maintain the critical configuration until the moderator feedback places the reactor in a subcritical condition.

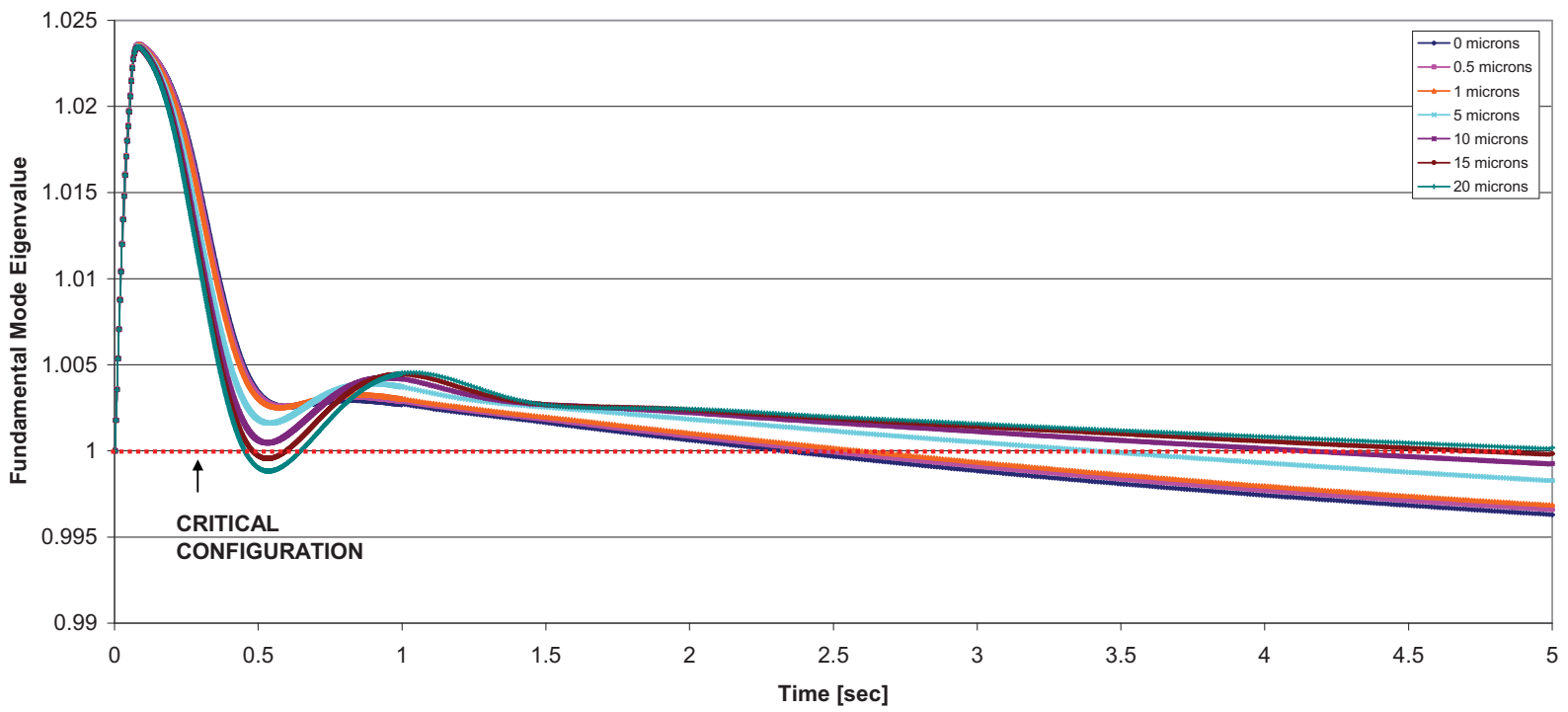

Figure 23. Fundamental mode eigenvalue with various gap sizes during a TCRE. 
In addition, the functionalization of the Table 1 parameters was enhanced by using polynomial fits. This provides an improved model of the heat transfer through the contact area between the porous carbon and IPyC layers. The results are shown in Figure 24 with the expected behavior in core relative power with various contact areas sizes.

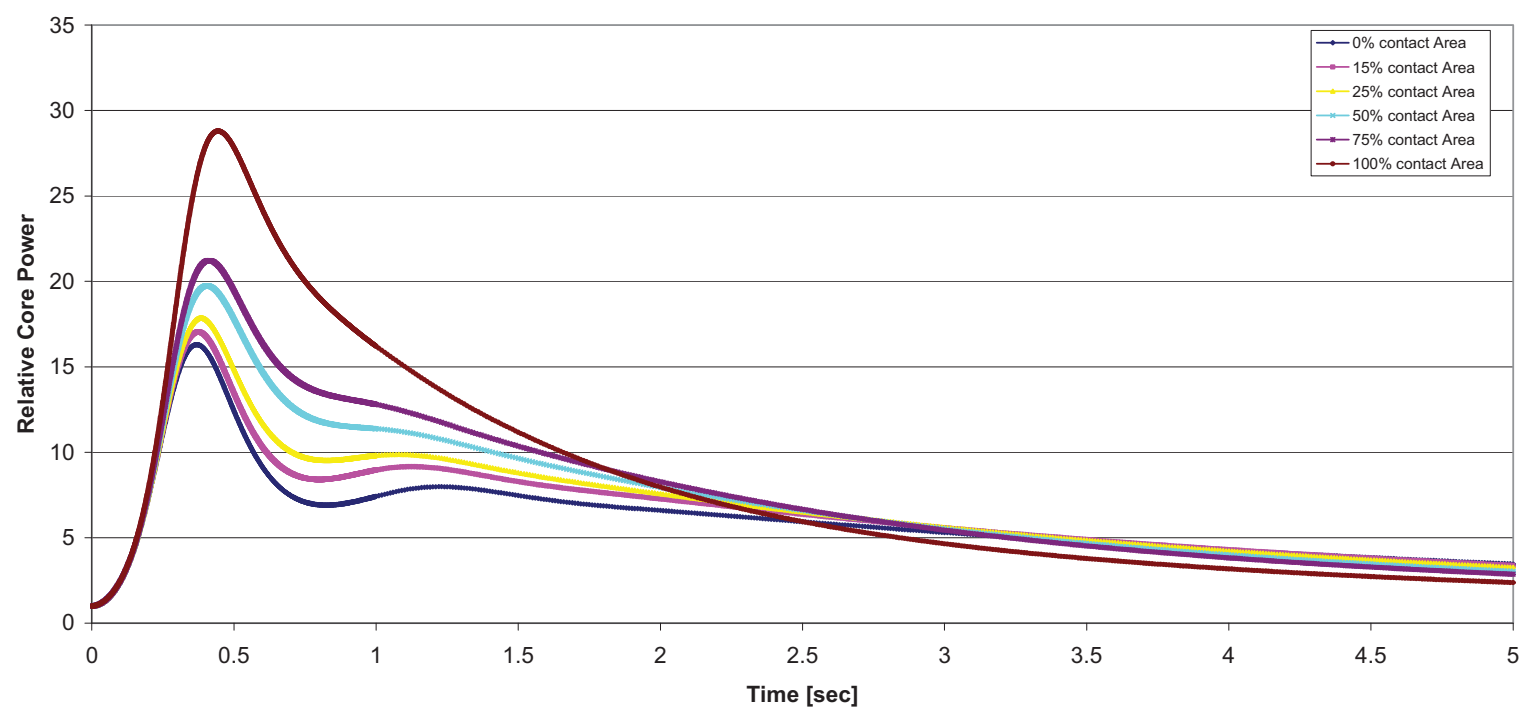

Figure 24. Relative core power with a $15 \mu \mathrm{m}$ gap and various contact areas during a TCRE.

\subsection{Analysis of an Earthquake-Initiated Transient Event}

Finally, results with the earthquake analysis methodology developed by Ougouag et al. are included in Figure 25. During the first second of simulation, small increases in the packing fraction produce enough negative Doppler feedback to start shutting down the reactor until the first significant increase in the global pebble packing fraction produces a small power escalation. This first turnaround point is magnified by the additional insertion from the relative rod withdrawal. The magnitude of the reactivity insertions increases as their relative position of the control rods with respect to the core increases. During the slow transient regions, both the QSHo and TDHe model without a gap yield similar results. Some regions of moderate dynamic response show relative power differences of $2.5 \%$. The TDHe model with a $15 \square \mathrm{m}$ gap and corrected gap conductivities yields a lower power profile at the beginning of the transient and a higher power profile towards the end of the event. The relative power differences between this 15 $\square \mathrm{m}$ gap and the QSHo models are about 4\%.

A few other power increases are visible throughout the transient. These events demonstrate the fine balance between the negative reactivity insertions due to Doppler feedback and the positive reactivity insertions due to densification and the relative control rod withdrawal during the event. Eigenvalue calculations indicate that the reactor remains in a subcritical state until a large reactivity insertion overcomes the Doppler feedback 8 seconds into the transient, as shown in Figure 26. The reactor remains delayed-supercritical for 1.5 seconds. 


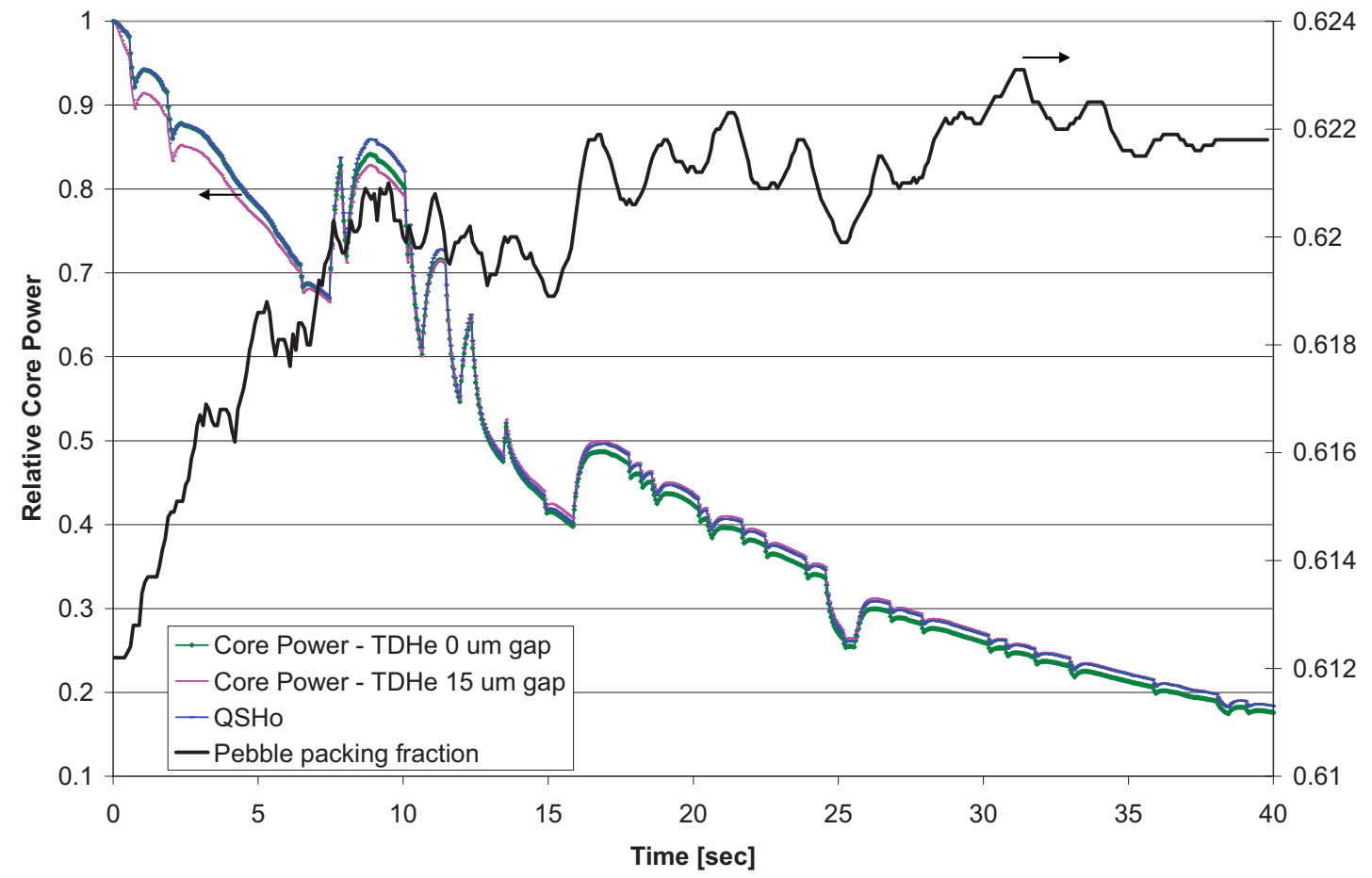

Figure 25. Relative core power during an earthquake transient in the PBMR-400.

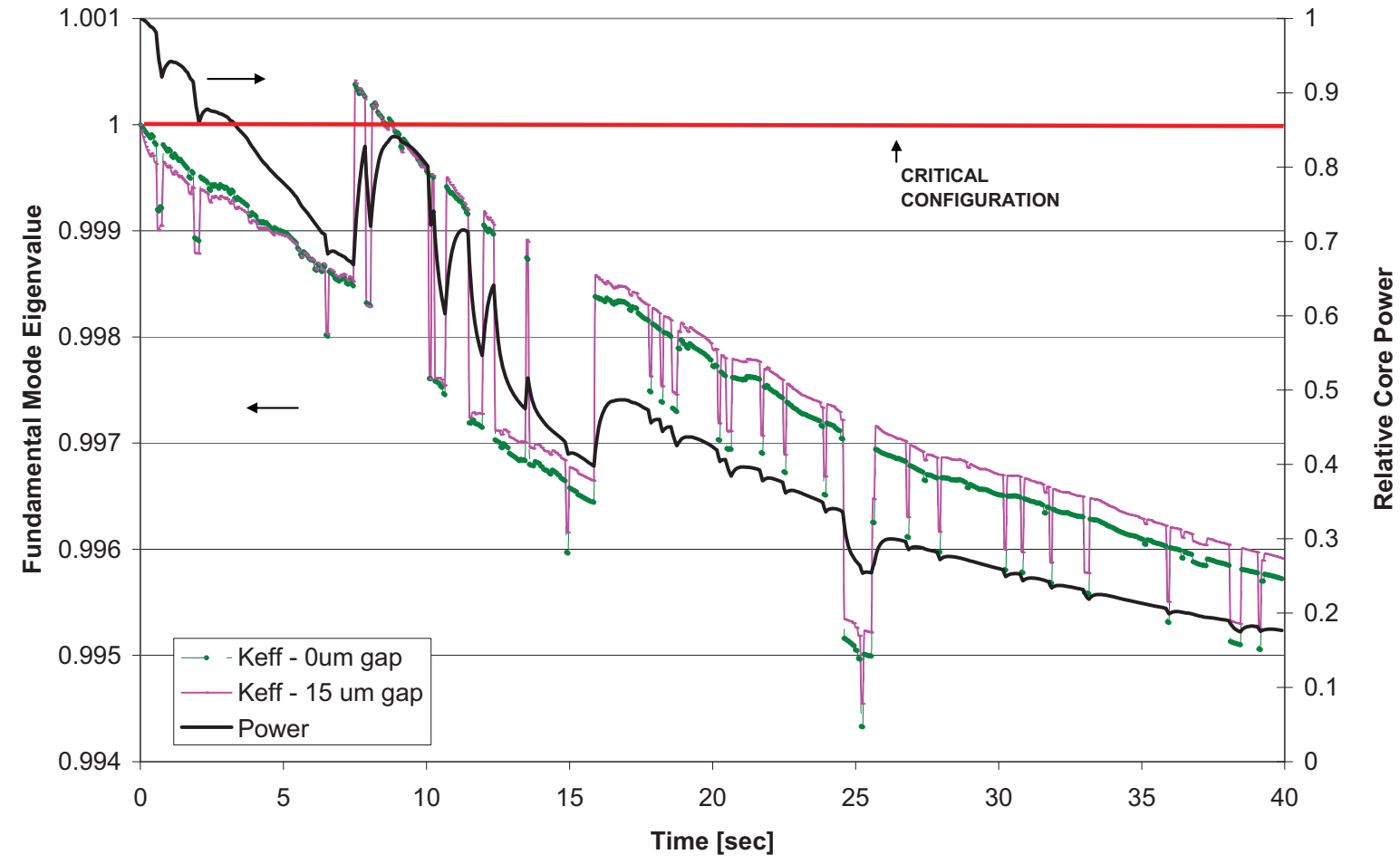

Figure 26. Fundamental mode eigenvalue during an earthquake transient in the PBMR-400. 
Figure 27 shows how both the average fuel and moderator temperatures approach the same asymptotic value expected for a slow transient. The average fuel temperature and power fluctuations are in good agreement and clearly represent the strong negative fuel temperature feedback of this reactor.

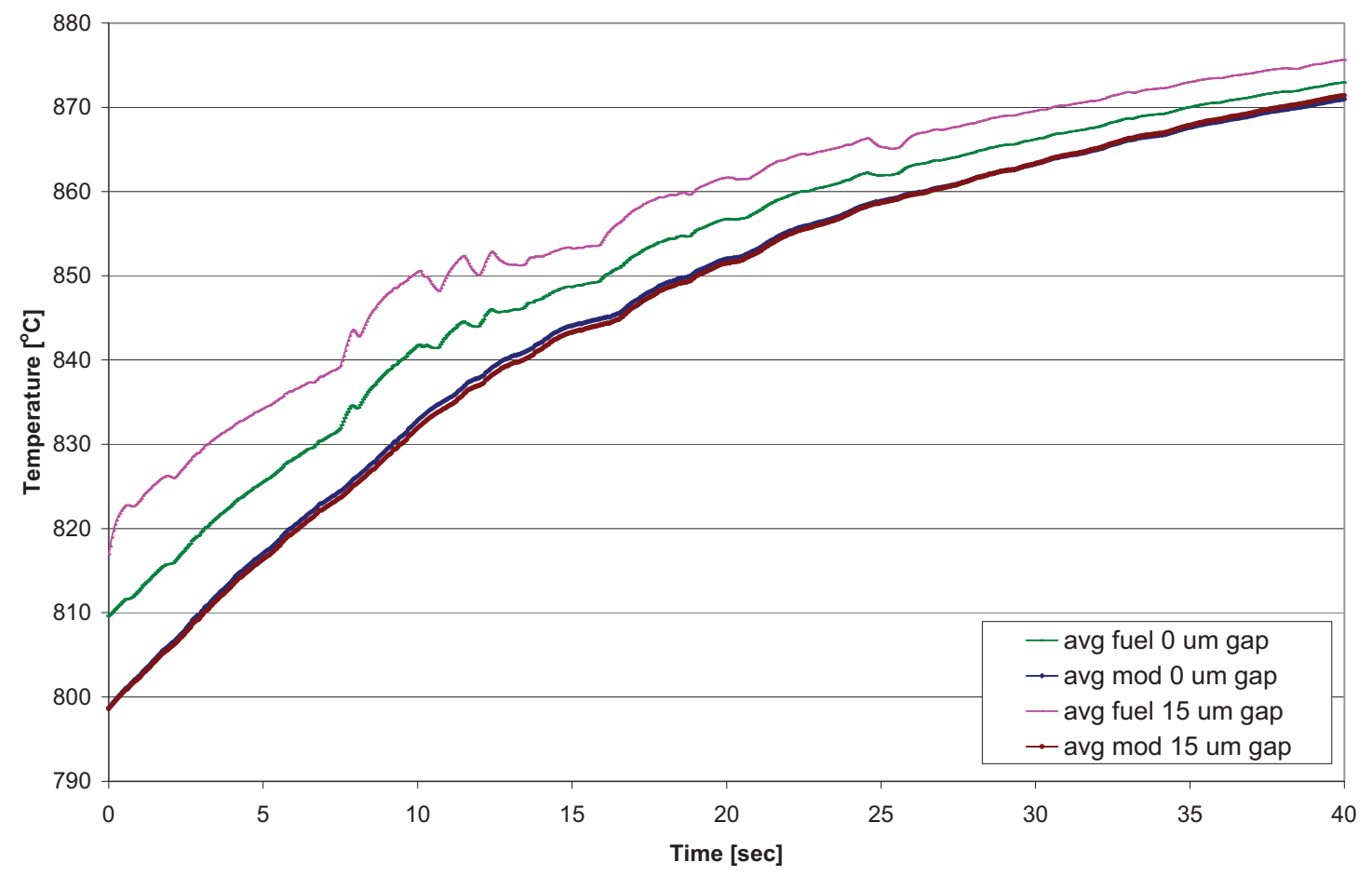

Figure 27. Fuel and moderator temperatures during the earthquake transient in the PBMR-400. 


\section{CONCLUSIONS}

A simple and efficient way of calculating fuel temperature in TRISO-fueled reactors has been developed and implemented into the Next Generation Nuclear Plant (NGNP) analysis package CYNODTHERMIX-KONVEK. The model was benchmarked against analytic solutions and it performed well in code-to-code comparison versus Heating 7.3. The results show that both the quasi-static and the timedependent heterogeneous models are great improvements over the homogenous model for the study of the HTGR core behavior during fast transient. They also show that a time-dependent heterogeneous model is able to capture dynamic effects, which the quasi-static models are unable to capture for both fast and moderately slow transients. The fuel temperature calculations performed with the CYNOD-THERMIXKONVEK suite are comparable to those of TINTE.

The presence of a gap in all or most TRISO fuel can change the dynamic behavior of the reactor. Results indicate that the higher fuel temperatures obtained with the gap models enhance the Doppler response of the reactor, but can lead to unexpected behavior and re-criticality in a short time due to the swing in the heat generation rate and rapid fuel cooling.

In addition, an early capability to perform fuel performance calculations for HTRs within the framework of a safety analysis simulator is introduced. This enables the user to undertake fuel performance simulations under more realistic conditions that include the dynamic effects of transients. 


\section{RECOMMENDATIONS}

Since the TRISO temperatures are based on the average or "representative" TRISO model, a better method to determine the maximum fuel temperature in each region of the core is needed.

Cooling effects for the fuel kernel are important to correctly capture the Doppler feedback effect. The development of a TRISO-level radiative heat transfer model would capture additional cooling effects for the fuel kernels.

The gas release models require further development and verification against established fuel performance models. 


\section{REFERENCES}

Childs, K. W., 2007, “HEATING 7.3,” PSR-0199/05, NEA, 2007.

Hiruta, H., et al., 2008, "CYNOD: a Neutronics Code for Pebble Bed Modular Reactor Coupled Transient Analysis," HTR2008, September 28-October 1, 2008, 4th International Topical Meeting on High Temperature Reactor Technology.

Martin, D. G., "The Mathematical Basis of STRESS3 and STAPLE, HTR-F WP3/DGM/03/04," November 2003.

Merrill, M. H., 1963, "Calculation Procedures for Evaluating Transients in Semihomogeneous Power Reactors," Reactor Kinetics and Control, Atomic Energy Commission Symposium 2.

Miller, G. K., D. L., Knudson, "An Evaluation of the Gap Between the Buffer and IPyC Layers During Irradiation of a TRISO-Coated Fuel Particle,” INL Engineering Design File 6872, April 2006.

Miller G. K., et al., "Current Capabilities of the Fuel Perforamce Modeling Code Parfume," High Temperature Reactor Technology, Beijing, China, September 22-24, 2004.

NEA, “OECD/NEA/NSC PBMR Coupled Neutronic/Thermal Hydraulics Transient Benchmark: The PBMR-400 Core Design,” Draft 07, 2007.

Ougouag, A. M., J., Ortensi, H., Hiruta, “Analysis of an Earthquake-Initiated-Transient in a PBR,” Inter. Conf. Math. Comp. Methods. \& Reactor Phys. (M\&C), Saratoga Springs, New York, May 3-7, 2009.

Rademer, T., W. Bernnat, G. Lohnert, 2004, "Coupling of Neutronics and Thermal-Hydraulics Codes for the Simulation of Transients of Pebble Bed HTR Reactors," High Temperature Reactor Technology, Beijing, China, September 22-24, 2004.

INEEL, "RELAP5-3D@ Manuals, Volume 4: Models and Correlations," INEEL-EXT-98-00834V1,06/2005.

Scherer, W., and E. Teuchert, 1989, “TINTE,” H. Gerwin, Nucl. Sci. Eng., Vol. 103, pp. 302-312.

Stainsby, R., et al., 2008, "Development of Local Heat Transfer Models for Safety Assessment of the Pebble Bed High Temperature Gas-Cooled Reactor Cores," High Temperature Reactor Technology, Washington, USA, September 28-October 1, 2008.

Stainsby, R., et al., 2008, "Development of Local Heat Transfer Models for the Safety Assessment of Prismatic Modular High Temperature Gas-Cooled Reactor Cores," High Temperature Reactor Technology, Washington, USA, September 28-October 1, 2008.

Strydom, G., 2008, “TINTE Transient Results for the OECD 400 MW PBMR Benchmark,” ICAPP '08, Anaheim, CA, USA, June 8-12, 2008.

Teuchert, E., et al., 1994, V.S.O.P. ('94) Computer Code System for Reactor Physics and Fuel Cycle Simulation - Input Manual and Comments, April 1994.

Ubbink, O., et al., 2008, "PBMR Fuel Kernel Model for the Prediction of Accurate Temperature Profiles," ICONE16, Orlando, Florida, USA, May 11-15, 2008. 


\section{Appendix A}

\section{Analytic Solution to the 1-D Spherical Steady State Heat Conduction Equation}




\section{Appendix A}

\section{Analytic Solution to the 1-D Spherical Steady State Heat Conduction Equation}

The 1-D spherical geometry steady-state heat conduction equation with constant volumetric heat generation rate is:

$\frac{d^{2} T}{d r^{2}}+\frac{2}{r} \frac{d T}{d r}+\frac{q^{\prime \prime}}{k}=0$

Letting $\varphi=\frac{d T}{d r}$ and solving via the integrating factor yields:

$\varphi(r)=\frac{d T}{d r}=-\frac{r q^{\prime \prime}}{3 k}+\frac{C_{1}}{r^{2}}$

Integrating again leads to:

$T(r)=-\frac{r^{2} q^{\prime \prime}}{6 k}-\frac{C_{1}}{r}+C_{2}$

Eq. A-1

The temperature field in the innermost heated region is obtained by applying a Neumann $\left.\frac{d T}{d r}\right|_{r=0}=0$ and Dirichlet $T\left(r_{i+1}\right)=T_{i+1}$ boundary conditions to Equation A-1:

$T_{\text {heated }}(r)=\frac{q_{i}^{\prime \prime}}{6 k_{i}}\left(r_{i+1}^{2}-r^{2}\right)+T_{i+1}$

The temperature field in non-heated regions is obtained by imposing to Equation A-1 a non-zero heat flux at the lower boundary, $-\left.k_{1} \frac{d T}{d r}\right|_{r=r_{i}}=\frac{r_{f s} q_{1}^{\prime \prime}}{3}$, yielding:

$T_{\text {unheated }}(r)=\frac{r_{f s}^{3} q_{1}^{\prime \prime \prime}}{3 k_{i}}\left(\frac{1}{r}-\frac{1}{r_{i-1}}\right)+T_{i-1}$

Where $r_{f s}$ is the fuel surface.

Average fuel temperatures in each region can be determined with: 


$$
\langle T(r)\rangle=\frac{\int_{0}^{2 \pi} d \phi \int_{0}^{\pi} \sin \theta d \theta \int_{0}^{r_{1}} T(r) r^{2} d r}{\int_{0}^{2 \pi} d \phi \int_{0}^{\pi} \sin \theta d \theta \int_{0}^{r_{1}} r^{2} d r}
$$

Therefore, the average temperature in the fuel region under steady-state condition is:

$\left\langle T_{\text {heated }}\right\rangle=\frac{r_{1}^{2}\left\langle q^{\prime \prime}\right\rangle}{15 k_{1}}+T_{2}$

The average temperature in the non-heated regions under steady-state conditions is:

$$
\left\langle T_{\text {unheated }}\right\rangle=-q^{\prime \prime} r_{1}^{3} \frac{\left(r_{i-1}^{3}-3 r_{i-1} r_{i}^{2}+2 r_{i}^{3}\right)}{6 k_{i} r_{i-1}\left(r_{i}^{3}-r_{i-1}^{3}\right)}+T_{i-1}
$$

The node and cell average temperatures can be determined with Equations A-2 to A-5 given an outer boundary condition and a volumetric heat generation rate. 
Appendix B

\section{Numerical Solution to the 1-D Spherical Parabolic Heat Conduction Equation}




\section{Appendix B}

\section{Numerical Solution to the 1-D Spherical Parabolic Heat Conduction Equation}

Starting from the heat flux formulation of the conservation law:

$-\nabla \cdot \vec{q}(r)+q_{t r}^{\prime \prime}(r)=\rho(r) C_{p}(r) \frac{\partial T(r, t)}{\partial t}$

Imposing a theta differencing scheme and the assumption that $\rho(r) C_{p}(r)$ do not change during the time step leads to:

$-(1-\theta) \nabla \cdot \vec{q}^{n}+(1-\theta) q_{n}^{\prime \prime}-\theta \nabla \cdot \vec{q}^{n+1}+\theta q_{n+1}^{\prime \prime}=\rho(r) C_{p}(r) \frac{T^{n+1}-T^{n}}{t^{n+1}-t^{n}}$

Performing a heat balance by integrating the equation over the volume yields:

$$
\begin{aligned}
& -(1-\theta) \iiint_{V_{i}} \nabla \cdot \vec{q}^{n} d V+(1-\theta) \iiint_{V_{i}} q_{n}^{\prime \prime \prime} d V-\theta \iiint_{V_{i}} \nabla \cdot \vec{q}^{n+1} d V+\theta \iiint_{V_{i}} q_{n+1}^{\prime \prime} d V \\
& =\iiint_{V_{i}} \rho(r) C_{p}(r) \frac{T^{n+1}-T^{n}}{t^{n+1}-t^{n}} d V
\end{aligned}
$$

Assuming the density and heat capacity to be homogeneous in the calculation cell leads to the following RHS for Equation B-1:

$R H S=\rho C_{p} \iiint_{V_{i}} \frac{T^{n+1}-T^{n}}{t^{n+1}-t^{n}} d V$

The node-wise temperatures can be related to cell averaged temperatures with:

$\widetilde{T}_{i}^{n}=\frac{\iiint_{V_{i}} T^{n} d V}{\iiint_{V_{i}} d V}=\frac{\iiint_{V_{i}} T^{n} d V}{V_{i}}$

Where:

$$
V_{i}=\frac{r n_{i+1}^{3}-r n_{i}^{3}}{3}
$$


Equation B-1 becomes:

$$
\begin{aligned}
& -(1-\theta) \iiint_{V_{i}} \nabla \cdot \vec{q}^{n} d V+(1-\theta) \iiint_{V_{i}} q_{n}^{\prime \prime \prime} d V-\theta \iiint_{V_{i}} \nabla \cdot \vec{q}^{n+1} d V+\theta \iiint_{V_{i}} q_{n+1}^{\prime \prime \prime} d V \\
& =\widetilde{C}_{i}\left(\frac{\widetilde{T}_{i}^{n+1}-\widetilde{T}_{i}^{n}}{t^{n+1}-t^{n}}\right)
\end{aligned}
$$

Where the effective heat capacity is $\widetilde{C}_{i}=\rho C_{p} V_{i}$

Using Gauss' divergence theorem and assuming constant heat generation in the volume we obtain:

$-(1-\theta) A_{i+1} \vec{q}^{n}\left(r_{i+1}\right) \cdot \hat{n}_{i+1}+(1-\theta) A_{i} \vec{q}^{n}\left(r_{i}\right) \cdot \hat{n}_{i}-\theta A_{i+1} \vec{q}^{n+1}\left(r_{i+1}\right) \cdot \hat{n}_{i+1}$

$+\theta A_{i} \vec{q}^{n+1}\left(r_{i}\right) \cdot \hat{n}_{i}+(1-\theta) q_{n}^{\prime \prime} V_{i}+\theta q_{n+1}^{\prime \prime} V_{i}=\left(\frac{\widetilde{T}_{i}^{n+1}-\widetilde{T}_{i}^{n}}{t^{n+1}-t^{n}}\right) \widetilde{C}_{i}$

where

$\vec{q}^{n}\left(r_{i}\right)=-\left.k_{i} \frac{d T^{n}}{d r}\right|_{r_{i}}$ and $A_{i}=r_{i}^{2}$

Using a simple finite difference to approximate the temperature gradient leads to the following heat flux representations:

$q_{i+\varepsilon}=-k_{i} \frac{\widetilde{T}_{i}-T_{i}}{\Delta r_{i} / 2}$ and $q_{i-\varepsilon}=-k_{i-1} \frac{T_{i}-\widetilde{T}_{i-1}}{\Delta r_{i-1} / 2}$

Imposing continuity of the heat flux with the approximate equations:

$k_{i} \frac{\widetilde{T}_{i}-T_{i}}{\Delta r_{i}}=k_{i-1} \frac{T_{i}-\widetilde{T}_{i-1}}{\Delta r_{i-1}}$

$\frac{k_{i}}{\Delta r_{i}}\left(\widetilde{T}_{i}-T_{i}\right)=\frac{k_{i-1}}{\Delta r_{i-1}}\left(T_{i}-\widetilde{T}_{i-1}\right)$

$\frac{k_{i}}{\Delta r_{i}} \widetilde{T}_{i}-\frac{k_{i}}{\Delta r_{i}} T_{i}=\frac{k_{i-1}}{\Delta r_{i-1}} T_{i}-\frac{k_{i-1}}{\Delta r_{i-1}} \widetilde{T}_{i-1}$

This enables the interpolation of one nodal temperature value from two adjacent cell-averaged values:

$T_{i}=\frac{\frac{k_{i-1}}{\Delta r_{i-1}} \widetilde{T}_{i-1}+\frac{k_{i}}{\Delta r_{i}} \widetilde{T}_{i}}{\frac{k_{i}}{\Delta r_{i}}+\frac{k_{i-1}}{\Delta r_{i-1}}}$ 
Inserting this temperature interpolator in the definition of the heat flux:

$q_{i}=-\frac{2 k_{i}}{\Delta r_{i}} \widetilde{T}_{i}+\frac{2 k_{i}}{\Delta r_{i}} T_{i}$

$q_{i}=-\frac{2 k_{i}}{\Delta r_{i}} \widetilde{T}_{i}+\frac{2 k_{i}}{\Delta r_{i}} \frac{\frac{k_{i-1}}{\Delta r_{i-1}} \widetilde{T}_{i-1}+\frac{k_{i}}{\Delta r_{i}} \widetilde{T}_{i}}{\frac{k_{i}}{\Delta r_{i}}+\frac{k_{i-1}}{\Delta r_{i-1}}}$

Simplifying the equation leads to:

$q_{i}=-\frac{2 k_{i} k_{i-1}}{\left(\Delta r_{i-1} k_{i}+\Delta r_{i} k_{i-1}\right)} \widetilde{T}_{i}+\frac{2 k_{i} k_{i-1}}{\left(\Delta r_{i-1} k_{i}+\Delta r_{i} k_{i-1}\right)} \widetilde{T}_{i-1}$

Therefore, we have the following discretizations for the heat flux at the boundaries:

$\vec{q}_{i}^{n}=-\frac{2 k_{i} k_{i-1}}{\left(\Delta r_{i-1} k_{i}+\Delta r_{i} k_{i-1}\right)} \widetilde{T}_{i}+\frac{2 k_{i} k_{i-1}}{\left(\Delta r_{i-1} k_{i}+\Delta r_{i} k_{i-1}\right)} \widetilde{T}_{i-1}$

Eq. B-4

${\overrightarrow{q_{i+1}}}^{n}=-\frac{2 k_{i+1} k_{i}}{\left(\Delta r_{i} k_{i+1}+\Delta r_{i+1} k_{i}\right)} \widetilde{T}_{i+1}+\frac{2 k_{i+1} k_{i}}{\left(\Delta r_{i} k_{i+1}+\Delta r_{i+1} k_{i}\right)} \widetilde{T}_{i}$

Inserting Equations B-4 and B-5 in the heat balance Equation B-3 leads to the final discretization:

$\theta \frac{2 A_{i+1} k_{i+1} k_{i}}{\left(\Delta r_{i} k_{i+1}+\Delta r_{i+1} k_{i}\right)} \widetilde{T}_{i+1}^{n+1}-\theta\left(\frac{2 A_{i+1} k_{i+1} k_{i}}{\left(\Delta r_{i} k_{i+1}+\Delta r_{i+1} k_{i}\right)}+\frac{2 A_{i} k_{i} k_{i-1}}{\left(\Delta r_{i-1} k_{i}+\Delta r_{i} k_{i-1}\right)}\right) \widetilde{T}_{i}^{n+1}$

$+\theta \frac{2 A_{i} k_{i} k_{i-1}}{\left(\Delta r_{i-1} k_{i}+\Delta r_{i} k_{i-1}\right)} \widetilde{T}_{i-1}^{n+1}=\left(\frac{\widetilde{T}_{i}^{n+1}-\widetilde{T}_{i}^{n}}{\Delta t^{n+1}}\right) \widetilde{C}_{i}$

$-(1-\theta) \frac{2 A_{i+1} k_{i+1} k_{i}}{\left(\Delta r_{i} k_{i+1}+\Delta r_{i+1} k_{i}\right)} \widetilde{T}_{i+1}^{n}+(1-\theta)\left(\frac{2 A_{i+1} k_{i+1} k_{i}}{\left(\Delta r_{i} k_{i+1}+\Delta r_{i+1} k_{i}\right)}+\frac{2 A_{i} k_{i} k_{i-1}}{\left(\Delta r_{i-1} k_{i}+\Delta r_{i} k_{i-1}\right)}\right) \widetilde{T}_{i}^{n}$

$-(1-\theta) \frac{2 A_{i} k_{i} k_{i-1}}{\left(\Delta r_{i-1} k_{i}+\Delta r_{i} k_{i-1}\right)} \widetilde{T}_{i-1}^{n}$

$-\left[(1-\theta) q_{n}^{\prime \prime}+\theta q_{n+1}^{\prime \prime}\right] Y_{i}$

Rearranging yields a three-point formulation:

$a_{i, i+1} \widetilde{T}_{i+1}^{n+1}+a_{i, i} \widetilde{T}_{i}^{n+1}+a_{i, i-1} \widetilde{T}_{i-1}^{n+1}=\widehat{Q}_{i}^{\prime \prime}+b_{i, i+1} \widetilde{T}_{i+1}^{n}+b_{i, i} \widetilde{T}_{i}^{n}+b_{i, i-1} \widetilde{T}_{i-1}^{n}$

Eq. B-6

With the coefficients:

$a_{i, i+1}=\theta \frac{2 A_{i+1} k_{i+1} k_{i}}{\left(\Delta r_{i} k_{i+1}+\Delta r_{i+1} k_{i}\right)}$ 


$$
\begin{aligned}
& a_{i, i}=-\left[\theta\left(\frac{2 A_{i+1} k_{i+1} k_{i}}{\left(\Delta r_{i} k_{i+1}+\Delta r_{i+1} k_{i}\right)}+\frac{2 A_{i} k_{i} k_{i-1}}{\left(\Delta r_{i-1} k_{i}+\Delta r_{i} k_{i-1}\right)}\right)+\frac{\widetilde{C}_{i}}{\Delta t^{n+1}}\right] \\
& a_{i, i-1}=\theta \frac{2 A_{i} k_{i} k_{i-1}}{\left(\Delta r_{i-1} k_{i}+\Delta r_{i} k_{i-1}\right)} \\
& b_{i, i+1}=-(1-\theta) \frac{2 A_{i+1} k_{i+1} k_{i}}{\left(\Delta r_{i} k_{i+1}+\Delta r_{i+1} k_{i}\right)} \\
& b_{i, i}=\left[(1-\theta)\left(\frac{2 A_{i+1} k_{i+1} k_{i}}{\left(\Delta r_{i} k_{i+1}+\Delta r_{i+1} k_{i}\right)}+\frac{2 A_{i} k_{i} k_{i-1}}{\left(\Delta r_{i-1} k_{i}+\Delta r_{i} k_{i-1}\right)}\right)-\frac{\widetilde{C}_{i}}{\Delta t^{n+1}}\right] \\
& b_{i, i-1}=-(1-\theta) \frac{2 A_{i} k_{i} k_{i-1}}{\left(\Delta r_{i-1} k_{i}+\Delta r_{i} k_{i-1}\right)} \\
& \widehat{Q}_{i}^{\prime \prime}=-\left[(1-\theta) q_{n}^{\prime \prime}+\theta q_{n+1}^{\prime \prime \prime}\right] Y_{i}
\end{aligned}
$$

The resulting matrix is symmetric and can be easily solved with direct or iterative methods.

The theta differencing scheme allows the variation of the time discretization from a first order implicit method $\theta=1$ to a first order explicit method $\theta=0$. Second order accuracy is achieved with the Crank-Nicholson method $\theta=0.5$.

\section{Imposition of Boundary Conditions}

An interior Neumann boundary condition leads to the following equation for the innermost cell:

$$
\begin{aligned}
& -\left[\theta \frac{2 A_{2} k_{1} k_{2}}{\left(k_{2} \Delta r_{1}+\Delta r_{2} k_{1}\right)}+\frac{\widetilde{C}_{1}}{t^{n+1}-t^{n}}\right] \widetilde{T}_{1}^{n+1}+\theta \frac{2 A_{2} k_{1} k_{2}}{\left(k_{2} \Delta r_{1}+\Delta r_{2} k_{1}\right)} \widetilde{T}_{2}^{n+1}=-\left[(1-\theta) q_{n}^{\prime \prime \prime}+\theta q_{n+1}^{\prime \prime \prime}\right]_{i 1} \\
& -(1-\theta) \frac{2 A_{2} k_{1} k_{2}}{\left(k_{2} \Delta r_{1}+\Delta r_{2} k_{1}\right)}\left(\widetilde{T}_{2}^{n}-\widetilde{T}_{1}^{n}\right)-\frac{\widetilde{C}_{1}}{\Delta t^{n+1}} \widetilde{T}_{1}^{n}
\end{aligned}
$$

A mixed condition on the outer boundary can be readily built with $\alpha= \begin{cases}1 & \text { Dirichlet B.C. } \\ 0 & \text { Neumann B.C }\end{cases}$

$$
\begin{aligned}
& {\left[\theta\left(-\alpha \frac{k_{N} 2 A_{N+1}}{\Delta r_{N}}-\frac{k_{N-1} k_{N} 2 A_{N}}{\left(k_{N} \Delta r_{N-1}+\Delta r_{N} k_{N-1}\right)}\right)-\frac{\widetilde{C}_{N}}{t^{n+1}-t^{n}}\right] \widetilde{T}_{N}^{n+1}+\theta \frac{k_{N-1} k_{N} 2 A_{N}}{\left(k_{N} \Delta r_{N-1}+\Delta r_{N} k_{N-1}\right)} \widetilde{T}_{N-1}^{n+1}=-\left[(1-\theta) q_{n}^{\prime \prime \prime}+\theta q_{n+1}^{\prime \prime \prime}\right] V_{i}} \\
& -\alpha \frac{k_{N} 2 A_{N+1}}{\Delta r_{N}} T_{g}+\left[(1-\theta)\left(\alpha \frac{k_{N} 2 A_{N+1}}{\Delta r_{N}}+\frac{k_{N-1} k_{N} 2 A_{N}}{\left(k_{N} \Delta r_{N-1}+\Delta r_{N} k_{N-1}\right)}\right)-\frac{\widetilde{C}_{N}}{t^{n+1}-t^{n}}\right] \widetilde{T}_{N}^{n}-(1-\theta) \frac{k_{N-1} k_{N} 2 A_{N}}{\left(k_{N} \Delta r_{N-1}+\Delta r_{N} k_{N-1}\right)} \widetilde{T}_{N-1}^{n}
\end{aligned}
$$




\section{Appendix C}

\section{Analytic Solution to the 1-D Spherical Parabolic Heat Conduction Equation}




\section{Appendix C}

\section{Analytic Solution to the 1-D Spherical Parabolic Heat Conduction Equation}

The purpose of this appendix is to find an analytic solution to the parabolic heat conduction equation

that can be used in the benchmarking of the numerical solution. To simplify the task, a one-region model with constant thermo-physical properties is employed.

The parabolic heat conduction equation with a heat source is:

$\frac{\partial^{2} T(r, t)}{\partial r^{2}}+\frac{2}{r} \frac{\partial T(r, t)}{\partial r}+\frac{q_{t r}^{\prime \prime}(r, t)}{k}=\frac{1}{\alpha} \frac{\partial T(r, t)}{\partial t} \quad 0<r<R$ for $\mathrm{t}>0$

where

$\alpha=\frac{k}{\rho C_{p}}$ (thermal diffusivity)

With boundary conditions:

$T(0, t)=$ finite

$T(R, t)=T_{\text {graphite }}$

Initial Condition:

$T(r)=T_{\text {graphite }}$ at $\mathrm{t}=0$

One can generate a homogenous boundary condition for the problem with a simple change of variables:

$\varphi(r, t)=T(r, t)-T_{\text {graphite }}$

$\frac{\partial^{2} \varphi(r, t)}{\partial r^{2}}+\frac{2}{r} \frac{\partial \varphi(r, t)}{\partial r}+\frac{q_{t r}^{\prime \prime}(r, t)}{k}=\frac{1}{\alpha} \frac{\partial \varphi(r, t)}{\partial t}$

$\varphi(0, t)=$ finite

$\varphi(R, t)=0$

Initial Condition:

$\varphi(r)=0$ at $\mathrm{t}=0$

Now one can solve the time-dependent heat generation problem with the Green's function method. Consider the homogeneous problem: 
$\frac{\partial^{2} \theta(r, t)}{\partial r^{2}}+\frac{2}{r} \frac{\partial \theta(r, t)}{\partial r}=\frac{1}{\alpha} \frac{\partial \theta(r, t)}{\partial t}$

$\theta(0, t)=$ finite for $\mathrm{t} \geq 0$

$\theta(R, t)=0$ for $\mathrm{t} \geq 0$

$\theta(r, t)=F(r)$ for $\mathrm{t}=0$

Let $U(r, t)=r \theta(r, t)$ to obtain:

$\frac{\partial^{2} U(r, t)}{\partial r^{2}}=\frac{1}{\alpha} \frac{\partial U(r, t)}{\partial t}$

Eq. C-5

$\mathrm{U}(\mathrm{r}=0)=\mathrm{U}(\mathrm{r}=\mathrm{R})=0$ or $\mathrm{t} \geq 0$

and

$\mathrm{U}(\mathrm{r}, \mathrm{t})=\mathrm{rF}(\mathrm{r})$ for $\mathrm{t}=0$

The general solution to Equation C-5 is:

$U(r, t)=e^{-\alpha \beta_{n}^{2} t}\left[A_{n} \sin \left(\beta_{n} r\right)+B_{n} \cos \left(\beta_{n} r\right)\right]$

Since $\mathrm{U}_{\mathrm{h}}(\mathrm{r}=0)=\mathrm{U}_{\mathrm{h}}(\mathrm{r}=\mathrm{R})=0$

$U(0, t)=e^{-\alpha \beta_{n}^{2} t}\left[A_{n} \sin \left(\beta_{n} 0\right)+B_{n} \cos \left(\beta_{n} 0\right)\right]=0$

$B_{n}=0$

and

$U(R, t)=\sin \left(\beta_{n} R\right)=0$

Therefore, the Eigen values are $\beta_{n}=\frac{n \pi}{R}$

$U(r, t)=\sum_{n=1}^{\infty} A_{n} e^{-\alpha \beta_{n}^{2} t} \sin \left(\beta_{n} r\right)$

since

$U(r, t)=r \theta(r, t)$

$\theta(r, t)=\sum_{n=1}^{\infty} A_{n} e^{-\alpha \beta_{n}^{2} t} \frac{\sin \left(\beta_{n} r\right)}{r}$

Applying the I.C. $\theta(r, t)=F(r) \mathrm{t}=0$ 


$$
\begin{aligned}
& \theta(r, 0)=\sum_{n=1}^{\infty} A_{n} \frac{\sin \left(\beta_{n} r\right)}{r}=F(r) \\
& \sum_{n=1}^{\infty} A_{n} \int_{0}^{R} r^{\prime^{\prime 2}} d r^{\prime} \frac{\sin \left(\beta_{n} r^{\prime}\right)}{r^{\prime}} \frac{\sin \left(\beta_{n} r^{\prime}\right)}{r^{\prime}}=\int_{0}^{R} r^{\prime 2} d r^{\prime} F\left(r^{\prime}\right) \frac{\sin \left(\beta_{n} r^{\prime}\right)}{r^{\prime}} \\
& A_{n}=\frac{2}{R} \int_{0}^{R} r^{\prime 2} d r^{\prime} F\left(r^{\prime}\right) \frac{\sin \left(\beta_{n} r^{\prime}\right)}{r^{\prime}}
\end{aligned}
$$

then

$$
\theta(r, t)=\int_{0}^{R} r^{\prime 2}\left[\frac{2}{R r^{\prime} r} \sum_{n=1}^{\infty} e^{-\alpha \beta_{n}^{2} t} \sin \left(\beta_{n} r^{\prime}\right) \sin \left(\beta_{n} r\right)\right] F\left(r^{\prime}\right) d r^{\prime}
$$

Therefore, the Green's function is:

$G\left(r, t \mid r^{\prime}, \tau\right)=\frac{2}{R r^{\prime} r} \sum_{n=1}^{\infty} e^{-\alpha \beta_{n}^{2}(t-\tau)} \sin \left(\beta_{n} r^{\prime}\right) \sin \left(\beta_{n} r\right)$

The solution to the non-homogeneous problem is obtained from:

$\varphi(r, t)=\frac{\alpha}{k} \int_{0}^{t} d \tau \int_{0}^{R} r^{\prime 2} G\left(r, t \mid r^{\prime}, \tau\right) q^{\prime \prime \prime}(r, \tau) d r^{\prime}$

Assuming a spatially independent heat generation rate leads to:

$\varphi(r, t)=\frac{\alpha}{k} \frac{2}{R r} \sum_{n=1}^{\infty} \sin \left(\beta_{n} r\right) e^{-\alpha \beta_{n}^{2} t} \int_{0}^{R} r^{\prime} \sin \left(\beta_{n} r^{\prime}\right) d r^{\prime} \int_{0}^{t} q^{\prime \prime \prime}(\tau) e^{\alpha \beta_{n}^{2} \tau} d \tau$

Carrying out the spatial integration gives the temperature field:

$$
\varphi(r, t)=-\frac{\alpha}{k} \frac{2 R}{r} \sum_{n=1}^{\infty} \frac{(-1)^{n}}{n \pi} \sin \left(\beta_{n} r\right) e^{-\alpha \beta_{n}^{2} t} \int_{0}^{t} q^{\prime \prime \prime}(\tau) e^{\alpha \beta_{n}^{2} \tau} d \tau
$$

\section{Case 1. Constant Heat Generation}

The time integration in Equation C-7 under the assumption of constant heat generation becomes:

$$
\varphi(r, t)=-q^{\prime \prime \prime} \frac{2 R^{3}}{k} \sum_{n=1}^{\infty} \frac{(-1)^{n}}{(n \pi)^{3}} \frac{\sin \left(\beta_{n} r\right)}{r}\left(1-e^{-\alpha \beta_{n}^{2} t}\right)
$$

\section{Case 2. Linear Heat Generation}

Assuming a linear heat generation rate of the form $q^{\prime \prime \prime}(t)=a_{1}+a_{2} t$ and carrying out the time integration: 


$$
\begin{aligned}
& \varphi(r, t)=-\frac{\alpha}{k} 2 R \sum_{n=1}^{\infty} \frac{(-1)^{n}}{n \pi} \frac{\sin \left(\beta_{n} r\right)}{r} e^{-\alpha \beta_{n}^{2} t}\left(\int_{0}^{t} a_{1} e^{\alpha \beta_{n}^{2} \tau} d \tau+\int_{0}^{t} a_{2} \tau e^{\alpha \beta_{n}^{2} \tau} d \tau\right) \\
& \varphi(r, t)=-\frac{\alpha}{k} 2 R \sum_{n=1}^{\infty} \frac{(-1)^{n}}{n \pi} \frac{\sin \left(\beta_{n} r\right)}{r} e^{-\alpha \beta_{n}^{2} t}\left(\frac{a_{1}}{\alpha \beta_{n}^{2}}\left(e^{\alpha \beta_{n}^{2} t}-1\right)+a_{2}\left(\frac{\alpha \beta_{n}^{2} t e^{\alpha \beta_{n}^{2} t}-e^{\alpha \beta_{n}^{2} t}+1}{\alpha^{2} \beta_{n}^{4}}\right)\right)
\end{aligned}
$$

Simplifying the above equation yields the temperature field equation under linear heat generation:

$$
\varphi(r, t)=-\frac{\alpha}{k} 2 R \sum_{n=1}^{\infty} \frac{(-1)^{n}}{n \pi} \frac{\sin \left(\beta_{n} r\right)}{r}\left(\frac{a_{1}}{\alpha \beta_{n}^{2}}\left(1-e^{-\alpha \beta_{n}^{2} t}\right)+a_{2}\left(\frac{\alpha \beta_{n}^{2} t-1+e^{-\alpha \beta_{n}^{2} t}}{\alpha^{2} \beta_{n}^{4}}\right)\right)
$$

The average temperature is:

$$
\begin{aligned}
& \langle\varphi(t)\rangle=\frac{\int_{r_{i}}^{r_{i+1}} \varphi(r, t) r^{2} d r}{\int_{r_{i}}^{r_{i+1}} r^{2} d r}= \\
& \frac{-\frac{2 \alpha R}{k} \sum_{n=1}^{\infty} \frac{(-1)^{n}}{n \pi}\left(\frac{a_{1}}{\alpha \beta_{n}^{2}}\left(1-e^{-\alpha \beta_{n}^{2} t}\right)+a_{2}\left(\frac{\alpha \beta_{n}^{2} t-1+e^{-\alpha \beta_{n}^{2} t}}{\alpha^{2} \beta_{n}^{4}}\right)\right) \frac{\left[\sin \left(\beta_{n} r_{i+1}\right)-\beta_{n} r_{i+1} \cos \left(\beta_{n} r_{i+1}\right)-\sin \left(\beta_{n} r_{i}\right)+\beta_{n} r_{i} \cos \left(\beta_{n} r_{i}\right)\right]}{\beta_{n}^{2}}}{\int_{r_{i}}^{r_{i+1}} r^{2} d r}
\end{aligned}
$$

\section{Case 3. Exponential Heat Source}

Under the assumption of exponential heat generation rate $q^{\prime \prime \prime}\left(\tau_{0}+\Delta \tau\right)=q^{\prime \prime \prime}\left(\tau_{0}\right) e^{\omega_{1}\left(\tau_{0}+\Delta \tau\right)}$.

The value of the exponential factor is:

$$
\frac{q^{\prime \prime \prime}\left(\tau_{0}+\Delta \tau\right)}{q^{\prime \prime \prime}\left(\tau_{0}\right)}=e^{\omega_{1}\left(\tau_{0}+\Delta \tau\right)} \text { and } \omega_{1}=\frac{\ln \left(q^{\prime \prime \prime}\left(\tau_{0}+\Delta \tau\right)\right)-\ln \left(q^{\prime \prime \prime}\left(\tau_{0}\right)\right)}{\left(\tau_{0}+\Delta \tau\right)}
$$

The generalized time-dependent source for a given time step is:

$$
\varphi(r, t)=-q^{\prime \prime \prime}\left(\tau_{0}\right) \frac{\alpha}{k} \frac{2 R}{r} \sum_{n=1}^{\infty} \frac{(-1)^{n}}{n \pi} \sin \left(\beta_{n} r\right) e^{-\alpha \beta_{n}^{2} t} \int_{0}^{t} e^{\left(\omega_{1}+\alpha \beta_{n}^{2}\right) \tau} d \tau
$$

The temperature field equation under exponential heat generation rate is:

$$
\varphi(r, t)=-q^{\prime \prime}\left(\tau_{0}\right) \frac{\alpha}{k} 2 R \sum_{n=1}^{\infty} \frac{(-1)^{n}}{n \pi} \frac{\sin \left(\beta_{n} r\right)}{r} \frac{\left(e^{\omega_{1} t}-e^{-\alpha \beta_{n}^{2} t}\right)}{\left(\omega_{1}+\alpha \beta_{n}^{2}\right)}
$$




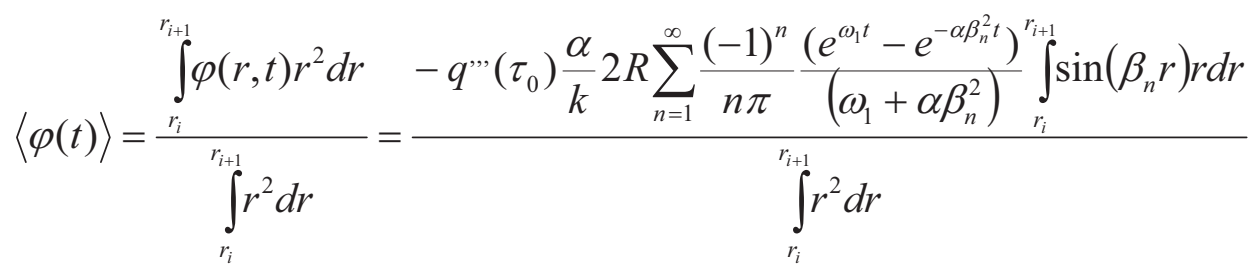

$$
\begin{aligned}
& \langle\varphi(t)\rangle=\frac{-q^{\prime \prime \prime}\left(\tau_{0}\right) \frac{\alpha}{k} 2 R \sum_{n=1}^{\infty} \frac{(-1)^{n}}{n \pi} \frac{\left(e^{\omega_{i} t}-e^{-\alpha \beta_{n}^{2} t}\right)}{\left(\omega_{1}+\alpha \beta_{n}^{2}\right)} \frac{\left[\sin \left(\beta_{n} r_{i+1}\right)-\beta_{n} r_{i+1} \cos \left(\beta_{n} r_{i_{1}}\right)-\sin \left(\beta_{n} r_{i}\right)+\beta_{n} r_{i} \cos \left(\beta_{n} r_{i}\right)\right]}{\beta_{n}^{2}}}{\int_{r_{i}}^{r_{+1}} r^{2} d r}
\end{aligned}
$$




\section{Appendix D}

\section{Thermo-Physical Properties}




\section{Appendix D}

\section{Thermo-Physical Properties}

The purpose of this appendix is to compile the best available thermo physical data for TRISO particles in the current literature to perform safety analysis calculations for TRISO-fueled reactors with UO2 kernels. These properties are valid for design basis accident conditions only. Severe accident analysis conditions are outside the scope of this work.

The models and data from Kovacs et al. are proprietary and are excluded from this external report. Therefore, the model included in the TDHe cannot be fully duplicated without the report from Kovacs et al.

\section{THERMO-PHYSICAL PROPERTIES OF $\mathrm{UO}_{2}$}

The thermo physical properties of $\mathrm{UO}_{2}$ are based on the recommendations from the fissile materials disposition program (Popov 2000).

\section{Thermal Conductivity of $\mathrm{UO}_{2}$}

The Lucuta model (Popov 2000) for irradiated $\mathrm{UO}_{2}$ is:

$$
k(T, B, p)=k_{0}(T) * F D^{*} F P^{*} F M * F R \quad[\mathrm{~W} / \mathrm{m} / \mathrm{K}]
$$

where

$$
\mathrm{T}=\text { temperature in Kelvin }
$$

$\mathrm{B}=$ burnup in at. $\%(1$ at. $\% \approx 9.375 \mathrm{GWd} / \mathrm{MTU}$ for $3-5 \%$ enriched fuel $)$

$p=\frac{\rho_{T D}-\rho}{\rho_{T D}}=$ porosity of $\mathrm{UO}_{2}$

Eq. D-2

$k_{0}(T)=$ conductivity of $100 \%$ dense $\mathrm{UO}_{2} \quad[\mathrm{~W} / \mathrm{m} / \mathrm{K}]$

$k_{0}(T)=\frac{115.8}{7.5408+17.692 t+3.6142 t^{2}}+7410.5 t^{-5 / 2} e^{-16.35 / t}$

Eq. D-3

$t=\frac{T(K)}{1000}$

$\mathrm{FD}=$ dissolved solid fission product factor [unit less]

$F D=\left(\frac{1.09}{B^{3.265}}+0.0643 \sqrt{\frac{T}{B}}\right) \arctan \left[\left(\frac{1.09}{B^{3.265}}+0.0643 \sqrt{\frac{T}{B}}\right)^{-1}\right]$

Eq. D-4

$\mathrm{FP}=$ precipitated solid fission product factor [unit less] 
$F P=1+\frac{0.019 B}{3-0.019 B}\left[1+e^{-(T-1200) / 100}\right]^{-1}$

Eq. D-5

$\mathrm{FM}=$ fuel porosity factor $\quad$ [unit less $]$

$F M=\frac{1-p}{1+2 p}$

Eq. D-6

$\mathrm{FR}=$ radiation damage factor [unit less]

$F R=1-\frac{0.2}{1+e^{(T-900) / 80}}$

Eq. D-7

The results from the $\mathrm{UO}_{2}$ conductivity model are shown in Figure D-1.

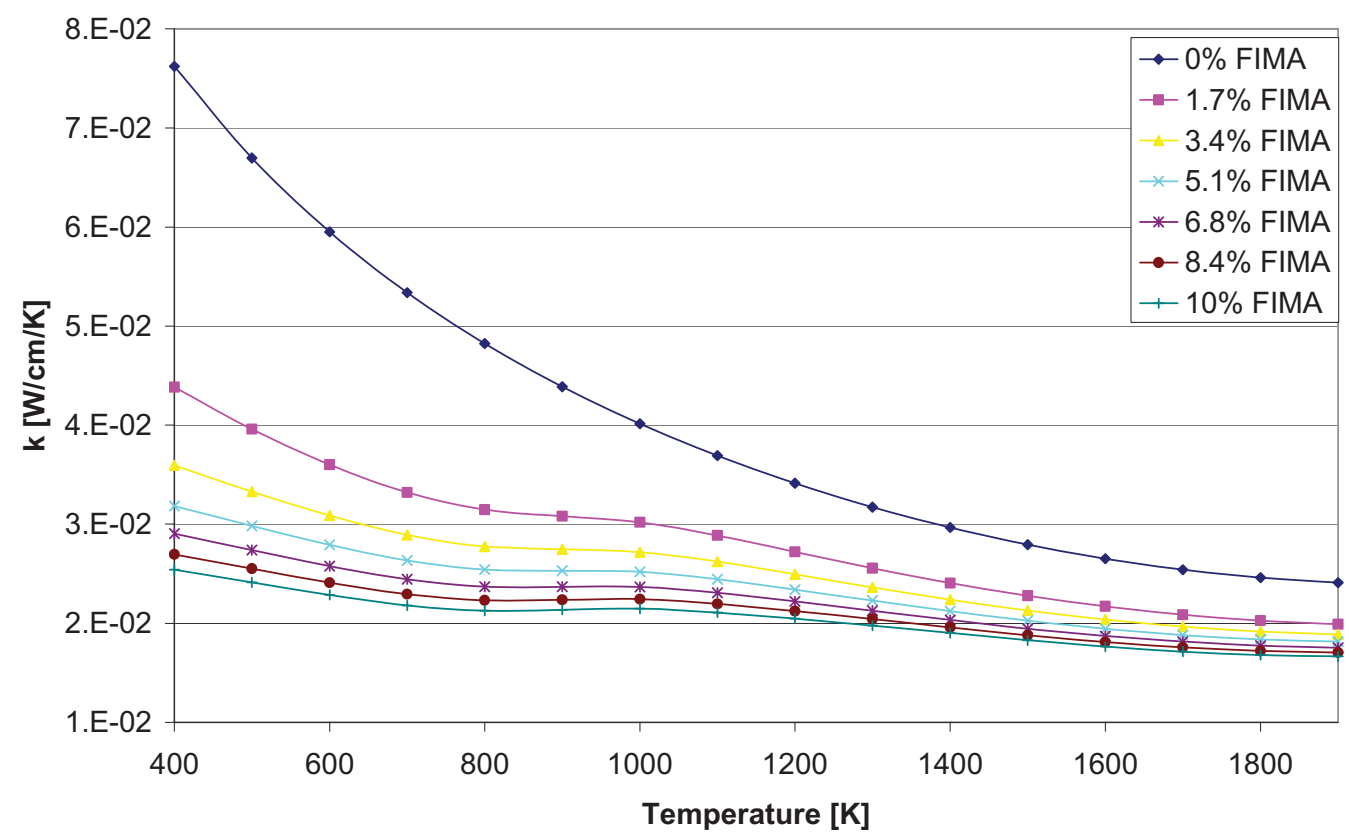

Figure D-1. Thermal conductivity of $\mathrm{UO}_{2}$ as a function of temperature and burnup.

\section{Specific Heat Capacity of $\mathrm{UO}_{2}$}

The specific heat capacity model covers the temperature range $298.15 \mathrm{~K} \leq \mathrm{T}<3120 \mathrm{~K}$ and it is functionalized as:

$$
\begin{aligned}
C_{p}(T)= & 302.27\left(\frac{548.68}{T}\right)^{2} \frac{e^{548.68 / T}}{\left(e^{548.68 / T}-1\right)^{2}}+ \\
& 2 * C_{2}(B) T+8.741 E 7 * 18,531.7 \frac{e^{18,531.7 / T}}{T^{2}}
\end{aligned}
$$


where

$$
\begin{array}{ll}
C_{p}(T) & =[\mathrm{J} / \mathrm{kg} / \mathrm{K}] \\
\mathrm{t} & =\mathrm{T} / 1000 \\
\mathrm{~T} & =\text { Temperature in } \mathrm{K} \\
C_{2}(B)= & 8.463 E-3\left(1+0.011^{*} B\right) \\
\mathrm{B} & =\text { burnup in atom percent }
\end{array}
$$

\section{Density of $\mathrm{UO}_{2}$}

The density as a function of temperature is calculated with:

$$
\rho(T)=\rho(273)\left(\frac{L(273)}{L(T)}\right)^{3} \quad\left[\mathrm{Kg} / \mathrm{m}^{3}\right.
$$

where

$\rho(273)=10,970 \mathrm{Kg} / \mathrm{m} 3$, is the density of $\mathrm{UO}_{2}$ at $273 \mathrm{~K} . \mathrm{L}(273)$ and $\mathrm{L}(\mathrm{T})$ are the lengths at $273 \mathrm{~K}$ and at temperature $\mathrm{T}(\mathrm{K})$, respectively.

In the temperature Range $273 \mathrm{~K} \leq \mathrm{T}<923 \mathrm{~K}$ :

$L(T)=L(273)\left(9.9734 \mathrm{E}-1+9.802 \mathrm{E}-6 \mathrm{~T}-2.705 \mathrm{E}-10 \mathrm{~T}^{2}+4.391 \mathrm{E}-13 \mathrm{~T}^{3}\right)$

And in the temperature Range $923 \mathrm{~K} \leq \mathrm{T}<3120 \mathrm{~K}$

$$
L(T)=L(273)\left(9.9672 \mathrm{E}-1+1.179 \mathrm{E}-5 \mathrm{~T}-2.429 \mathrm{E}-9 \mathrm{~T}^{2}+1.219 \mathrm{E}-12 \mathrm{~T}^{3}\right)
$$

\section{THERMO-PHYSICAL PROPERTIES OF PYC AND POROUS CARBON}

It is difficult to find consistent data for pyrolytic carbons since their thermo-physical properties are highly dependent on the manufacturing process, the source of hydrocarbons, and the irradiation temperature. This library provides a basic dataset that should not be used in final design calculations. The library should be updated with the as-built data that emerges from the design specific TRISO fuel characterization program.

\section{Thermal Conductivity of PyC and Porous Carbon}

The thermal conductivity measurements of isotropic pyrolytic carbon performed by Bokros et al. were fitted into a power law equation. The sample parameters were: a Bacon Anisotropy Factor of 1.00, a density of $1.93 \mathrm{~g} / \mathrm{cc}$, and a layer spacing of $3.410 \AA$. The temperature-dependent $[\mathrm{K}]$ thermal conductivity is:

$\mathrm{k}_{\mathrm{PyC}}=2.443 \mathrm{~T}^{-0.574} \mathrm{FM}\left[\mathrm{W} \mathrm{cm}^{-1} \mathrm{~K}^{-1}\right]$

Eq. D-12

The porosity correction factor FM is determined with the simplified Maxwell-Eucken model developed by Biancheria (Olander 1976): 
$\mathrm{FM}=\frac{1-p}{1+(\alpha-1) p} \quad\left[\mathrm{~W} \mathrm{~cm}{ }^{-1} \mathrm{~K}^{-1}\right]$

Eq. D-13

where

$p=\frac{1.93-\rho}{1.93}$

Eq. D-14

The values of $\alpha$ range from 1.5 for spheres to 3 for oblate ellipsoids with an axial ratio of 10 . This model uses an average value $\alpha=2.2$ based on a density an average density of $1.45 \mathrm{~g} / \mathrm{cc}$. Dobranich indicates that the porosity correction for the porous carbon region is approximately 0.25 to 0.5 times the conductivity of the PyC, which compares well with the value of 0.314 obtained with $\alpha=2.2$.

For irradiation dependent conductivities Bokros et al. provides a data set at 3.03E25 DNE fluence $\left[\mathrm{n} / \mathrm{m}^{2}\right]$ :

${ }^{\text {ir }} \mathrm{k}_{\mathrm{PyC}}=100.8 \mathrm{~T}^{-2.322} \mathrm{FM}\left[\mathrm{W} \mathrm{cm}{ }^{-1} \mathrm{~K}^{-1}\right]$ (irradiated at $950^{\circ} \mathrm{C}$ )

Eq. D-15

Thermal conductivities for fluences in between 0 and 3.03E25 DNE are determined via linear interpolation between the two results from Equations D-12 and D-15. Conductivities for fluences beyond 3.03E25 DNE are obtained with the correction factor developed in the German program at the Jülich Research center (Nabielek 1991) with an irradiation temperature of $950^{\circ} \mathrm{C}$ :

${ }^{\mathrm{ir}} \mathrm{k}_{\mathrm{PyC}}=2.443 T^{-0.574}\left[1-0.3662\left(1-e^{-1.1028 \Gamma}\right)-0.03554 \Gamma\right] \mathrm{FM}$

where

$\Gamma=$ neutron fluence in $10^{25} \mathrm{~m}^{-2} \mathrm{DNE}$ units

Figures D-2 and D-3 show the values of the conductivity for PyC and porous carbon, respectively. The shape of the 2 Dido Nickel Equivalent (DNE) fluence curve in the PyC plot for Bokros is different than that obtained with the Jülich correction, but the variation is not significant. The un-irradiated shape of the Bokros curve is the same as the un-irradiated shape of the Jülich data; therefore, the fluence corrections from the Jülich program should yield reasonable approximations assuming that the dose rates did not vary significantly. 


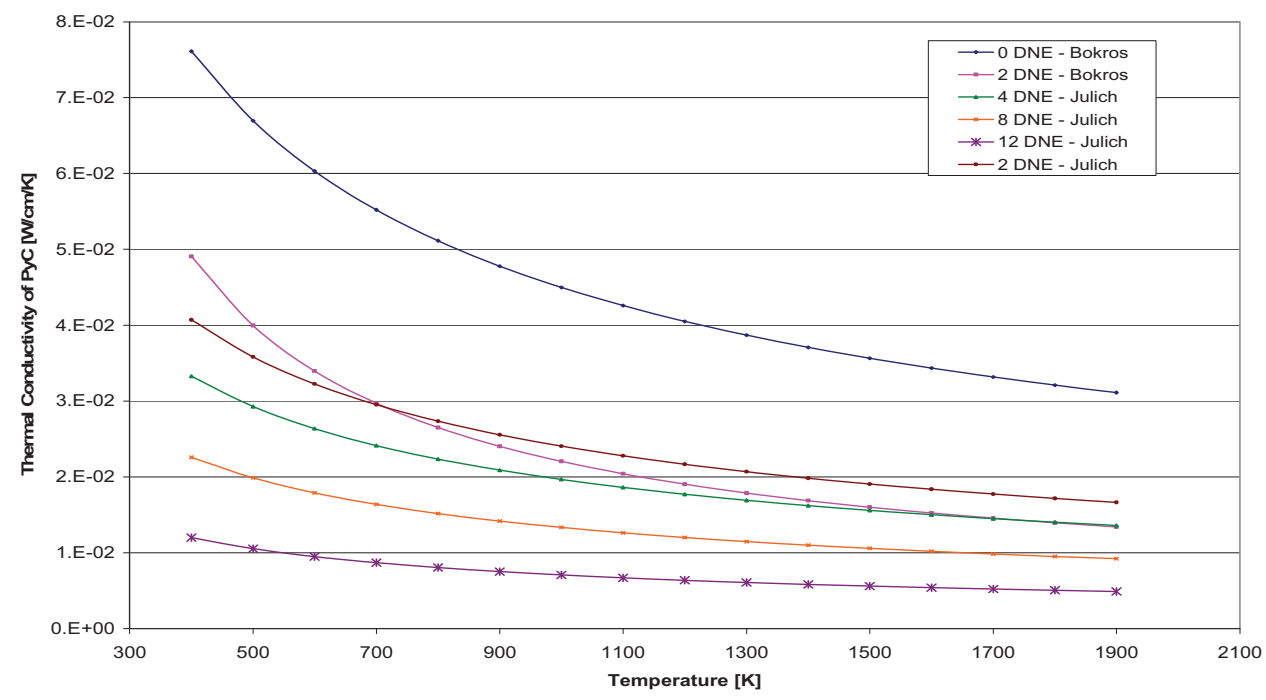

Figure D-2. Thermal conductivity of the PyC layer as a function of temperature and fluence.

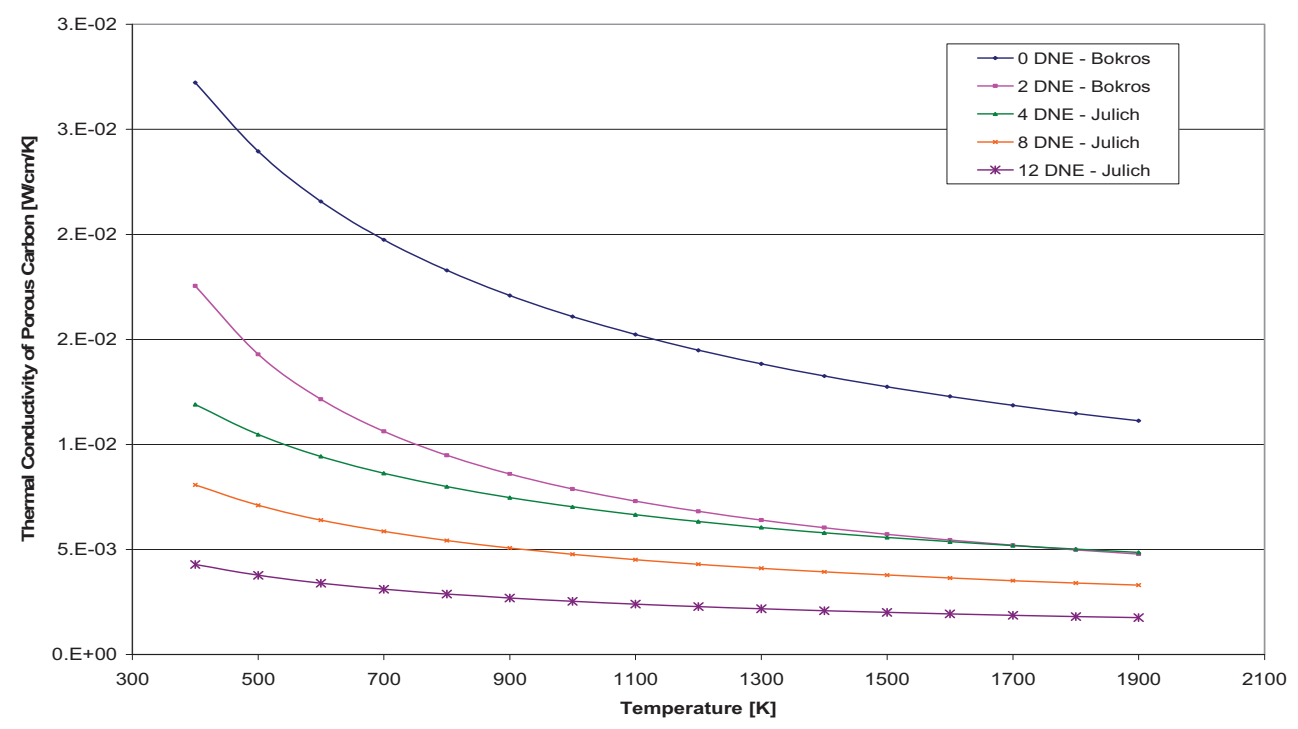

Figure D-3. Thermal conductivity of the porous carbon layer as a function of temperature and fluence.

\section{Specific Heat Capacity of PyC and Porous Carbon}

The specific heat capacity of the PyC and porous carbon layers are based on a data fit from the nearisotropic H-451 graphite with a density of $1.74 \mathrm{~g} / \mathrm{cc}$ from the Graphite Handbook:

$C_{p}=\left(0.54212-2.42667 \mathrm{E}-6 \mathrm{~T}-9.02725 \mathrm{E} 1 \mathrm{~T}^{-1}-4.34493 \mathrm{E} 4 \mathrm{~T}^{-2}\right.$

$\left.+1.59309 \mathrm{E}^{-3} \mathrm{~T}^{-3}-1.43688 \mathrm{E} 9 \mathrm{~T}^{-4}\right) \cdot 4184 \cdot F M$

Eq. D-17

where

$$
C_{p}=[\mathrm{J} / \mathrm{kg} / \mathrm{K}] \text { Temperature Range } 250 \mathrm{~K} \leq \mathrm{T}<3000 \mathrm{~K}
$$


The porosity correction factor uses a porosity based on the sample density:

$p=\frac{1.74-\rho}{1.74}$

Eq. D-18

\section{Density of PyC and Porous Carbon}

The densities of the $\mathrm{PyC}$ and the porous carbon layers will be input parameters for the model, if no values are specified, $1.9 \mathrm{~g} / \mathrm{cc}$ and $0.97 \mathrm{~g} / \mathrm{cc}$, respectively, are used as default.

\section{THERMO PHYSICAL PROPERTIES OF SIC}

\section{Thermal Conductivity of SiC}

Nabielek et al. (Nabielek 1982) recommend the following correlation for the heat conductivity in the SiC layer:

$k_{\text {unirr }}=\frac{17885}{T}+2 \quad[\mathrm{~W} / \mathrm{m} / \mathrm{K}]$

where $\mathrm{T}$ is in Kelvin.

Irradiation effects on the thermal conductivity of $\mathrm{SiC}$ are quite dramatic. A reduction of $50-70 \%$ for $4 \mathrm{E} 25 \mathrm{n} / \mathrm{m} 2 \mathrm{DNE}$ (Dido Nickel Equivalent) was documented at an irradiation temperature of $1100^{\circ} \mathrm{C}$ (Ho 1993). Since no clear fluence and temperature-dependent correlation exists to date, an exponential correlation is suggested by Ho for the irradiation-dependent conductivity:

$k_{\text {irr }}=k_{\text {unirr }} e^{-0.1277 \Gamma} \quad[\mathrm{W} / \mathrm{m} / \mathrm{K}]$

where

$\Gamma=$ neutron fluence in $10^{25} \mathrm{~m}^{-2} \mathrm{DNE}$ units

Figure D-4 shows the Thermal conductivity curves for SiC. 


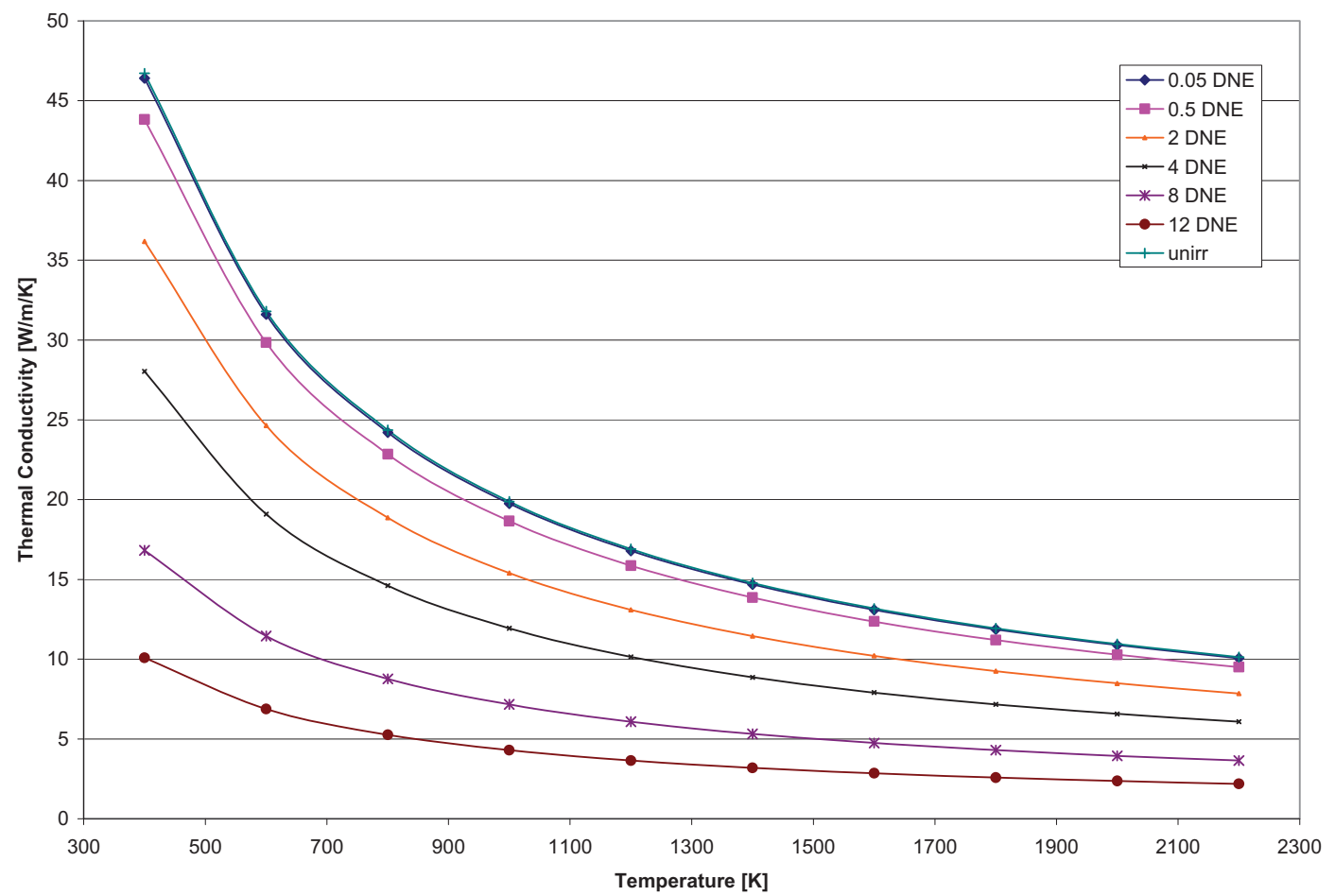

Figure D-4. Temperature and fluence-dependent thermal conductivity of SiC.

\section{Specific Heat Capacity of SiC}

Snead et al. recommend Equation D-21 in the temperature range $200 \mathrm{~K} \leq \mathrm{T}<2400 \mathrm{~K}$ and assume that the material property remains unchanged under irradiation:

$$
\begin{aligned}
& C_{p}=925.65+0.3772 T-7.9259 E-5 T^{2}-\frac{3.1946 E 7}{T^{2}} \\
& C_{p}=[\mathrm{J} / \mathrm{kg} / \mathrm{K}]
\end{aligned}
$$

\section{Density of SiC}

Snead et al. show that the density change in Chemical Vapor Deposition (CVD) SiC saturates quickly with dose at an irradiation temperature of $800^{\circ} \mathrm{C}$. The density change is in approximately a half percent. Furthermore the thermal expansion is also very small. Therefore, the $\mathrm{SiC}$ layer is assumed to retain the theoretical density of $4.21 \mathrm{~g} / \mathrm{cm}^{3}$. 


\section{THERMO-PHYSICAL PROPERTIES OF GASES FROM UO KERNELS $_{2}$}

The TRISO fuel model contains a gas release generation model used to determine the internal pressure. The internal pressure of the TRISO is used, subsequently, in the determination of the gas conductivity for the void region of the fuel.

\section{Determination of the Internal Gas Pressure of the TRISO}

The calculation of the internal gas pressure for each particular species uses the Redlich-Kwong equation of state with constants tabulated in Table 2-3 of the report by Kovacs et al.

\section{Determination of the Steady State Gaseous Fission Product Concentrations}

The number of moles of fission gases in the void regions and the number of moles of fission gases created in the fuel kernel are calculated using Equations 2-6 and 2-3 from Kovacs et al., respectively.

\section{Determination of the Steady State Gaseous Fission Product Concentrations}

The fraction of gases that are released into the void region can be calculated with a Booth release model. The model assumes that initially there are no gases present, the generation of fission products is homogeneous, and under steady state conditions (Nabielek 1982):

$$
F_{D}=1.0-\frac{6}{D^{\prime} t} \sum_{n=1}^{\infty} \frac{1-e^{-n^{2} \pi^{2} D^{\prime} t}}{n^{4} \pi^{4}}
$$

Where $\mathrm{t}$ is the irradiation time in seconds. For $\mathrm{Xe}$ and $\mathrm{Kr}$ in $\mathrm{UO}_{2}$ the effective diffusivity is given by (Nabielek 2004):

$D^{\prime}=5.0 E-3 e^{-Q_{o} / R T}$

where

$$
\begin{aligned}
& \text { Qo }=155.4 \mathrm{~kJ} / \mathrm{mol} \\
& \mathrm{R}=8.315 \mathrm{~J} / \mathrm{mol} / \mathrm{K}
\end{aligned}
$$

$\mathrm{T}$ is the irradiation temperature $[\mathrm{K}]$

Equation D-22 can yield high results for $\mathrm{Xe}$ and $\mathrm{Kr}$, therefore a burnup dependent factor is introduced (Nabielek 1982):

$$
F_{S S}=\beta F_{D}
$$

Three regimes for the retention at grain boundaries are modeled: complete retention, partial retention, saturation with no retention. For $\mathrm{UO}_{2}$ the critical saturation:

$$
\beta= \begin{cases}0.0 & \mathrm{~F}_{\mathrm{D}} B u<0.5 \\ \frac{2}{9} \mathrm{~F}_{\mathrm{D}} B u-\frac{1}{9} & \mathrm{~F}_{\mathrm{D}} B u<0.5 \\ 1.0 & \mathrm{~F}_{\mathrm{D}} B u>5\end{cases}
$$


The model was verified against the calculations by Nabielek (2004), which produce an F-factor of 0.46 with an irradiation temperature of $950^{\circ} \mathrm{C}$ and at $20 \%$ Fissions per Initial Metal Atom FIMA.

\section{Determination of the Transient Fission Product Concentrations}

For transient conditions we use the transient and burst effect approximation developed by Bernard et al. (2002):

$c_{K r / X e}=\operatorname{Max}\left\{c_{0}\left[1-F_{T R}\left(t-t_{0}\right)\right]-c_{B 0} \exp \left(-D^{\prime} \frac{t-t_{0}}{0.05}\right) ; c_{s s}\right\}$

Or, in terms of the number of moles of fission gases retained:

$n_{K r / X e}=\operatorname{Max}\left\{n_{0}\left[1-F_{T R}\left(t-t_{0}\right)\right]-n_{B 0} \exp \left(-D^{\prime} \frac{t-t_{0}}{0.05}\right) ; n_{s s}\right\}$

where

$\mathrm{F}_{\mathrm{TR}}=$ fractional release of xenon or krypton gas from the grains via diffusion

$\mathrm{n}_{0}=$ number of moles of xenon or krypton at time $\mathrm{t}_{0}$ inter and intra-granular

$\mathrm{n}_{\mathrm{B} 0}=$ number of inter-granular moles of xenon and krypton at $\mathrm{t}_{0}$

$\mathrm{n}_{\mathrm{ss}}=$ number of moles of $\mathrm{Xe}$ or $\mathrm{Kr}$ at steady state for peak transient power

$\mathrm{a}=$ grain size $($ assumed $\sim 10 \mu \mathrm{m})$ is:

The fractional release of xenon and krypton via diffusion for a constant temperature in each time step

$F_{T R}=1.0-6 \sum_{n=1}^{\infty} \frac{e^{-n^{2} \pi^{2} D^{\prime} \Delta t}}{n^{2} \pi^{2}}$

For steady-state operation and at or above the grain boundary saturation threshold the inter-granular concentration can be calculated with:

$n_{B 0}=\frac{3 N_{S}}{2 a} V_{\text {void }}$

The calculation of the saturation surface density $N_{S}$ is based on the bubble model by Dowling et al. and for an ideal gas is determined with:

$N_{S}=\frac{4}{3} \frac{f_{c} r_{b}}{k T} \frac{f(\theta)}{\sin ^{2} \theta} P_{b u b}$

where

$f(\theta)=1-\frac{3}{2} \cos (\theta)+\frac{1}{2} \cos ^{3}(\theta)$

Eq. D-31 
$P_{b u b}=\left(\frac{2 \gamma}{r_{b}}+P_{e x t}\right)=$ bubble pressure

Eq. D-32

For a hypothetical dihedral angle $2 \theta=100^{\circ}, \frac{f(\theta)}{\sin ^{2} \theta}=0.287$.

According to Bernard et al. (1997) the surface specific energy $\gamma=1 \mathrm{~J} / \mathrm{m}^{2}, \mathrm{r}_{\mathrm{b}}=0.5 \mu \mathrm{m}, \mathrm{fc}=0.25$, and with $\mathrm{R}=8.31 \mathrm{E}-6 \mathrm{~m}^{3} \cdot \mathrm{MPa} \cdot \mathrm{K}^{-1} \cdot \mathrm{mol}^{-1}$ we obtain:

$N_{S}=\frac{5.76 \mathrm{E}-3}{T}\left(4.0+P_{e x t}\right)$

Eq. D-33

With $\mathrm{N}_{\mathrm{s}}$ in $\mathrm{mol} / \mathrm{m}^{2}$ and $\mathrm{P}_{\text {ext }}$ is in $\mathrm{MPa}$

The maximum xenon or krypton concentration at steady state for peak transient is assumed to occur at a pressure of $120 \mathrm{MPa}$, with a void volume of $5.96 \mathrm{E}-11 \mathrm{~m}^{3}$, and with $80 \%$ of the gas in the gas mixture being composed of $\mathrm{Xe}$ and $\mathrm{Kr}$ :

$n_{s s}=\frac{6.88 E-4}{T}$

Eq. D-34

\section{Determination of CO Concentrations}

Similarly to the determination of the fission product concentrations, the number of moles of $\mathrm{CO}$ in the oxide fuel kernel is calculated with Equation 2-5 from Kovacs et al. 1982):

The number of oxygen gases released per fission event is calculated with (Nabielek 1991, Proksch

$(O / f)_{S S}=8.32 E-11 t^{2} \exp \left(-\frac{162.7 \mathrm{~kJ} / \mathrm{mol}}{R T}\right)$

Eq. D-35

where

$\mathrm{O} / \mathrm{f}=$ Oxygen released at the end of irradiation (atoms per fission)

$\mathrm{T}=$ time-averaged particle surface temperature during irradiation $(\mathrm{K})$

Equation D-35 is valid for the ranges of temperature $950^{\circ} \mathrm{C}<\mathrm{T}<1525^{\circ} \mathrm{C}$ and time 66 days $<\mathrm{t}<550$ days. The authors mention that some extrapolation is admissible, but for the PBR design with a multi-pass refueling scheme the total residence time can be near 940 days, as shown in Figure D-5. Since no other data is available at this time we will use the same equation. 


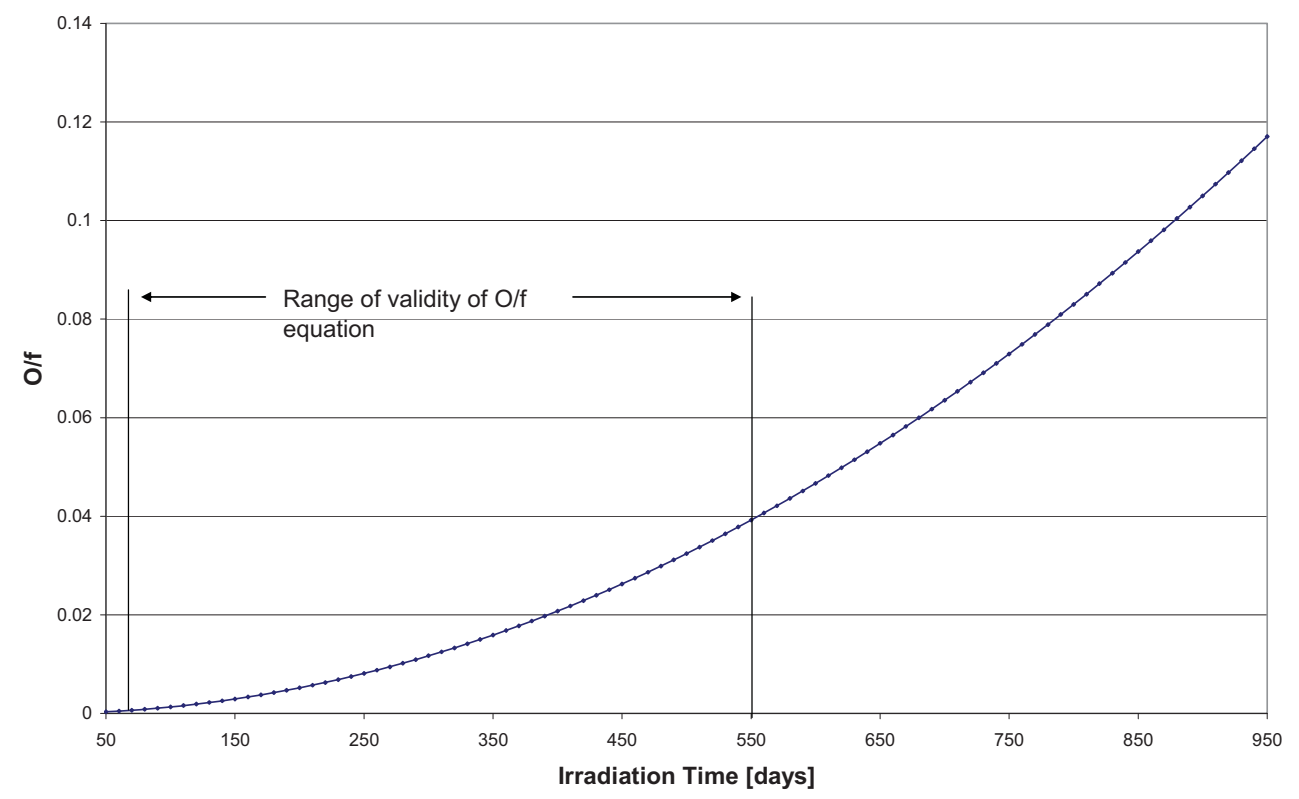

Figure D-5. Range of validity of $\mathrm{O} / \mathrm{f}$ equation in a multi-pass PBR with an average particle surface temperature of $1000^{\circ} \mathrm{C}$.

The same equation during heating is modified to the equation proposed by Liang et al.:

$$
(O / f)_{T R}=(O / f)_{S S} 10^{-4040\left(\frac{1}{T_{h}}-\frac{1}{T_{i}+75}\right)}
$$

where

$$
\begin{aligned}
& \mathrm{T}_{\mathrm{h}}=\text { heating temperature } \\
& \mathrm{T}_{\mathrm{i}}=\text { irradiation temperature } \\
& \mathrm{t}=\text { irradiation time in days }
\end{aligned}
$$

The $\mathrm{O} / \mathrm{f}$ model was verified against the calculations by Nabielek (2004), which yield an $\mathrm{O} / \mathrm{f}$ of 0.025 with an irradiation temperature of $950^{\circ} \mathrm{C}$ and at $20 \%$ FIMA.

\section{Determination of Gas Void Volume}

The amount of void volume available for the gas mixture is calculated with Equation 2-11 from Kovacs et al.

\section{Conductivity of the Gas Mixture}

The data for the thermal conductivity of the gases and the calculation methodology has been obtained from RELAP5-3DC. The individual gas conductivities are calculated with:

$\mathrm{k}=\mathrm{AT}^{\mathrm{B}}$

where the Temperatures are in $\mathrm{K}$ and the values of parameters A and $\mathrm{B}$ are shown in Table D-1. 
Table D-1. Parameters A and B used in gas conductivity calculation per Equation D-37.

\begin{tabular}{|l|l|l|l|}
\hline \multicolumn{1}{|c|}{ Gas Species } & \multicolumn{1}{c|}{$\begin{array}{c}\text { A } \\
\left(\mathrm{W} / \mathrm{cm}^{-K^{1+B}}\right)\end{array}$} & \multicolumn{1}{c|}{ B } & \multicolumn{1}{c|}{ Ref. } \\
\hline Carbon Monoxide & $5.050 \mathrm{e}-6$ & 0.6954 & CB Davis \\
\hline Krypton & $8.247 \mathrm{E}-7$ & 0.8363 & RELAP Manual \\
\hline Xenon & $4.351 \mathrm{E}-7$ & 0.8616 & RELAP Manual \\
\hline
\end{tabular}

The conductivities for the gas mixture are calculated with:

$$
k_{g}=\sum_{i=1}^{N} \frac{k_{i} X_{i}}{X_{i}+\sum_{j=1}^{N} \Phi_{i j} X_{j}}
$$

where

$$
\Phi_{i j}=\frac{\left[1+\left(\frac{k_{i}}{k_{j}}\right)^{1 / 2}\left(\frac{M_{i}}{M_{j}}\right)^{1 / 4}\right]^{2}}{\left[8\left(1+\frac{M_{i}}{M_{j}}\right)\right]^{1 / 2}}
$$

$$
\begin{aligned}
& N=\text { number of gases in the mixture } \\
& M_{i}=\text { molecular weight of the } \mathrm{i}^{\text {th }} \text { species } \\
& \mathrm{X}_{\mathrm{i}}=\text { model fraction if the } \mathrm{i}^{\text {th }} \text { species } \\
& \mathrm{k}_{\mathrm{i}}=\text { thermal conductivity of the component }
\end{aligned}
$$

\section{Density of the Gas Mixture}

From ideal gas law we have:

$$
P V=\frac{m}{M} R T
$$

Solving Eq. D-40 for the density leads to:

$$
\rho=\frac{m}{V}=\frac{P M}{R T}
$$

In terms of partial pressures Equation D-41 can be re-written as:

$\rho_{N}=\frac{m}{V}=\frac{P}{P} \frac{\sum_{i=1}^{N} P_{i} M_{i}}{R T}$

Eq. D-42 
From Dalton's Law of Partial Pressures:

$x_{i}=\frac{P_{i}}{P}$

Eq. D-43

where

$x_{\mathrm{i}}=$ mole fraction of any individual gas component in a gas mixture

$P_{\mathrm{i}}=$ partial pressure of any individual gas component in a gas mixture

Introducing Equation D-43 into Equation D-42:

$\rho_{N}=\frac{m}{V}=P \frac{\sum_{i=1}^{N} \frac{P_{i}}{P} M_{i}}{R T}=P \frac{\sum_{i=1}^{N} x_{i} M_{i}}{R T}$

Eq. D-44

where

$\mathrm{P}$ is the total pressure of the gas mixture

$P_{\mathrm{i}}=$ partial pressure of any individual gas component in a gas mixture

$x_{\mathrm{i}}=$ mole fraction of any individual gas component in a gas mixture

$\mathrm{Mi}=$ molecular weight

\section{Specific Heat Capacity of the Gas Mixture}

The calculation of the specific heat capacity of a gas mixture is based on Eq. 4.2-35 in the RELAP53DC manual for the specific internal energy of a mixture of gases. Taking the derivative of Eq. 4.2-35 with respect to temperature we obtain:

$C_{v}=\sum_{i=1}^{n} C_{i, v} X_{i}$

where

$C_{i, v}=$ specific heat capacity of the $\mathrm{i}^{\text {th }}$ species $[\mathrm{J} / \mathrm{kg} \cdot \mathrm{K}]$

$X_{i}=$ molar fraction of the $\mathrm{i}^{\text {th }}$ species

Taking the derivative with respect to temperature from the specific internal energy equation 4.2-34 from the RELAP5-3D@ manual, we obtain the specific heat capacity for the gas:

$C_{v, i}=C_{o, i}+D_{o, i}\left(T_{g}-T_{o}\right)+E_{o, i}\left(T_{g}-T_{o}\right)^{2}+F_{o, i}\left(T_{g}-T_{o}\right)^{3}$

where

$\mathrm{T}_{\mathrm{g}}=$ gas temperature $[\mathrm{K}]$

$\mathrm{T}_{\mathrm{o}}=250 \mathrm{~K}$

The various gas specific parameters are listed in Table D-2. 
Table D-2. Values $\mathrm{C}_{\mathrm{o}, \mathrm{i}}, \mathrm{D}_{\mathrm{o}, \mathrm{i}}, \mathrm{E}_{\mathrm{o}, \mathrm{i}}$, and $\mathrm{F}_{\mathrm{o}, \mathrm{i}}$ for $\mathrm{Kr}$, Xe, and CO.

\begin{tabular}{|c|c|c|c|c|}
\hline Gas & $\begin{array}{c}\mathbf{C}_{\mathbf{o}, \mathbf{n i}} \\
(\mathbf{J} / \mathbf{k g} \bullet \mathbf{K})\end{array}$ & $\begin{array}{c}\mathbf{D}_{\mathbf{0}, \mathbf{n i}} \\
\left(\mathbf{J} / \mathbf{k g} \bullet \mathbf{K}^{\mathbf{2}}\right)\end{array}$ & $\begin{array}{c}\mathbf{E}_{\mathbf{0}, \mathbf{n i}} \\
\left.\mathbf{( J / k g} \cdot \mathbf{K}^{\mathbf{3}}\right)\end{array}$ & $\begin{array}{c}\mathbf{F}_{\mathbf{0}, \mathbf{n i}} \\
\left.\mathbf{( J / k g} / \mathbf{K}^{\mathbf{4}}\right)\end{array}$ \\
\hline Krypton & 148.824 & 0.0035 & 0.0 & 0.0 \\
\hline Xenon & 94.9084 & 0.0035 & 0.0 & 0.0 \\
\hline $\begin{array}{c}\text { Carbon } \\
\text { Monoxide }\end{array}$ & 694.2758 & 0.3421647 & $-4.216078 \times 10^{-4}$ & $1.503636 \times 10^{-8}$ \\
\hline
\end{tabular}




\section{Appendix D References}

Bernard L. C., E. Bonnaud, "Finite volume method for fission gas release modeling," J. Nuc. Mat. 244, 1997, p. 75.

Bernard L. C., J. L. Jacoud, P. Vesco, “An efficient model for the analysis of fission gas release,” J. Nuc. Mat. 302, 2002, p. 125.

Bokros J. C., G. B. Engle, R. J. Price, Research on Graphite. GA-9099, 1968.

Davis C. B., "The Addition of Oxygen, Carbon Dioxide, and Carbon Monoxide Noncondensable Gases into RELAP5-3DC," R5/3D-03-05, April 2003.

Dobranich D., "Heat Transfer and Thermal Stress Analyses of the Multilayered Spherical Fuel Particles of a Particle Bed Space Nuclear Reactor," SAND-90-1032, 1991.

Dowling D. M., R. J. White, M. O. Tucker, "The effect if irradiation-induced re-solution of fission gas release," J. Nuc. Mat. 110, 1982, p. 37.

General Atomics, “Graphite Handbook,” DOE-HTGR-88111, 1988.

Ho F.H. et al., "Material models of Pyrocarbon and Pyrolityc Silicon Carbide," CEGA-002820, Rev. 1, 1993.

Homan, Nabielek, Yang, Julich-1502, 1978.

IAEA-TECDOC-978, "Fuel performance and fission product behavior in gas cooled reactors," 1997.

Kasten P. R., et al., "Fuel Performance in Modular High-Temperature Gas-Cooled Reactors", Interner Bericht-KFA-ISR-IB-12/94, October 1994.

Kovacs W. J., K. Bongartz, D. Goodin, “TRISO-coated HTGR Fuel Pressure-Vessel Performance Models," GA-A16807, 1983.

Liang, T. X., H. S. Zhao, C. H. Tang, K. Verfondern, "Irradiation performance and modeling of HTR-10 coated fuel particles," Nucl. Eng. Des. 236, 2006, p. 1922.

Nabielek H., "Partikeln und Brennelemente für den HTR,” KFA-HTA Report, 1991.

Nabielek H., K. Fukuda, K. Miato, T. Ogawa, "Calculation of Particle Temperatures in NSRR Tests," JAERI, unpublished draft from March 13, 1992.

Nabielek H., K. Verforndern, H. Werner, "Can we predict coated particle failure?" Technical Meeting on Current Status and Future Prospects of Gas Cooled Reactor Fuels," IAEA, Vienna, June 7-9 2004.

Nabielek, H., B. F. Myers, "Fission Product Retention HTR Fuel," Gas Cooled Reactors Today, BNES, London, 1982.

Olander D. R., "Fundamental Aspects of Nuclear Reactor Fuel Elements,” National Technical Information Services, 1976.

Popov S. G., J. J. Carbajo, "Thermo physical Properties of MOX and $\mathrm{UO}_{2}$ Fuels Including the Effects of Irradiation," ORNL/TM-2000/351, July 2000.

Proksch E., Strigl A., Nabielek H., "Production of Carbon Monoxide during Burn-up of $\mathrm{UO}_{2}$ Kerneled HTR Fuel Particles," J. Nuc. Mat., 107, 1982, p. 280.

"RELAP5-3D C Manuals, Volume 4: Models and Correlations," INEEL-EXT-98-00834-V1, 06/2005.

Snead L. L et al., "Handbook of SiC properties for fuel performance modeling," J. Nucl. Sci., 371, 2007, pp. 329-377. 